The Optimal Inflation Rate in New Keynesian Models

Olivier Coibion
College of William and Mary

Yuriy Gorodnichenko

U.C. Berkeley and NBER

Johannes Wieland

U.C. Berkeley

College of William and Mary

Department of Economics

Working Paper Number 91

June 2010 
COLLEGE OF WILLIAM AND MARY

DEPARTMENT OF ECONOMICS

WORKING PAPER \# 91

June 2010

\title{
The Optimal Inflation Rate in New Keynesian Models
}

\begin{abstract}
We study the effects of positive steady-state inflation in New Keynesian models subject to the zero bound on interest rates. We derive the utility-based welfare loss function taking into account the effects of positive steady-state inflation and show that steady-state inflation affects welfare through three distinct channels: steady-state effects, the magnitude of the coefficients in the utility-function approximation, and the dynamics of the model. We solve for the optimal level of inflation in the model and find that, for plausible calibrations, the optimal inflation rate is low, less than two percent, even after considering a variety of extensions, including price indexation, endogenous price stickiness, capital formation, model uncertainty, and downward nominal wage rigidities. On the normative side, price level targeting delivers large welfare gains and a very low optimal inflation rate consistent with price stability.
\end{abstract}

JEL Codes: Optimal inflation, New Keynesian, zero bound, price level targeting. Keywords: E3, E4, E5.

Olivier Coibion

Department of Economics

College of William and Mary

Williamsburg, VA 23187

ocoibion@wm.edu
Yuriy Gorodnichenko

University of California, Berkeley

Department of Economics

Berkeley, CA 94720-3880

ygorodni@econ.berkeley.edu
Johannes Wieland

University of California, Berkeley

Department of Economics

Berkeley, CA 94720-3880

jwieland@econ.berkeley.edu 
"The crisis has shown that interest rates can actually hit the zero level, and when this happens it is a severe constraint on monetary policy that ties your hands during times of trouble. As a matter of logic, higher average inflation and thus higher average nominal interest rates before the crisis would have given more room for monetary policy to be eased during the crisis and would have resulted in less deterioration of fiscal positions. What we need to think about now is whether this could justify setting a higher inflation target in the future."

Olivier Blanchard, February $12^{\text {th }}, 2010$

\section{Introduction}

One of the defining features of the current economic crisis has been the zero bound on nominal interest rates. With standard monetary policy running out of ammunition in the midst of one of the sharpest downturns in post-World War II economic history, some have suggested that central banks should consider allowing for higher target inflation rates than would have been considered reasonable just a few years ago. We contribute to this question by explicitly incorporating positive steady-state inflation in a New Keynesian model. We derive the loss function and characterize the effects of non-zero steady-state inflation on welfare. In particular, we show that steady-state inflation affects welfare through three distinct channels: steady-state effects, the magnitude of the coefficients in the utility-function approximation, and the dynamics of the model. By incorporating the zero bound on nominal interest rates, we then solve for the optimal rate of inflation. Our baseline finding is that the optimal rate of inflation is low, less than two percent a year, even when we allow for a variety of features that would tend to lower the costs of positive steady-state inflation.

Modern monetary models of the business cycle are almost exclusively based on the assumption of zero steady-state inflation. However, recent work has emphasized that allowing for positive steady-state inflation is both qualitatively and quantitatively important. For example, Cogley and Sbordone (2008) show that accounting for positive steady-state inflation significantly affects empirical estimates of the New Keynesian Phillips Curve. Kiley (2007) and Ascari and Ropele (2009) show that the Taylor principle is not sufficient to guarantee a unique rational expectations equilibrium in New Keynesian models for even moderate levels of inflation. Coibion and Gorodnichenko (2009) show that once one incorporates this feature of New Keynesian models into historical monetary policy analysis, the preVolcker monetary policy rule ensured the presence of self-fulfilling expectational fluctuations despite likely satisfying the Taylor principle, a reflection of the high target rate of inflation over this time period. This paper builds on this literature by explicitly incorporating positive steady-state inflation into welfare calculations, so that one can more precisely measure the costs and benefits of steady-state inflation in a fully micro-founded model. 
Our first contribution is thus to solve for the loss function in an otherwise standard New Keynesian model with labor as the only factor of production under positive steady-state inflation, thereby laying the groundwork for welfare analysis. We show that allowing for positive steady-state inflation has several effects on the loss function. First, there are important steady-state effects as, with sticky prices, positive inflation leads to first-order price dispersion which causes an inefficient reallocation of resources among firms, thereby lowering aggregate welfare. Second, positive steady-state inflation raises the welfare cost of a given amount of inflation volatility. Third, incorporating positive steady-state inflation leads to the appearance of new terms in the utility-approximation, such as the variance of price dispersion and covariance of price dispersion with output and inflation, although these effects are quantitatively small when steady-state inflation is low.

Our second contribution is to integrate the zero bound on nominal interest rates into our welfare analysis of New Keynesian models with positive steady-state inflation. Our approach for modeling the zero bound follows Bodenstein et al (2009). This approach, unlike that in Christiano et al (2009) or Eggertsson and Woodford (2004), solves for the duration of the zero bound endogenously, whereas the latter impose an exogenous probability of exiting the zero bound. This is important because the welfare costs of inflation are a function of the variance of inflation and output, which themselves depend on the frequency at which the zero bound is reached as well as the duration of zero bound episodes. We find, for example, that the variance of the output gap is rapidly falling with positive steady-state inflation because the zero-bound on interest rates generates disproportionately large fluctuations in the gap which become less prevalent as steady-state inflation rises. In addition, the interaction of the zero-lower bound with positive steady-state inflation leads to a U-shape in the relationship between inflation variance and the steady-state level of inflation: at low levels of inflation, the variance of inflation falls as steady-state inflation rises because of the zero-bound effect, but at higher levels of inflation, the relationship is reversed as the increased forward-looking behavior of price setting decisions under positive steady-state inflation dominates the zero-bound effect. In short, when the zero lower bound is hit, the standard policy tools of the central bank lose their ability to stabilize the economy and, as a result, macroeconomic volatility rises. ${ }^{1}$ This plays a critical role in determining the optimal level of inflation in the model.

Our third contribution is then to solve for the rate of inflation that maximizes welfare in the presence of the zero bound on nominal interest rates. We show numerically that the welfare loss function with respect to aggregate inflation is generally concave with respect to steady-state inflation, such that the optimal rate of inflation is positive, reflecting the effects of the zero bound. However, for plausible

\footnotetext{
${ }^{1}$ Note that we assume that monetary policy-makers are indeed constrained by the zero-bound on interest rates, in the sense that we do not allow for non-standard monetary policy actions. Allowing for such additional policy tools would lead to even lower optimal rates of inflation if such tools are effective in stabilizing the economy during zerobound episodes.
} 
calibrations of the structural parameters of the model and the properties of the shocks driving the economy, the optimal inflation rate is quite low: less than two percent per year.

We show that this result is robust to a vast set of alternative parameter calibrations as well as the inclusion of capital in the model. We also extend our baseline model to consider several mechanisms which might raise the optimal rate of inflation. For example, in the presence of uncertainty about the true parameter values, policy-makers might want to ensure against parameter values that would imply larger costs of hitting the zero bound by choosing a higher steady-state inflation rate. We address this possibility in two ways. First, we calculate the optimal inflation rate taking into account the uncertainty about parameter values and find that this raises the optimal inflation rate only modestly, from $1.2 \%$ to $1.4 \%$ per year. Second, we repeatedly draw from the distribution of parameters and calculate the optimal inflation rate for each draw. We find that the $90 \%$ confidence interval of optimal inflation rates ranges from $0.4 \%$ to $2.1 \%$ a year, which closely mirrors the target range for inflation of most modern central banks.

Similarly, one might be concerned that our findings hinge on modeling price stickiness as in Calvo (1983). We address this concern in two ways. First, we allow for the possibility that the degree of price rigidity varies systematically with the steady state level of inflation but find that this modification does not change the optimal inflation rate. Secondly, we replace the Calvo assumption with prices of fixed durations, as in Taylor (1977). Using this alternative pricing structure has no significant impact on the optimal inflation rate.

Tobin (1972) suggests an additional factor which might push the optimal inflation rate higher: downward nominal wage rigidity. By facilitating the downward adjustment of real wages in the presence of downward wage rigidity, positive inflation can be desirable. We incorporate this "greasing the wheels" effect by imposing downward nominal wage rigidity in our model. Strikingly, this addition significantly lowers the optimal inflation rate. The intuition for this somewhat surprising finding is that downward wage rigidity lowers the volatility of marginal costs and therefore of inflation. In addition, in the face of a negative demand shock, marginal costs decline by less in the presence of downward-wage rigidity, leading to a smaller decline in inflation and hence, via the Taylor rule, a smaller change of interest rates. Thus, the zero-lower bound binds less frequently which further reduces the benefits of positive inflation.

The optimal rate of inflation has long been a source of interest for macroeconomists and a variety of costs have been proposed. The key cost of inflation in our baseline model is the price dispersion associated with sticky prices. Because not all firms change prices every period, inflation leads to differences in prices across firms even in the non-stochastic steady state which induce an inefficient reallocation of resources across firms. Other potential costs of inflation are likely to be quantitatively small (such as shoe-leather and menu costs) or to be associated with unanticipated inflation (such as 
uncertainty risks from redistribution among lenders and borrowers) rather than anticipated inflation, which is the focus of our analysis. Of course, there could be a stronger link between the level of inflation and the volatility of inflation than implied by our model, in which case our findings would tend to underestimate the costs of inflation. For example, if positive steady-state inflation is more likely to lead to indeterminacy as suggested by Kiley (2007), Ascari and Ropele (2009) and Coibion and Gorodnichenko (2009), then an additional cost of inflation would be the increase in the probability of moving into a state where sunspot shocks could generate further volatility. Because our baseline results point to optimal levels of inflation well below the indeterminacy region, incorporating this mechanism would likely lead to only minor downward revisions in our estimates of the optimal rate of inflation.

Friedman (1969) argued that the optimal rate of inflation must be negative to equalize the marginal cost and benefit of holding money. Because our model is that of a cashless economy, this cost of inflation is not present in our model, but would tend to lower the optimal rate of inflation even further, as emphasized by Khan, King and Wolman (2003), Schmitt-Grohe and Uribe (2007, 2010) and Aruoba and Schorfheide (2009). Similarly, a long literature has studied the costs and benefits of the seignorage revenue to policymakers associated with positive inflation, a feature which we also abstract from since seignorage revenues for countries like the U.S. are quite small, as are the deadweight losses associated with it. ${ }^{2}$ More recent work has increasingly emphasized the effects of the zero bound on interest rates, such as Walsh (2009), Billi (2009), and Williams (2009). A key difference between the approach taken in this paper and such previous work is that we explicitly model the effects of positive steady-state inflation on the steady-state, dynamics, and loss function of the model whereas previous work has instead relied on New Keynesian models linearized around a zero steady-state level of inflation, as in Billi (2009) or Walsh (2009), or on non-microfounded models such as Williams (2009). Also, these papers do not explicitly take into account the effects of positive steady-state inflation on the approximation to the utility function. ${ }^{3}$

One of the most significant advantages of working with a micro-founded model and its implied welfare function is the ability to engage in normative analysis. In addition to studying the optimal inflation rate in the model, we are also able to study the welfare effects of the systematic response of policy-makers to endogenous fluctuations (i.e. the coefficients of the Taylor rule) in conjunction with the optimal steady-state rate of inflation. The most striking finding from this analysis is that even modest price-level targeting would raise welfare by non-trivial amounts for any steady-state inflation rate. In addition, by reducing the volatility of inflation and output, and therefore the frequency of being at the

\footnotetext{
${ }^{2}$ See for example Cooley and Hansen (1991) and Summers (1991).

${ }^{3}$ Fuchi et al (2008) study the optimal inflation rate for Japan allowing for the zero-lower bound on interest rates, price stickiness, nominal wage rigidity and the opportunity cost of holding money and find a range between $0.5 \%$ and $2 \%$. However, they also do not explicitly take into account the effects of positive steady-state inflation on the dynamics of the model nor on the utility function approximation.
} 
zero lower bound on interest rates, price-level targeting leads to much lower optimal rates of inflation than in our baseline findings. In short, the optimal policy rule for the model can closely be characterized by the name of "price stability" as typically stated in the legal mandates of most central banks.

Section 2 presents the baseline New Keynesian model and derivations when allowing for positive steady-state inflation, including the associated loss function. Section 3 includes our baseline calibration of the model as well as the results for the optimal rate of inflation while section 4 investigates the robustness of our baseline results to parameter values. Section 5 then considers extensions of the baseline model which could potentially lead to higher estimates of steady-state inflation. Section 6 considers additional normative implications of the model while section 7 concludes.

\section{A New Keynesian Model with Positive Steady-State Inflation}

We consider a standard New Keynesian model with a representative consumer, a continuum of monopolistic producers of intermediate goods, a fiscal authority and a central bank.

\subsection{Model}

The representative consumer aims to maximize the present discount value of the utility stream from consumption and leisure

$$
\max E_{t} \sum_{j=0}^{\infty} \prod_{s=0}^{j}\left[\beta_{t+s}\right]\left\{\ln C_{t+j}-h \ln C_{t+j-1}-\frac{\eta}{\eta+1} \int_{0}^{1} N_{t+j}(i)^{1+\eta^{-1}} d i\right\}
$$

where $C$ is consumption of the final good, $N_{t}(i)$ is labor supplied to individual industry $i, h$ is the degree of external habit formation, $\eta$ is the Frisch labor supply elasticity and $\beta_{t}$ is the time-varying discount factor. The budget constraint each period is given by

$$
\xi_{t+j}: C_{t+j}+\frac{S_{t+j}}{P_{t+j}} \leq \int_{0}^{1} \frac{N_{t+j}(i) W_{t+j}(i)}{P_{t+j}} d i+\frac{S_{t+j} R_{t+j-1}}{P_{t+j}}+T_{t+j}
$$

where $S$ is the stock of one-period bonds held by the consumer, $R$ is the gross nominal interest rate, $P$ is the price of the final good, $W(i)$ is the nominal wage earned from labor in industry $i, T$ is transfers and profits from ownership of firms, and $\xi$ is the shadow value of wealth. The first order conditions from this utility-maximization problem are then:

$$
\begin{aligned}
& C_{t+j}^{-1}-h \beta_{t+j+1} C_{t+j}^{-1}=\xi_{t+j} \\
& N_{t+j}(i)^{1 / n}=\xi_{t+j} \frac{W_{t+j}(i)}{P_{t+j}} \\
& \frac{\xi_{t+j}}{P_{t+j}}=E_{t+j} \beta_{t+j+1} \xi_{t+j+1} \frac{R_{t+j+1}}{P_{t+j+1}}
\end{aligned}
$$

Production of the final good is done by a perfectly competitive sector which combines a continuum of intermediate goods into a final good per the following aggregator 


$$
Y_{t}=\left[\int_{0}^{1} Y_{t}(i)^{(\theta-1) / \theta} d i\right]^{\theta /(\theta-1)}
$$

where $Y_{t}$ is the final good and $Y(i)$ is intermediate good $i$, while $\theta$ denotes the elasticity of substitution across intermediate goods, yielding the following demand curve for goods of intermediate sector $i$

$$
Y_{t}(i)=Y_{t}\left(P_{t}(i) / P_{t}\right)^{-\theta}
$$

and the following expression for the aggregate price level

$$
P_{t}=\left[\int_{0}^{1} P_{t}(i)^{1-\theta} d i\right]^{1 /(1-\theta)}
$$

The production of each intermediate good is done by a monopolist facing a production function linear in labor

$$
Y_{t}(i)=A_{t} N_{t}(i)
$$

where $A$ denotes the level of technology, common across firms. Each intermediate good producer has sticky prices, modeled as in Calvo (1983) where $1-\lambda$ is the probability that each firm will be able to reoptimize its price each period. We allow for indexation of prices to steady-state inflation by firms who do not reoptimize their prices each period, with $\omega$ representing the degree of indexation ( 0 for no indexation to 1 for full indexation). Denoting the optimal reset price of firm $i$ by $B(i)$, re-optimizing firms solve the following profit-maximization problem

$$
\max E_{t} \sum_{j=0}^{\infty} \lambda^{j} Q_{t, t+j}\left[Y_{t+j}(i) B_{t}(i) \bar{\Pi}^{\omega j}-W_{t+j}(i) N_{t+j}(i)\right]
$$

where $Q$ is the stochastic discount factor and $\bar{\Pi}$ is the gross steady-state level of inflation. The optimal relative reset price is then given by

$$
\frac{B_{t}(i)}{P_{t}}=\frac{\theta}{\theta-1} \frac{\sum_{j=0}^{\infty} \lambda^{j} Q_{t, t+j} Y_{t+j}\left(P_{t+j} / P_{t}\right)^{\theta+1} \bar{\Pi}^{-\omega \theta}\left(M C(i)_{t+j} / P_{t+j}\right)}{\sum_{j=0}^{\infty} \lambda^{j} Q_{t, t+j} Y_{t+j}\left(P_{t+j} / P_{t}\right)^{\theta} \bar{\Pi}^{-\omega(\theta-1)}}
$$

where firm-specific marginal costs can be related to aggregate variables using

$$
\frac{M C_{t+j}(i)}{P_{t+j}}=\left(\frac{C_{t+j}}{\left(1-h \beta_{t+j+1}\right) A_{t+j}}\right)\left(\frac{Y_{t+j}}{A_{t+j}}\right)^{1 / \eta}\left(\frac{B_{t}(i)}{P_{t}}\right)^{-\theta / \eta}\left(\frac{P_{t+j}}{\bar{\Pi}^{\omega} P_{t}}\right)^{\theta / \eta} .
$$

Given these price-setting assumptions, the dynamics of the price level are governed by

$$
P_{t}^{1-\theta}=(1-\lambda) B_{t}^{1-\theta}+\lambda P_{t-1}^{1-\theta} \bar{\Pi}^{\omega(1-\theta)}
$$

We allow for government consumption of final goods $\left(G_{t}\right)$, so the goods market clearing condition for the economy is

$$
Y_{t}=C_{t}+G_{t} \text {. }
$$

We define the aggregate labor input as 


$$
N_{t+j}=\left[\int_{0}^{1} N_{t+j}(i)^{(\theta-1) / \theta}\right]^{\theta /(\theta-1)}
$$

\subsection{Steady-state and log-linearization}

Following Coibion and Gorodnichenko (2009), we log-linearize the model around the steady-state in which inflation need not be zero. Since positive trend inflation may imply that the steady state and the flexible price level of output differ, we adopt the following notational convention. Variables with a bar denote steady state values, e.g. $\bar{Y}_{t}$ is the steady state level of output. We assume that technology is a random walk and hence we normalize all non-stationary real variables by the level of technology. Lowercase letters denote the $\log$ of a variable, e.g. $y_{t}=\log \left(Y_{t}\right)$ is the $\log$ of current output. We let hats on lower case letters denote deviations from steady state, e.g. $\hat{y}_{t}=y_{t}-\bar{y}_{t}$ is the approximate percentage deviation of output from steady state. Since we define the steady state as embodying the current level of technology, deviations from steady state are stationary. Finally, we denote deviations from the flexible price level steady state with a tilde, e.g. $\tilde{y}_{t}=y_{t}-\bar{y}_{t}^{F}$ is the approximate percentage deviation of output from its flexible price steady state, where the superscript $F$ denotes a flexible price level quantity. Define the net steady state level of inflation as $\bar{\pi}=\log (\bar{\Pi})$. The log-linearized consumption Euler equation is

$$
-\hat{c}_{t}=E_{t}\left[-\hat{c}_{t+1}+\hat{r}_{t}-\hat{\pi}_{t+1}+\left(1+\frac{h \beta}{1-h \beta}\right) \hat{\beta}_{t+1}-\frac{h \beta}{1-h \beta} \hat{\beta}_{t+2}\right]
$$

and the goods market clearing condition becomes

$$
\hat{y}_{t}=\bar{c}_{y} \hat{c}_{t}+\bar{g}_{y} \hat{g}_{t}
$$

where $\bar{c}_{y}$ and $\bar{g}_{y}$ are the steady-state ratios of consumption and government to output respectively. Also, integrating over firm-specific production functions and log-linearizing yields

$$
\hat{y}_{t}=\hat{n}_{t}
$$

Allowing for positive steady-state inflation primarily affects the price-setting component of the model. For example, the steady-state level of the output gap (which is defined as the deviation of steady state output from its flexible price level counterpart $\left.\bar{X}_{t}=\bar{Y}_{t} / \bar{Y}_{t}^{F}\right)$ is given by

$$
\bar{X}^{\frac{(\eta+1)}{\eta}}=\frac{1-\left[1-\lambda \beta^{-1} \bar{\Pi}^{(1-\omega) \theta}\right]\left(\frac{1-\lambda \bar{\Pi}^{(1-\omega)(\theta-1)}}{1-\lambda}\right)^{\frac{\eta+\theta}{\eta(\theta-1)}}}{\lambda \beta^{-1} \bar{\Pi}^{(1-\omega) \theta(\eta+1) / \eta}} .
$$

Note that the steady-state level of the gap is equal to one when steady-state inflation is zero (i.e., $\bar{\Pi}=1$ ) or when the degree of price indexation is exactly equal to one. As emphasized by Ascari and Ropele (2007), there is a non-linear relationship between the steady-state levels of inflation and output. For very low but positive levels of inflation, the steady-state output gap is increasing in steady-state inflation but the sign is quickly reversed so that the output gap is expanding with steady-state inflation for most positive levels of inflation. 
Secondly, positive steady-state inflation affects the relationship between aggregate inflation and the re-optimizing price. Specifically, the relationship between the two in the steady state is now given by

$$
\left(\frac{\bar{B}}{P}\right)=\left(\frac{1-\lambda}{1-\lambda \bar{\Pi}^{(1-\omega)(\theta-1)}}\right)^{1 /(\theta-1)}
$$

and the log-linearized equation is described by

$$
\hat{\pi}_{t}=\left(\frac{1-\lambda \bar{\Pi}^{(1-\omega)(\theta-1)}}{\lambda \bar{\Pi}^{(1-\omega)(\theta-1)}}\right) \hat{b}_{t} \Rightarrow \quad \hat{b}_{t}=M \hat{\pi}_{t}
$$

which implies that inflation is less sensitive to changes in the re-optimizing price as steady-state inflation rises. This effect reflects the fact that, with positive steady-state inflation, firms which reset prices have higher prices than others and receive a smaller share of expenditures, thereby reducing the sensitivity of inflation to these price changes. Indexation of prices works to offset this effect however, with fullindexation completely restoring the usual relationship between reset prices and inflation.

Similarly, positive steady-state inflation has important effects for the log-linearized reset price equation, which is given by

$$
\begin{aligned}
\left(1+\frac{\theta}{\eta}\right) \hat{b}_{t} & =\left(1-\gamma_{2}\right) \sum_{j=0}^{\infty} \gamma_{2}^{j}\left(\frac{1}{\eta} E_{t} \hat{y}_{t+j}+E_{t} \hat{c}_{t+j}-\frac{h \beta}{1-h \beta} \hat{\beta}_{t+j+1}\right) \\
& +E_{t} \sum_{j=1}^{\infty}\left(\gamma_{2}^{j}-\gamma_{1}^{j}\right)\left(\hat{g} y_{t+j}-\hat{r}_{t+j-1}\right)+\sum_{j=1}^{\infty}\left[\gamma_{2}^{j}\left(1+\frac{\theta(\eta+1)}{\eta}\right)-\gamma_{1}^{j} \theta\right] E_{t} \hat{\pi}_{t+j}+\hat{m}_{t}
\end{aligned}
$$

where $m_{t}$ is the cost-push shock, $\gamma_{1}=\lambda \beta^{-1} \bar{\Pi}^{(1-\omega)(\theta-1)}$ and $\gamma_{2}=\lambda \beta^{-1} \bar{\Pi}^{(1-\omega) \theta)}$ so that without steady-state inflation or full indexation we have $\gamma_{1}=\gamma_{2}$. Consider how positive steady-state inflation affects the relative reset price $b_{t}$. First, higher steady-state inflation raises $\gamma_{2}$, so that the weights in the output gap term shift away from the current gap and more towards future output gaps. This reflects the fact that as the relative reset price falls over time, the firm's future losses will tend to grow very rapidly. Thus, a sticky-price firm must be relatively more concerned with marginal costs far in the future when steadystate inflation is positive. Second, the relative reset price now depends on the discounted sum of future differences between output growth and interest rates. Note that this term disappears when steady-state inflation is zero. This factor captures the scale effect of aggregate demand in the future. The higher aggregate demand is expected to be in the future, the bigger the firm's losses will be from having a deflated price. The interest rate captures the discounting of future gains. When $\bar{\Pi}=1$, steady-state inflation is zero, these two factors cancel out on average. Positive steady-state inflation, however, induces the potential for much bigger losses in the future which makes these effects first-order. Thus, as with the output gap, positive steady-state inflation induces more forward-looking behavior on the part of firms. Third, positive steady-state inflation raises the coefficient on expected inflation. This reflects the fact that the higher is expected inflation, the more rapidly the firm's price will depreciate, the higher it must set its reset price. Thus, positive steady-state inflation makes firms more forward-looking in their price-setting decisions by raising the importance of future marginal costs and inflation, as well as by 
inducing them to also pay attention to future output growth and interest rates. Finally, note that with fullindexation of prices, the effects of steady-state inflation on the reset price equation are completely eliminated, while partial indexation mitigates some of the effects of positive steady-state inflation. In summary, the properties of the Philips curve, which is the bridge between nominal and real quantities, depend on the level of steady-state inflation.

To close the model, we assume that the log deviation of the desired gross interest rate from its steady state value, $r_{t}^{*}$ follows a Taylor rule

$\hat{r}_{t}^{*}=\rho_{1} \hat{r}_{t-1}^{*}+\rho_{2} \hat{r}_{t-2}^{*}+\left(1-\rho_{1}-\rho_{2}\right)\left[\phi_{\pi}\left(\pi_{t}-\pi^{*}\right)+\phi_{y}\left(y_{t}-y^{*}\right)+\phi_{g y}\left(g y_{t}-g y^{*}\right)+\phi_{p}\left(p_{t}-p_{t}^{*}\right)\right]+\varepsilon_{t}^{r}$

where $\phi_{\pi}, \phi_{y}, \phi_{g y}, \phi_{p}$ capture the strength of the policy response to deviations of inflation, the output gap, the output growth rate and the price level from their respective targets, parameters $\rho_{1}$ and $\rho_{2}$ reflect interest rate smoothing, while $\varepsilon_{t}^{r}$ is a policy shock. We set $\pi^{*}=\bar{\pi}, p_{t}^{*}=\pi^{*} t=\bar{\pi} t$ and $g y^{*}=\overline{g y}$ which means that the central bank has no inflationary or output bias. The growth rate of output is related to the output gap by

$$
g y_{t}=\hat{y}_{t}-\hat{y}_{t-1}+\left(a_{t}-a_{t-1}\right) .
$$

Since the actual level of the net interest rate is bounded by zero, the log deviation of the gross interest rate is bounded by $\hat{r}_{t}=\log \left(R_{t}\right)-\log (\bar{R}) \geq-\log (\bar{R})=-\bar{r}$ and the dynamics of the actual interest rate are given by

$$
\hat{r}_{t}=\max \left\{\hat{r}_{t}^{*},-\bar{r}\right\}
$$

\subsection{Shocks}

We assume that technology follows a random walk process with drift:

$$
a_{t}=a_{t-1}+\mu+\varepsilon_{t}^{a} .
$$

Each of the discount factor, government, and Phillips Curve shocks follow AR(1) processes

$$
\begin{aligned}
& \hat{\beta}_{t}=\rho_{\beta} \hat{\beta}_{t-1}+\varepsilon_{t}^{\beta}, \\
& \hat{g}_{t}=\rho_{g} \hat{g}_{t-1}+\varepsilon_{t}^{g}, \\
& \hat{m}_{t}=\rho_{m} \hat{m}_{t-1}+\varepsilon_{t}^{m} .
\end{aligned}
$$

We assume that $\varepsilon_{t}^{a}, \varepsilon_{t}^{\beta}, \varepsilon_{t}^{g}, \varepsilon_{t}^{m}, \varepsilon_{t}^{r}$ are mutually and serially uncorrelated.

\subsection{Welfare function}

To quantify welfare for different levels of steady-state inflation, we use a second-order approximation to the household utility function as in Woodford (2003). We show our main results in a series of lemmas culminating in Proposition 1. All proofs are in Appendix A.

First of all, we decompose utility described in equation (1) into utility due to consumption and (dis)utility due to labor supply. Lemmas 1 and 2 provide second order approximations for each component. 
Lemma 1. Utility from consumption in equation (1) is given by

$$
u\left(C_{t}\right)-h u\left(C_{t-1}\right)=\tilde{c}_{t}-h \tilde{c}_{t-1}+\text { h.o.t. }
$$

where $\tilde{c}_{t}=\log \left(C_{t} / C_{t}^{F}\right)$ is the percent deviation of consumption from its flexible-price level and h.o.t. means higher order terms.

Lemma 2. Using production function (9), define $\tilde{v}\left(Y_{t}(i)\right) \equiv v\left(N_{t}(i)\right) \equiv N_{t}(i)^{1+1 / \eta}$. Then

$$
\tilde{v}\left(Y_{t}(i)\right) \approx \bar{Y}_{t}^{F} \tilde{v}_{\bar{Y}_{t}^{F}}^{\prime}\left\{\tilde{y}_{t}(i)+\frac{1}{2}\left(1+\eta^{-1}\right) \tilde{y}_{t}^{2}(i)\right\}+\text { t.i.p. }+ \text { h.o.t. }
$$

where $\tilde{y}_{t}(i)=\log \left(Y_{t}(i) / \bar{Y}_{t}^{F}\right)$ is the deviation of firm $i$ 's output from flexible-price level of output $\bar{Y}_{t}^{F}, \eta$ is the Frisch elasticity of labor supply, t.i.p. stands for terms independent from policy, h.o.t. means higher order terms. Correspondingly, the total disutility from labor supply is

$$
\int_{0}^{1} \tilde{v}\left(Y_{t}(i)\right) d i=\bar{Y}_{t}^{F} \tilde{v}_{\bar{Y}_{t}^{F}}^{\prime}\left\{E_{i} \tilde{y}_{t}(i)+\frac{1}{2}\left(1+\eta^{-1}\right) \int_{0}^{1} \tilde{y}_{t}^{2}(i) d i\right\}+\text { t.i.p. }+ \text { h.o.t. }
$$

Proof: See Proposition 6.3 in Woodford (2003).

The key insight from Lemmas 1 and 2 is that welfare is diminished when consumption is low relative to its flexible-price level and when the cross-sectional dispersion of output is large. Equation (19) provides a sense of how the deviation of output (and consumption) is affected by steady-state inflation on average. To understand and assess the implications of cross-sectional output dispersion, we need to examine the cross-sectional dispersion of prices.

Denote the cross-sectional dispersion of prices at time $t$ with $\Delta_{t}=\operatorname{var}_{i}\left(\log \left(P_{t}(i)\right)\right)$ and let $\bar{\Delta}$ be the cross-sectional dispersion of prices in the non-stochastic steady state. It is straightforward to show that $\bar{\Delta}=\bar{\pi}^{2 \lambda(1-\omega)^{2}} \frac{{ }^{2}}{(1-\lambda)^{2}}$ where $\bar{\Delta}$ is increasing in price stickiness $\lambda$ and steady-state inflation $\bar{\pi}$ and decreasing in the degree of indexation $\omega$. Define $\bar{P}_{t}=E_{i} \log P_{t}(i)$ as the average (across firms) $\log$ price of goods.

Lemma 3. The difference between the log price index $P_{t}$ and the average log price across firms $\bar{P}_{t}$ is given by

$$
\ln P_{t}-\bar{P}_{t}=Q_{p}^{0}+\frac{1-\theta}{2} Q_{p}^{1}\left(\Delta_{t}-\bar{\Delta}\right)+\text { h.o.t. }
$$

where $Q_{p}^{0}=\frac{1-\theta}{2} \frac{\bar{\Delta}}{\left[1+\frac{1}{2}(1-\theta)^{2} \bar{\Delta}\right]^{2}}$ and $Q_{p}^{1}=\frac{1-\frac{1}{2}(1-\theta)^{2} \bar{\Delta}}{\left[1+\frac{1}{2}(1-\theta)^{2} \bar{\Delta}\right]^{3}}$.

Lemma 3 is a manifestation of Jensen's inequality. Note that since $\bar{\Delta}$ is quadratic in $\bar{\pi}$, the dispersion of prices $\bar{\Delta}$ is approximately zero when $\bar{\pi} \approx 0$ and therefore $Q_{p}^{0} \approx 0, Q_{p}^{1} \approx 1$ so that $\ln P_{t}-$ 
$\bar{P}_{t} \approx \frac{1-\theta}{2} \Delta_{t}$, which is the standard result. Again, since $\bar{\Delta}$ is quadratic in $\bar{\pi}$, one can show that $\partial Q_{p}^{0} / \partial \bar{\pi} \approx 0$, $\partial Q_{p}^{1} / \partial \bar{\pi} \approx 0$ when $\bar{\pi} \approx 0$.

Using Lemma 3, we describe the dynamic properties of the price dispersion in Lemma 4.

Lemma 4. Let $\Xi_{t} \equiv \Delta_{t}-\bar{\Delta}$ be the deviation of cross-section price dispersion from its non-stochastic steady state level $\bar{\Delta}$. Then

$$
\begin{aligned}
\Xi_{t} & =\Gamma_{2}\left(\pi_{t}-\bar{\pi}\right)+\lambda \Gamma_{1} \Xi_{t-1}+\Xi_{t-1}^{2} \Gamma_{0}\left\{\frac{(1-\theta)^{2}}{4}\left[Q_{p}^{1}\right]^{2}\left[\left(\lambda \Gamma_{1}\right)^{2}+\lambda\left(1-2 \lambda \Gamma_{1}\right)\right]\right\} \\
& +\left(\pi_{t}-\bar{\pi}\right)^{2} \Gamma_{0}\left\{(1-\lambda) M^{2}+\lambda+\frac{(1-\theta)^{2}}{4}\left[Q_{p}^{1}\right]^{2} \Gamma_{2}^{2}+(1-\lambda)(1-\theta) M Q_{p}^{1} \Gamma_{2}-\lambda(1-\theta) Q_{p}^{1} \Gamma_{2}\right\} \\
& +\left(\pi_{t}-\bar{\pi}\right) \Xi_{t-1} \Gamma_{0}\left\{(1-\lambda)(1-\theta) Q_{p}^{1}\left[M \lambda \Gamma_{1}+\left(1-\lambda \Gamma_{1}\right)\right]+\frac{(1-\theta)^{2}}{2}\left[Q_{p}^{1}\right]^{2} \Gamma_{2} \lambda\left(\Gamma_{1}-1\right)\right\}+\text { h.o.t. }
\end{aligned}
$$

where

$$
\begin{aligned}
& \Gamma_{0}=\left\{1+(\theta-1) Q_{p}^{1}\left[(1-\lambda)\left(\bar{b}+Q_{p}^{0}\right)-\lambda(1-\omega) \bar{\pi}\right]\right\}^{-1}, \\
& \Gamma_{1}=\left[1-(\theta-1)(1-\omega) Q_{p}^{1} \bar{\pi}\right] \Gamma_{0}, \\
& \Gamma_{2}=2\left\{(1-\lambda) M\left(\bar{b}+Q_{p}^{0}\right)+\lambda(1-\omega) \bar{\pi}\right\} \Gamma_{0},
\end{aligned}
$$

$\bar{b}$ is the log of the optimal reset price in the non-stochastic steady state.

This lemma shows that the cross-sectional price dispersion is a function of its past values as well as the deviation of inflation from its steady state level. In the vicinity of $\bar{\pi}=0, \Gamma_{0} \approx 1, \Gamma_{1} \approx 1, \Gamma_{2} \approx 0$ and thus cross-sectional price dispersion varies very little over time. This is because it no longer depends on the first-order deviations of inflation from its steady state value but rather is a function only of second-order terms and thus can be ignored as negligible. This is the standard result for welfare calculations in a zero steady state inflation environment (see e.g. Proposition 6.3 in Woodford (2003)). However, $\partial \Gamma_{0} / \partial \bar{\pi}>$ $0, \partial \Gamma_{1} / \partial \bar{\pi}<0, \partial \Gamma_{2} / \partial \bar{\pi}>0$ locally at $\bar{\pi} \approx 0$. Hence, deviations of inflation from its steady state level have an increasingly strong effect on the cross-sectional price dispersion as $\bar{\pi}$ rises. Also observe that for $\bar{\pi} \approx 0$ only the first and second terms in the right hand side of (34) are non-negligible. However, as one moves away from $\bar{\pi} \approx 0$, other terms become important too.

Using the demand condition (7), we can link the cross-sectional dispersion of output to the crosssectional dispersion of prices:

$$
\tilde{y}_{t}(i)=\log Y_{t}(i)-\log \bar{Y}_{t}^{F}=\log Y_{t}-\log \bar{Y}_{t}^{F}-\theta\left\{\log P_{t}(i)-\log P_{t}\right\}
$$

and hence

$$
\Upsilon_{t} \equiv \operatorname{var}_{i} \hat{y}_{t}(i)=\operatorname{var}_{i} \tilde{y}_{t}(i)=\theta^{2} \operatorname{var}_{i}\left(\log \left(P_{t}(i)\right)\right)=\theta^{2} \Delta_{t} .
$$

Let $\bar{Y}$ be the cross-sectional dispersion of output in the non-stochastic steady state. The remaining piece in the second-order approximation of household's utility is $E_{i} \hat{y}_{t}(i)$, which is the average deviation of output 
from flexible price level at the firm level. Using the insight of Lemma 3 , we can relate $E_{i} \hat{y}_{t}(i)$ to the deviation of output from its flexible-price level at the aggregate level.

Lemma 5. If the deviation of output from its flexible-price level at the aggregate level is defined as $\tilde{y}_{t}=\log \left(Y_{t} / \bar{Y}_{t}^{F}\right)$, then

$$
E_{i} \tilde{y}_{t}(i)=\tilde{y}_{t}-Q_{y}^{0}-\frac{1}{2} \frac{\theta-1}{\theta} Q_{y}^{1}\left(\Upsilon_{t}-\bar{\Upsilon}\right)+\text { h.o.t. }
$$

where $Q_{y}^{0}=\frac{1}{2} \frac{\theta-1}{\theta} \frac{\bar{\Upsilon}}{\left[1+\frac{1}{2}\left(\frac{\theta-1}{\theta}\right)^{2} \bar{\Upsilon}\right]^{2}}$ and $Q_{y}^{1}=\frac{1-\frac{1}{2}\left(\frac{\theta-1}{\theta}\right)^{2} \bar{\Upsilon}}{\left[1+\frac{1}{2}\left(\frac{\theta-1}{\theta}\right)^{2} \bar{\Upsilon}\right]^{3}}$.

Similar to the cross-sectional price dispersion, one can show that, since $\bar{\Upsilon}$ is quadratic in $\bar{\pi}, Q_{y}^{0} \approx 0$, $Q_{y}^{1} \approx 1$ and $\partial Q_{y}^{0} / \partial \bar{\pi} \approx 0, \partial Q_{y}^{1} / \partial \bar{\pi} \approx 0$ when $\bar{\pi} \approx 0$.

The central result can be summarized with the following proposition

Proposition 1. Given Lemmas 1-5, the second order approximation to per period utility in eq. (1) is $\Theta_{0}+\Theta_{1} \operatorname{var}\left(\hat{y}_{t}\right)+\Theta_{2} \operatorname{cov}\left(\hat{y}_{t}, \Xi_{t}\right)+\Theta_{3} \operatorname{var}\left(\Xi_{t}\right)+\Theta_{4} \operatorname{var}\left(\hat{\pi}_{t}\right)+\Theta_{5} \operatorname{cov}\left(\hat{\pi}_{t}, \Xi_{t-1}\right)$

where $\Xi_{t}$ is the deviation of price dispersion from non-stochastic steady state and parameters $\Theta_{i}, i=0, \ldots, 5$ depend on the steady state inflation $\bar{\pi}$ and are given by

$$
\begin{aligned}
\Theta_{0}= & {\left[1-h-(1-\beta h)(1-\Phi)\left(1-\left(1+\frac{1}{\eta}\right) Q_{y}^{0}\right)\right] \log (\bar{X}) } \\
& -\frac{(1-\beta h)(1-\Phi)}{\left(1-\bar{g}_{y}\right)}\left[\left(1+\frac{1}{\eta}\right)\left[Q_{y}^{0}\right]^{2}-Q_{y}^{0}+\frac{\theta-1}{\theta} Q_{y}^{1}\left[\frac{1}{2}-\left(1+\frac{1}{\eta}\right) Q_{y}^{0}\right] \bar{\Upsilon}\right] \\
& -\frac{1}{2} \frac{(1-\beta h)\left(1+\frac{1}{)}(1-\Phi)\right.}{\left(1-\bar{g}_{y}\right)}[\log (\bar{X})]^{2}-\frac{1}{2} \frac{(1-\beta h)}{\left(1-\bar{g}_{y}\right)}\left[Q_{y}^{1}\left(\frac{1}{\theta}-1\right)-Q_{y}^{1}+\left(1+\frac{1}{\eta}\right)\left(1+\frac{\theta-1}{\theta} Q_{y}^{0} Q_{y}^{1}\right)\right] \theta^{2} \bar{\Delta}, \\
\Theta_{1}= & -\frac{1}{2} \frac{(1-\beta h)\left(1+\frac{1}{\eta}\right)}{\left(1-\bar{g}_{y}\right)}, \\
\Theta_{2}= & \frac{1}{2} \frac{(1-\beta h)\left(1+\frac{1}{\eta}\right)}{\left(1-\bar{g}_{y}\right)} \frac{\theta-1}{\theta} Q_{y}^{1} \theta^{2}, \\
\Theta_{3}= & -\frac{1}{8} \frac{(1-\beta h)\left(1+\frac{1}{\eta}\right)}{\left(1-\bar{g}_{y}\right)}\left(\frac{\theta-1}{\theta}\right)^{2}\left[Q_{y}^{1}\right]^{2} \theta^{4} \\
\Theta_{4}= & -\frac{1}{2} \frac{(1-\beta h)}{\left(1-\bar{g}_{y}\right)} \theta^{2} \Gamma_{3}\left\{\left[Q_{y}^{1}\left(\frac{1}{\theta}-1\right)+\left(1+\eta^{-1}\right)\left(1+\frac{\theta-1}{\theta} Q_{y}^{0} Q_{y}^{1}\right)\right]-\left(1+\frac{1}{\eta}\right) \frac{\theta-1}{\theta} Q_{y}^{1} \log (\bar{X})\right\}, \\
\Theta_{5}= & -\frac{1}{2} \frac{(1-\beta h)}{\left(1-\bar{g}_{y}\right)} \theta^{2} \Gamma_{4}\left\{\left[Q_{y}^{1}\left(\frac{1}{\theta}-1\right)+\left(1+\eta^{-1}\right)\left(1+\frac{\theta-1}{\theta} Q_{y}^{0} Q_{y}^{1}\right)\right]-\left(1+\frac{1}{\eta}\right) \frac{\theta-1}{\theta} Q_{y}^{1} \log (\bar{X})\right\}, \\
\Gamma_{3}= & \frac{\Gamma_{0}}{\left(1-\lambda \Gamma_{1}\right)}\left\{(1-\lambda) M^{2}+\lambda+\frac{(1-\theta)^{2}}{4}\left[Q_{p}^{1}\right]^{2} \Gamma_{2}^{2}+(1-\lambda)(1-\theta) M Q_{p}^{1} \Gamma_{2}-\lambda(1-\theta) Q_{p}^{1} \Gamma_{2}\right\}, \\
\Gamma_{4}= & \frac{\Gamma_{0}}{1-\lambda \Gamma_{1}}\left\{(1-\lambda)(1-\theta) Q_{p}^{1}\left[M \lambda \Gamma_{1}+\left(1-\lambda \Gamma_{1}\right)\right]+\frac{(1-\theta)^{2}}{2}\left[Q_{p}^{1}\right]^{2} \Gamma_{2} \lambda\left(\Gamma_{1}-1\right)\right\},
\end{aligned}
$$




$$
\begin{aligned}
& \Gamma_{5}=\frac{\Gamma_{0}}{1-\lambda \Gamma_{1}}\left\{\frac{(1-\theta)^{2}}{4}\left[Q_{p}^{1}\right]^{2}\left[\left(\lambda \Gamma_{1}\right)^{2}+\lambda\left(1-2 \lambda \Gamma_{1}\right)\right]\right\}, \\
& \Phi=-\log \left(\frac{\theta-1}{\theta}\right) .
\end{aligned}
$$

Although the complexity of equation (45) may seem daunting, it illustrates the three mechanisms via which inflation affects welfare: the steady-state effects, the effects on the coefficients of the utilityfunction approximation, and the dynamics of the economy via the second moments of macroeconomic variables. First, the term $\Theta_{0}$ captures the steady-state effects from positive steady-state inflation, which hinge on the increase in the cross-sectional steady-state dispersion in prices (and therefore in inefficient reallocations of resources across sectors) associated with positive steady-state inflation. ${ }^{4}$ Note that as $\bar{\pi}$ approaches zero, $\Theta_{0}$ converges to zero. For positive $\bar{\pi}, \Theta_{0}$ is strictly negative. Furthermore, one can show that in the vicinity of $\bar{\pi} \approx 0, \partial \Theta_{0} / \partial \bar{\pi}<0$ that is the welfare loss from steady-state effects is increasing in the steady-state level of inflation. This is intuitive since, except for very small levels of inflation, the steady state level of output declines with higher trend inflation because the steady state cross-sectional price dispersion rises. Consistent with this effect being driven by the increase in dispersion, one can show that the steady-state effect is eliminated with full indexation of prices and mitigated with partial indexation.

Second, the coefficient on the variance of output around its steady state $\Theta_{1}<0$ does not depend on the steady-state level of inflation. This term is directly related to the disutility of cross-sectional dispersion of labor supply. A part of this disutility is brought about by the variance of output around its steady state which is not a direct function of steady-state inflation. However, this does not imply that positive trend inflation does not impose any output cost. Rather, trend inflation reduces the steady state level of output, which is already captured by $\Theta_{0}$. Once this is taken into account, then log utility implies that a given level of output variance around the (new) steady state is as costly as it was before. Furthermore, the variance of output around its steady state depends on the dynamic properties of the model which are affected by the level of steady-state inflation.

The coefficient on the variance of inflation $\Theta_{4}<0$ captures the sensitivity of the welfare loss due to the cross-sectional dispersion of prices. One can also show analytically that for $\bar{\pi} \approx 0, \partial \Theta_{4} / \partial \bar{\pi}<0$ so that the cross-sectional dispersion of prices becomes ceteris paribus costlier in terms of welfare. This result reflects the fact that firms who have not adjusted their prices for long periods have very low relative prices and therefore high relative production levels. Since higher production requires higher levels of employment and the marginal disutility of sector-specific labor is increasing in labor input, it becomes

\footnotetext{
${ }^{4}$ The parameter $\Phi$ measures the deviation of the flexible-price level of output from the flexible-price perfectcompetition level of output. See Woodford (2003) for derivation.
} 
more costly to produce a given level of output as the steady-state level of inflation rises. Furthermore, $\Theta_{4}$ decreases in the elasticity of substitution across goods, the Frisch labor supply elasticity, and the Calvo parameter $\lambda$ which governs the stickiness of prices.

Although $\Theta_{2}>0, \Theta_{3}<0, \Theta_{5}>0$ are not negligible when $\bar{\pi} \approx 0$, the terms multiplied by these coefficients are negligible when steady-state level of inflation is approximately zero ${ }^{5}$. As $\bar{\pi}$ rises, the importance of these terms increases and we keep track of these terms to have a better approximation to the utility function. Again, one can show that $\partial \Theta_{2} / \partial \bar{\pi} \approx 0$ (this is because $\bar{\Upsilon}$ is quadratic in $\bar{\pi}$ ), $\partial \Theta_{3} /$ $\partial \bar{\pi}>0$ and $\partial \Theta_{5} / \partial \bar{\pi}>0$ in the neighborhood of $\bar{\pi}=0$.

The coefficient on the variance of price dispersion $\Theta_{3}$ captures the welfare loss from variations in the average cross-sectional labor input. We already know that when price dispersion is high, then the dispersion in labor input is also high. Since the marginal disutility of labor is increasing, a higher dispersion in labor input will increase the average cost of production across industries thereby raising the price and reducing the average labor input. The variation in price dispersion therefore induces additional variation in the cross-sectional average of labor input which lowers welfare because of increasing marginal disutility of labor. When $\bar{\pi}=0$ this effect is small and can be ignored. However, with positive trend inflation the variation in price dispersion is much larger as firms with fixed prices face consistently falling relative prices and firms that can reset prices will set it above the prevailing average price. This implies that variations in average labor input are much larger with positive trend inflation and have to be included in the welfare analysis. $\Theta_{3}$ is decreasing in trend inflation, since with higher trend inflation firms pay more attention to future economic variables than the current level of price dispersion when setting their reset prices and so the effect of price dispersion on today's average labor input is less pronounced.

Since the covariance of the deviation of output from steady state and the cross-sectional dispersion of prices and the covariance of inflation and the cross-sectional dispersion of prices are positive, parameters $\Theta_{2}>0$ and $\Theta_{5}>0$ help us avoid double counting of the welfare effects from the increased variability of output, inflation and the cross-sectional price dispersion.

Note that when $\bar{\pi}=0$, equation (45) reduces to the standard second-order approximation of the utility function as in Proposition 6.4 of Woodford (2003). ${ }^{6}$

\section{Calibration and Optimal Inflation}

Having derived the approximation to the utility function, we now turn to solving for the optimal inflation rate. Because utility depends on the variance and covariance of macroeconomic variables, this will be a function of the structural parameters and shock processes. Therefore, we first discuss our parameter

\footnotetext{
${ }^{5}$ When $\bar{\pi}=0$, the terms $\operatorname{cov}\left(\hat{y}_{t}, \Xi_{t}\right), \operatorname{var}\left(\hat{y}_{t}, \Xi_{t}\right), \operatorname{cov}\left(\hat{\pi}_{t}, \Xi_{t-1}\right)$ are of third order or higher.

${ }^{6}$ There is a slight difference between our approximation and the approximation in Woodford (2003) since we focus on the per period utility while Woodford calculated the present value.
} 
selection, then consider the implications for the optimal inflation rate in the model. We investigate the robustness of our results to parameter values in a later section.

\subsection{Parameters}

Our baseline parameter values are illustrated in Table 1. For the utility function, we set $\eta$, the Frisch labor supply elasticity, equal to one and the degree of external habit formation $h$ to 0 . The steady-state discount factor $\beta$ is set to 0.993 to match the real rate of $2.2 \%$ per year on 6-month commercial paper or assets with similar short-term maturities. We set the elasticity of substitution across intermediate goods $\theta$ to 10 , so that steady-state markups are equal to $11 \%$. This size of the markup is consistent with estimates presented in Burnside (1996) and Basu and Fernald (1997). The degree of price stickiness $(\lambda)$ is set to 0.55, which amounts to firms resetting prices approximately every 7 months on average. This is midway between the micro estimates of Bils and Klenow (2004), who find that firms change prices every 4 to 5 months, and those of Nakamura and Steinsson (2008), who find that firms change prices every 9 to 11 months.

The degree of price indexation is assumed to be zero in the baseline for three reasons. First, the workhorse New Keynesian model is based only on price stickiness, making this the most natural benchmark (Clarida et al (1999), Woodford (2003), and Gali (2008)). Second, any price indexation implies that firms are constantly changing prices, a feature strongly at odds with the empirical findings of Bils and Klenow (2004) and more recently Nakamura and Steinsson (2008), among many others. Third, while indexation is often included to replicate the apparent role for lagged inflation in empirical estimates of the NKPC (see Gali and Gertler 1999), Cogley and Sbordone (2008) show that once one controls for steady-state inflation, estimates of the NKPC reject the presence of indexation in price setting decisions. However, we relax the assumption of no indexation in section 4.1.

The coefficients for the Taylor rule are taken from Coibion and Gorodnichenko (2009). These estimates point to strong long-run responses by the central bank to inflation and output growth (2.5 and 1.5 respectively) and a moderate response to the output gap (0.43). We set the steady-state growth rate of real GDP per capita to be $1.5 \%$ per year $\left(\overline{G Y}=1.015^{0.25}\right)$, as in Coibion and Gorodnichenko (2009). The steady-state share of consumption is set to 0.80 and therefore the share of government spending is twenty percent. The calibration of the shocks is primarily taken from the estimated DSGE model of Smets and Wouters (2007), with the exception of the discount factor shocks which are taken from Justiniano and Primiceri (2008) which provides better identification of these shocks. We investigate the sensitivity of our results to many of these parameter choices in subsequent sections.

In our baseline model, positive steady-state inflation is costly primarily because it leads to more price dispersion and therefore less efficient allocations. On the other hand, positive steady-state inflation

gives policy-makers more room to avoid the zero lower bound (ZLB) on interest rates. Therefore, a key determinant of the tradeoff between the two depends on how frequently the ZLB is binding for different 
steady-state rates of inflation. To illustrate the implications of our parameter calibration for how often we hit the ZLB, Figure 1 plots the fraction of time spent at the ZLB from simulating our model for different steady-state levels of the inflation rate. In addition, we plot the steady-state level of the nominal interest rate associated with each inflation rate, where the steady-state nominal rate in the model is determined by $\bar{R}=\bar{\Pi} \cdot \overline{G Y} / \bar{\beta}$. Our calibration implies that with a steady-state inflation rate of approximately $3.5 \%$, the average rate for the U.S. since the early 1950's, the economy should be at the ZLB approximately 4 percent of the time. With U.S. interest rates at the ZLB since late 2008 and expected to remain so until at least the end of 2010, this yields a historical frequency of being at the ZLB of approximately 3-4 percent (i.e. around 2 years out of 60 ).

In addition, this calibration agrees with the historical changes in interest rates associated with post-WWII U.S. recessions. For example, starting with the 1958 recession and excluding the current recession, the average decline in the Federal Funds Rate during a recession has been 4.76 percentage points. $^{7}$ The model predicts that the average nominal interest rate with $3.5 \%$ steady-state inflation is around $8 \%$, so the ZLB would not have been binding during the average recession, consistent with the historical experience. Only the 1981-82 recession led to a decline in nominal interest rates that would have been sufficiently large to reach the ZLB (8.66\% drop in interest rates), but did not because nominal interest rates and estimates of steady-state inflation over this period were much higher than their average values. Thus, with 3-3.5\% inflation, our calibration implies that it would take unusually large recessions for the ZLB to become binding. In addition, Figure 1 indicates that at much lower levels of steady-state inflation, the ZLB would be binding much more frequently. For example, at a zero steady-state inflation rate, the ZLB would be binding nearly $17 \%$ of the time. Given the historical experience of the U.S., this also seems reasonable. The model predicts a steady-state level of interest rates of less than $4.5 \%$ when steady-state inflation is zero, and five out the last eight recessions (again excluding the current episode) were associated with decreases in interest rates that exceeded this value (specifically the 1969, 1973, 1982, 1990 and 2001 recessions). Thus, we interpret our parameterization as providing a reasonable representation of the likelihood of hitting the ZLB for different inflation rates given the historical experience of the U.S.

\subsection{Optimal Inflation}

Having derived the dynamics of the model, parameterized the shocks, and obtained the second-order approximation to the utility function, we now simulate the model for different levels of steady-state inflation and compute expected utility across steady-state inflation rates. The results are plotted in Figure

\footnotetext{
${ }^{7}$ This magnitude is calculated by taking the average level of the fed funds rate (FFR) over the last 6 months prior to the start of each recession as defined by the NBER and subtracting the minimum level of the FFR reached in the aftermath of that recession.
} 
2. Note first that utility is increasing at very low levels of inflations, which reflects the fact that zero inflation is not optimal when the zero bound is present. Second, the peak level of utility is reached when the inflation rate is $1.2 \%$ at an annualized rate. This is at the bottom end of the target range of most central banks, which commonly ranges from 1-3\%. Thus, our baseline results imply that taking into account the zero bound on interest rates raises the optimal level of inflation, but with no additional benefits to inflation included in the model, the optimal inflation rate is within the standard range of inflation targets. Third, inflation rates above the optimal level monotonically lower utility. Fourth, the costs of even moderate inflation are nontrivial. For example, a $4 \%$ annualized inflation rate would lower utility by $2 \%$ relative to the optimal level, which given log utility in consumption could be interpreted as equivalent to a permanent $2 \%$ decrease in the level of consumption.

In addition, Figure 2 illustrates the importance of taking into account the fact that positive steadystate inflation alters both the number of terms that appear in the utility-function approximation as well as their coefficients. For example, if we replicate our simulations but approximate utility via the standard approximation, both in terms of coefficients and terms included (i.e. use the approximation in Woodford (2003, page 403)), the optimal inflation rate would be 3.4\%. If we allowed for all of the terms to appear in the utility function but did not take into account the effects of positive steady-state inflation on the coefficients, the optimal level of inflation would rise to $5.2 \%$. Thus, the full characterization of the effects of steady-state inflation on the utility function approximation is a quantitatively important component of the optimal inflation rate derived here.

To get a sense of which factors drive these results, Figure 3 plots the coefficients of the secondorder approximation to the utility function from Proposition 1. In short, the results confirm the analytical derivatives of the coefficients from section 2.4 around $\bar{\pi} \approx 0$. First, rising inflation has important negative steady-state effects on utility, as the increasing price dispersion inefficiently lowers the steadystate level of production and consumption. For example, $6 \%$ inflation lowers utility by $4 \%$ relative to zero inflation via the steady-state effects. Second, the coefficient on the variance of output around its steady state is independent of $\bar{\pi}$ even though the new steady state level of output is lower. This reflects our assumption of log-utility in consumption. Third, the coefficient on the inflation variance is becoming increasingly negative. This reflects the fact that when the steady state level of price dispersion is already high (and steady-state output correspondingly low) then a temporary increase in price dispersion due to higher or lower inflation is even more costly. Moving from zero inflation to six percent inflation raises the coefficient on inflation variance by $40 \%$ in absolute value. This illustrates the importance of taking into account the effects of $\bar{\pi}$ on the coefficients of the utility function approximation. Ignoring this effect would thus tend to understate the costs of higher inflation by ignoring the fact that, holding the inflation variance constant, higher $\bar{\pi}$ raises the utility cost of the variance in inflation. 
Figure 4 plots the effects of steady-state inflation on the moments of the macroeconomic variables that directly affect utility, i.e. the dynamic effects of steady-state inflation and the zero bound on interest rates. In addition, we plot the corresponding moments in the absence of the zero-bound on interest rates to characterize the contribution of the zero-bound on macroeconomic dynamics. A notable feature of the figure is that output volatility rises much more rapidly as $\bar{\pi}$ falls when the zero bound on interest rates is present. Intuitively, with low $\bar{\pi}$ the ZLB is hit more often. With the nominal rate fixed at zero the central bank cannot stabilize the economy by cutting interest rates further and thus macroeconomic volatility increases. As we increase $\bar{\pi}$, the macroeconomic volatility (especially for output) diminishes.

The effect of changes in $\bar{\pi}$, however, is non-linear for the variance of inflation when we take into account the zero-bound on interest rates. At low levels of inflation, higher levels of $\bar{\pi}$ reduce the volatility in inflation for the same reason as for output: the reduced frequency of hitting the zero bound. On the other hand, higher steady-state inflation also tends to make price-setting decisions more forward-looking, so that inflation volatility will tend to rise with $\bar{\pi}$. When steady-state inflation rises past a specific value, the latter effect starts to dominate and the variance of inflation begins to rise with steady-state inflation. Given our baseline values, this switch occurs at an annualized steady-state inflation rate of approximately $3.5 \%$. In the absence of the zero-bound, the variance of inflation would be monotonically increasing with $\bar{\pi}$. These results indicate the importance of modeling both the zero-bound and the effects of $\bar{\pi}$ on the dynamics of the model.

Figure 5 plots the contribution of these different effects on the welfare costs of inflation, i.e. each of the terms in Proposition 1. These include the steady-state effects of $\bar{\pi}$ as well as the interaction of the effects of $\bar{\pi}$ on the coefficients of the utility function approximation and the dynamics of the economy. The most striking result is that the welfare costs and benefits of positive $\bar{\pi}$ are essentially driven by two components: the steady-state effect and the contribution of inflation variance to utility. All of the other effects are much smaller quantitatively. The contribution of the inflation variance is an inverted $U$, which reflects the U-shape pattern of inflation variance with respect to steady-state inflation as well as the negative and declining coefficient on the inflation variance in the utility function approximation.

\section{Robustness of the Optimal Inflation Rate to Alternative Parameter Values}

In this section, we investigate the robustness of the optimal inflation rate to our parameterization of the model. We focus particularly on the pricing and time preference parameters. ${ }^{8}$

\footnotetext{
${ }^{8}$ We investigated the sensitivity of our results to habit formation, the Frisch labor supply elasticity and other parameters. These had minor quantitative effects on our results; we omit them from the text in the interest of space.
} 


\subsection{Pricing Parameters}

Figure 6 plots the utility-approximation for different levels of $\bar{\pi}$ for alternative pricing parameters, as well as the optimal inflation rates associated with these parameter values. First, we consider the role of the elasticity of substitution $\theta$. Note that the welfare costs of inflation are larger when $\theta$ is high. This result captures the fact that a higher elasticity of substitution generates more real rigidity and therefore more persistence in fluctuations, thereby raising the welfare cost of fluctuations for any $\bar{\pi}$. However, the effects of this parameter on the optimal $\bar{\pi}$ are relatively small: using a value of $\theta$ of 5 , half of our baseline and an upper bound on how big markups are in the economy, raises the optimal $\bar{\pi}$ to about $1.7 \%$ from our baseline of $1.2 \%$. This is well within the range of inflation targets employed by modern central banks.

We also investigate the role of price indexation. In our baseline, we assumed $\omega=0$, based on the fact that firms do not change prices every period in the data, as documented by Bils and Klenow (2004) and Nakamura and Steinsson (2008), as well as the results of Cogley and Sbordone (2008) who argue that once one controls for time-varying steady-state inflation, we cannot reject the null that $\omega=0$ for the US. However, because price-indexation is such a common component of New Keynesian models, we consider the effects of price indexation on our results. In general, price indexation has two effects. First, it leads to more inertia in inflation, which should tend to make business cycles more costly. On the other hand, it reduces the dispersion of prices, which offsets some of the costs of positive $\bar{\pi}$. The results in Figure 6 indicate that the latter effect is quantitatively more important: higher levels of indexation lead to higher optimal rates of inflation. With $\omega=0.5$, which is most likely an upper bound for empirically plausible degree of indexation in low-inflation economies like the US, the optimal $\bar{\pi}$ marginally exceeds $2 \%$.

Third, we investigate the effects of price stickiness. Our baseline calibration, $\lambda=0.55$, is midway between the findings of Bils and Klenow (2004) of median price durations of 4-5 months and those of Nakamura and Steinsson (2008) of median price durations of 9-11 months. We now consider values of $\lambda$ ranging from 0.50 to 0.65 . There is little impact on welfare for very low levels of inflation, but as the steady state inflation rate rises past $3 \%$, higher degrees of price stickiness are associated with much larger welfare losses than the baseline. ${ }^{9}$ This reflects the fact that with more price stickiness, price dispersion is greater, and this effect is amplified at higher levels of steady-state inflation, thereby generating much larger welfare losses. Nonetheless, this has only minor effects on the optimal inflation rate.

\subsection{Time Preference Parameters}

We also consider the sensitivity of our results to time-preference parameters. First, we reproduce our baseline welfare figure for different levels of the persistence to discount factor shocks. The results are

\footnotetext{
${ }^{9}$ In fact, if we increase $\lambda$ above 0.75 the model starts to run into indeterminacy regions which are potentially
} associated with unbounded volatility. 
quite sensitive to this parameter, which reflects the fact that these shocks play a crucial role in hitting the zero lower bound. For example, Figure 7 illustrates that when we raise the persistence of the shock from 0.95 to 0.96 , the optimal inflation rate rises from $1.2 \%$ to $2.3 \%$ because this increase in the persistence of the shock has a large effect on the frequency of hitting the ZLB. At 3.5\% inflation, the frequency of being at the lower bound doubles relative to our baseline scenario, thereby raising the benefit of higher steady-state inflation. The reverse occurs with lower persistence of discount factor shocks: the frequency of being at the ZLB declines sharply as does the optimal inflation rate. Similar results obtain when we vary the volatility of the discount factor shock. When we increase the standard deviation of these shocks to 0.004 from our baseline of 0.0031 , the optimal inflation rate rises to slightly over two percent. Again, this is driven by a higher frequency of being at the ZLB: at 3.5\% inflation, this alternative shock volatility implies the economy would be at the ZLB twice as often as under our baseline calibration.

Third, we consider the sensitivity of our results to the steady-state level of the discount factor $\beta$. This parameter is also important in determining the frequency at which the economy is at the ZLB since it affects the steady-state level of nominal interest rates. This is particularly important at low levels of steady-state inflation. As with the discount factor shock variables, a higher value of $\beta$ is associated with a lower steady-state level of nominal interest rates, so that the ZLB will be binding more frequently. For example, with $\beta=0.9975$ (which corresponds to a real rate of $1.75 \%$ per year), the ZLB is binding nearly $10 \%$ of the time when steady-state inflation is $3.5 \%$. This leads to higher optimal levels of inflation than implied by our baseline results. These robustness checks clearly illustrate how important the frequency at which the economy hits the ZLB is in terms of our results. Naturally, parameter changes which make the ZLB binding more often raise the optimal rate of inflation because higher $\bar{\pi}$ lowers the frequency of hitting the ZLB. Thus, the key point is not the specific values chosen for these parameters but rather having a combination of them that closely reproduces the historical frequency of hitting the ZLB for the U.S. In any case, even if we consider parameter values that double the frequency of hitting the ZLB at the historical average rate of inflation for the U.S., the optimal inflation rate rises only to about $2 \%$, which is the center of inflation targets for most central banks.

\section{What Could Raise the Optimal Inflation Rate?}

While our baseline model emphasizes the tradeoff between higher inflation to ensure against the zerobound on interest rates versus the utility costs of associated with larger price dispersion, previous research has identified additional factors beyond the lower-bound on nominal interest rates which might lead to higher levels of optimal inflation. In this section, we extend our analysis to assess their quantitative importance. First, we include capital formation in the model. Second, we allow for uncertainty about parameter values on the part of policy-makers. Third, we consider the possibility that the degree of price 
stickiness varies with $\bar{\pi}$. Fourth, we explore whether our results are sensitive to using Taylor pricing. Fifth, we integrate downward nominal wage rigidity, i.e. "greasing the wheels," into the model.

\subsection{Capital}

We consider how sensitive our results are to the introduction of capital. We present a detailed model in Appendix B and only provide a verbal description in this section. In this model, firms produce output with a Cobb-Douglas technology with capital share $\alpha=0.33$. We assume that all capital goods are homogeneous and can be equally well employed by all firms. Capital is accumulated by the representative consumer subject to a quadratic adjustment cost to capital and rented out in a perfectly competitive rental market. The aggregate capital stock depreciates at rate $\delta=0.02$ per quarter. We calculate the new steady state level of output relative to the flexible price level output and derive the analogue of Proposition 1 in Appendix B.

By allowing capital to freely move between firms we reduce the steady state welfare cost from trend inflation. Now firms that have a relatively low price can hire additional capital rather than sectorspecific workers to boost their output. Thus the disutility of labor does not increase by as much as it did in the labor-only model and this will be a force to raise the optimal inflation level. However, capital also reduces the likelihood of hitting the ZLB. Unlike the labor-only model, including capital permits positive savings and so we are less likely to be in a situation where an increase in the desire to save pushes interest rates all the way to zero. This channel will lower the optimal inflation rate in the capital model relative to the labor model. We now consider both these channels together.

In Figure 8 we plot utility for various steady-state inflation rates when we impose a moderate adjustment cost to capital $(\psi=3)$. Utility again peaks at a trend inflation rate of $1.4 \%$ per annum suggesting that capital reduces the costs and benefits of inflation in equal amounts. While steady state output is higher with capital, Figure 8 also reveals that we hit the ZLB much less frequently, which makes higher trend inflation less attractive.

\subsection{Model Uncertainty}

An additional feature that could potentially lead to higher rates of optimal inflation is uncertainty about the model on the part of policy-makers. If some plausible parameter values lead to much higher frequencies of hitting the zero-bound on interest rates or raise the output costs of being at the zero-bound, then policy-makers might want to insure against these outcomes by allowing for a higher steady-state inflation rate. To quantify this notion, we consider two exercises. First, we identify the inflation rate that maximizes expected utility taking into account parameter uncertainty. Second, we generate a distribution of optimal inflation rates from the distribution of parameters. 
Our starting point for both exercises is uncertainty about the parameters of the model. We characterize this uncertainty via the variance-covariance matrix of the estimated parameters from Smets and Wouters (2007). ${ }^{10}$ We place an upper bound of 0.975 on the persistence of the discount factor shock and raise its covariance with the discount factor shock by a factor of 1.25. This eliminates draws where the ZLB binds unrealistically often, in excess of $10 \%$ at $6 \%$ annual trend inflation. We then use the delta method to adjust the standard errors on the autoregressive parameters and the Frisch elasticity to reflect their bounded parameter space. To assess the optimal inflation rate given uncertainty about parameter values, we compute the expected utility associated with each level of steady-state inflation by repeatedly drawing from the distribution of parameter values. ${ }^{11}$ Figure 9 (Panel A) plots the levels of implied levels of expected utility associated with each steady-state level of inflation. Maximum utility is achieved with an inflation rate of $1.4 \%$ per year. As expected, this is higher than our baseline result, which reflects the fact that some parameter draws lead to much larger costs of being at the zero-bound, a feature which also leads to a much more pronounced inverted U-shape. Nonetheless, this optimal rate of inflation remains well within the bounds of current inflation targets of modern central banks.

Secondly, for each draw from the parameter space, we solve for the optimal inflation rate, thereby allowing us to characterize the uncertainty associated with our baseline results. Figure 9 (Panel B) plots the distribution function of these inflation rates. The $90 \%$ confidence interval of optimal inflation rates ranges from $0.4 \%$ to $2.1 \%$ per year, which again is very close to the target range for inflation of most central banks. In short, incorporating model uncertainty confirms our baseline finding that, even after taking into account the zero-bound on interest rates, the optimal inflation rate is low and close to current targeted levels.

\subsection{Endogenous Price Stickiness}

In our baseline analysis, we treat the degree of price rigidity as a structural parameter. However, theory implies that the cost to firms of not changing prices should rise as steady state inflation rises (Romer 1990). Higher levels of inflation should therefore tend to be associated with lower levels of price stickiness, which would tend to lower the welfare costs of business cycles. Thus, by ignoring this endogeneity, we might be overstating the costs of positive inflation and thereby underestimating the optimal rate of inflation.

The empirical evidence on the sensitivity of price rigidity to the inflation rate is mixed. Gagnon (2009), for example, finds a statistically significant relationship between the inflation rate and the

\footnotetext{
${ }^{10}$ Although we take estimates and variances for $\sigma_{b}$ and $\rho_{b}$ from Justiano and Primiceri (2008) and for parameters in the policy reaction function from Coibion and Gorodnichenko (2009), we preserve correlations between parameter estimates in the covariance matrix reported in Smets and Wounters (2007).

${ }^{11}$ Note that some parameter draws yield an indeterminate solution. In this case, we solve for the dynamics using the "continuous" solution as in Lubik and Schorfheide (2003).
} 
frequency of price changes for Mexico, but only when the inflation rate exceeds $10 \%$ per year. Dhyne et al (2005) find a positive relationship between the two for a cross-section of European countries, but the relationship is not statistically significantly different from zero once they control for a variety of other factors. Nakamura and Steinsson (2008) similarly estimate the relationship between annual inflation and the frequency of price changes using micro-level US data and find only mixed evidence of a statistically significant link between the two.

Despite the absence of a strong empirical link between price stickiness and the steady state level of inflation (at least for plausible US levels of inflation), we consider the sensitivity of our baseline results to a possible systematic link between the two. Specifically, we follow Nakamura and Steinsson's empirical approach and posit a linear relationship between the (monthly) frequency of price changes and the steady state annual rate of inflation, with the coefficient on inflation denoted by $\beta_{\pi}$. The average estimate of Nakamura and Steinsson across price measures and time periods is approximately $\beta_{\pi}=0.5$, and the upper bound of their confidence intervals is approximately 1 . We reproduce our analysis using these values, as well as our baseline assumption of $\beta_{\pi}=0$, and plot the results in Figure $10 .^{12}$ In each case, we calibrate the degree of price rigidity such that $\lambda=0.55$ (our baseline value) at a steady-state level of annual inflation of $3.5 \%$.

Panel A shows the implied variation in the degree of price stickiness. For the mean estimated degree of endogeneity from Nakamura and Steinsson (2008), the average duration between price changes varies from eight months to six months, while the upper bound on endogeneity of price stickiness yields durations ranging from nine months to five and a half months. Panel B shows that the frequency of hitting the zero-bound on interest rates is essentially unchanged across specifications: this reflects the fact that, for a given inflation rate, a higher frequency of price changes is associated with larger movements in inflation (and therefore hitting the zero bound more frequently) but these changes are less persistent (so the economy exits the zero-bound more rapidly), leaving the overall frequency of being at the zero bound largely unchanged across specifications. Panels C-F demonstrate the effects of endogeneity on the optimal inflation rate and the utility associated with different levels of steady-state inflation.

Hence, we have two key findings. First, the optimal inflation rate is unchanged with endogenous price stickiness, but the welfare costs of inflation at the optimal rate are rising with endogenous price setting. This reflects the fact that, given the same low optimal rate of inflation, more endogeneity is

\footnotetext{
${ }^{12}$ To be clear, we allow the degree of price stickiness to vary with the steady-state rate of inflation, but not with fluctuations in the inflation rate around its steady-state value. An alternative approach would be to model endogenous price setting via "menu" costs. Although we do not consider this approach explicitly here, one would expect two opposing effects on the optimal inflation rate from such an extension. First, paying the fixed costs of changing prices would lower welfare, and this cost would be rising with steady-state inflation as firms would reset their prices more often. On the other hand, because of selection effects, price dispersion should rise less rapidly with inflation than under time-dependent pricing models. It is unclear, ex ante, which effect would dominate.
} 
associated with higher degrees of price stickiness and therefore a higher cost of inflation. Second, despite the fact that the optimal rate of inflation is the same with endogenous price stickiness, the costs of much higher inflation are lower relative to our baseline, because higher inflation leads to more frequent price changes and therefore less costly fluctuations.

\subsection{Taylor pricing}

An alternative approach to Calvo pricing is the staggered contracts approach of Taylor (1977) in which firms set prices for a pre-determined duration of time. This pricing assumption can loosely be thought of as a lower bound on forward-looking behavior (conditional on price durations) since it imposes zero weight on expected profits beyond those of the contract length in the firm's reset price optimization. The derivation of the utility approximation as well as the structural log-linearized equations of the model is similar to Calvo pricing (Appendix D contains details for the utility approximation when the duration of price spells is equal to three quarters).

Figure 11 compares the results for the Taylor pricing (duration of price contracts equal to 3 and 4 quarters) with the results for the Calvo pricing. The optimal inflation rate for the Taylor model is 1.6 and 1.4 percent per year for price duration of 3 and 4 quarter respectively, which is close to the 1.2 percent per year found for the baseline Calvo model. Note also that the volatility of inflation and output gap (Panels C and D) as well as the frequency of hitting zero lower bound (Panel B) are approximately the same in all models. However, the Taylor model has smaller losses in welfare as the steady state level of inflation increases above 2 percent per year. For example, the welfare loss at the steady state inflation of 6 percent per year relative to the minimum loss is about 4 percent in the Calvo model but only about 1 percent in the Taylor model (Panel A). The key source of this difference is that the Taylor model assigns smaller steady state effects (Panel E) and a lower weight on inflation variability (Panel F) than the Calvo model does. ${ }^{13}$ Intuitively, since firms in the Calvo pricing may be stuck with a suboptimal price for a long time, the cost of positive steady state inflation is larger than in the Taylor model where firms are guaranteed to change the price in a fixed number of periods. In summary, although both the Taylor and Calvo models yield similar optimal inflation rates, these models provide different estimates of welfare gains from low steady state inflation.

\subsection{Downward Wage Rigidity}

A common motivation for positive steady-state inflation rates, beside the zero-lower bound and seigniorage, is the "greasing the wheels" effect raised by Tobin (1972). If wages are downwardly rigid, as usually found in the data (e.g., Dickens et al 2007), then positive steady-state inflation will facilitate the downward-adjustment of real wages required to adjust to negative shocks. To quantify the effects of

\footnotetext{
${ }^{13}$ The coefficient on the output variability is the same in the Taylor and Calvo models.
} 
downward nominal wage rigidity in our model, we integrate it in a manner analogous to the zero-bound on interest rates by imposing that changes in the aggregate nominal wage index be above a minimum bound

$$
\Delta \widehat{w}_{t}=\max \left\{\Delta \widehat{w}_{t}^{m}, \Delta \widehat{w}_{t}^{*}\right\}
$$

where $\Delta w_{t}^{*}$ is the change in wages that would occur in the absence of the zero-bound on nominal wages and $\Delta \widehat{w}_{t}^{m}$ is the lower-bound on nominal wage changes. Note that even with zero steady-state inflation, steady-state nominal wages grow at the rate of technological progress. Thus, we set $\Delta \widehat{w}_{t}^{m}$ to be equal to minus the sum of the growth rate of technology and the steady state rate of inflation.

Figure 12 presents the utility associated with different steady-state inflation rates under both the zero-bound on interest rates and downward-wage rigidity. The result is striking: the optimal inflation rate falls to practically zero with downward wage rigidity. Rather than pushing the optimal inflation rate higher, accounting for downward nominal wage rigidity actually lowers the optimal rate. The reason for this counterintuitive finding is illustrated in Panel B of Figure 12. With downward wage rigidity, marginal costs are much less volatile, so the variance of inflation is substantially reduced relative to the case with flexible wages. In addition, the fact that marginal costs are downwardly rigid means that, in the face of a negative demand shock, inflation will decline by less and therefore interest rates will fall less, making the zero bound bind less often. With $\bar{\pi}=0$, the zero bound binds approximately 6 percent of the time with downward wage rigidity but over 16 percent of the time with flexible wages. This decrease in the frequency at which the zero bound binds at low inflation rates reduces the benefit of higher trend inflation and leads to lower estimates of the optimal inflation rate. ${ }^{14}$

\section{Normative Implications}

We have so far been treating the question of the optimal inflation rate independently of the systematic response of the central bank to macroeconomic fluctuations. In this section, we consider the sensitivity of our baseline results to alternative coefficients for the central bank's response function as well as the normative question of how the central bank can optimize over both optimal inflation and its systematic response to the economy.

\subsection{Taylor Rule Parameters}

Our baseline Taylor rule parameters are taken from Coibion and Gorodnichenko (2009) based on the post-1982 era. However, as has been emphasized in the empirical literature on central banks' reaction functions, there is robust evidence of time-variation in the Federal Reserve's systematic response to

\footnotetext{
${ }^{14}$ Kim and Ruge-Marcia (2009) similarly find that downward wage rigidity, by itself, has little positive effect on the optimal inflation rate in an estimated DSGE model.
} 
economic fluctuations. ${ }^{15}$ In addition, like the steady-state inflation rate, the reaction function is under the control of policymakers so we are interested in studying the interaction of these policy variables on welfare. Thus, we consider the implications of alternative parameter values in the Taylor rule, illustrated in Figure 13. First, we consider long-run responses to inflation by the central bank ranging from 2 to 5 . The effects on welfare are unambiguous: stronger long-run responses to inflation raise welfare in the model for all inflation rates. Intuitively, this stronger systematic response reduces inflation and output volatility, thereby leading to a lower frequency of being at the ZLB and higher utility. However, this has little effect on the optimal inflation rate, which ranges from $1.3 \%$ when $\phi_{\pi}=2$ to $0.8 \%$ when $\phi_{\pi}=5$.

We also investigate the sensitivity to the central bank's response to the real side of the economy via output growth or the deviation of output from its steady state value. We find that stronger responses to output growth generally lower welfare while higher responses to output are welfare-improving. This finding is interesting for two reasons. First, Orphanides (2003) and Coibion and Gorodnichenko (2009) emphasize that one of the primary changes in U.S. monetary policy around the time of the Volcker disinflation was the switch from responding aggressively to the gap toward responding more aggressively to the growth rate of output. One advantage of the latter is that output growth is readily observable whereas the output gap is likely to be subject to much more real-time measurement error, as documented in Orphanides and van Nordern (2002). However, our results indicate that responding strongly to output growth actually reduces welfare in a New Keynesian model. Second, Coibion and Gorodnichenko (2009) show that responding to the output gap can be destabilizing in New Keynesian models under positive steady-state inflation because it can lead to indeterminacy. Responding to output growth, on the other hand, helps achieve determinacy for smaller responses to inflation when steady-state inflation is positive. Figure 13 indicates that conditional on staying in the determinacy region the welfare results go in the other direction. Hence, there is a tradeoff between the two measures in terms of stabilization: responding to the (properly measured) gap is welfare improving as long as the economy remains in the determinacy region, but increases the likelihood of switching to an indeterminate equilibrium with the possibility of sunspot fluctuations. Responding to the growth rate of output moves the economy away from the indeterminacy region but leads to lower welfare within the indeterminacy region. However, in terms of the optimal inflation rate, the distinction is minor and neither measure has much quantitative importance in determining the optimal inflation rate within the determinacy region of the parameter space.

\subsection{Price-Level Targeting, the Zero Bound, and the Optimal Inflation Rate}

While our baseline specification of the Taylor rule restricts the endogenous response of the central bank to inflation and the real side of the economy, an additional factor sometimes included is price-level

\footnotetext{
${ }^{15}$ See Clarida et al (2000), Orphanides (2003), Boivin (2006), and Coibion and Gorodnichenko (2009) for examples.
} 
targeting (PLT). While the evidence for central banks actually following price-level targeting remains scarce, PLT has nonetheless received substantial attention in the literature for several reasons. First, as emphasized in Woodford (2003), price-level targeting ensures determinacy under zero steady state inflation for any positive response to the price level gap. Second, Coibion and Gorodnichenko (2009) show that price-level targeting ensures determinacy for positive steady-state inflation rates as well, and is not subject to the deterioration of the Taylor principle as a result of positive steady-state inflation which occurs when the central bank responds only to inflation. Third, Gorodnichenko and Shapiro (2007) show that price-level targeting helps stabilizes inflation expectations, thereby yielding much smaller inflation and output volatility than would occur in inflation-targeting regimes.

We extend our baseline model to include price-level targeting in the central bank's reaction function $\left(\phi_{p}>0\right)$ in Figure 14 which shows the effects of PLT on welfare for different levels of steadystate inflation as well as its implications for the optimal rate of inflation. The results are quite dramatic. First, PLT strictly increases welfare for any level of steady-state inflation. Second, PLT leads to much lower levels of optimal inflation than inflation-targeting regimes. Even for moderate responses to the price level gap, the optimal level of inflation is approximately 0.5 percent per year. This magnitude practically means price level stability (rather than inflation stability) which is, in fact, the mandated objective for most central banks.

The intuition for why PLT delivers such a small optimal inflation rate is straightforward. First, as observed in Gorodnichenko and Shapiro (2007), PLT stabilizes expectations and has a profound effect on output and inflation volatility. In our simulations, the reduction in inflation and output volatility is so substantial that the welfare costs of inflation are almost exclusively driven by the steady-state effects. As a result of reduced volatility, the ZLB almost never binds. For example, with $\phi_{p}=0.3$, the ZLB binds less than two percent of the time at a steady-state level of inflation of 3.5\%. Second, even if the nominal rate hits zero, the policy rule remains a potent factor in stimulating the economy despite the ZLB because agents know that the deflationary pressures during the ZLB will have to be offset by above-average inflation in the future. This limits the downward movement in inflationary expectations and therefore the associated increase in real interest rates. In short, PLT limits the extent of deflationary spirals so that the exit from a binding ZLB occurs more rapidly and the welfare costs of the ZLB are substantially reduced. To give a sense of the magnitude of the associated welfare change, we note that by increasing $\phi_{p}$ from zero to 0.25 (combined with the appropriate change in the optimal rate of inflation), a policymaker could raise steady-state consumption by nearly two percent. Thus, these results provide a new justification for the consideration of PLT by monetary policymakers.

In addition, we consider a closely related issue: the degree of interest smoothing. Coibion and Gorodnichenko (2009) observe that PLT is very similar to a policy rule with high inertia, i.e., $\rho_{1}+\rho_{2}$ 
close to one. ${ }^{16}$ For simplicity, we abstract from the AR(2) interest-smoothing commonly found in empirical studies and instead restrict our attention to AR(1) interest smoothing: i.e. we set the AR(1) coefficient in the interest rate smoothing polynomial equal to $\rho_{1}+\rho_{2}$ and the $\operatorname{AR}(2)$ coefficient to zero. Figure 14 confirms that, like PLT, higher interest rate smoothing leads to lower levels of optimal steadystate inflation. ${ }^{17}$ However, unlike PLT, this decrease in the optimal inflation rate is associated with lower welfare after $\rho_{1}+\rho_{2}$ passes 0.91 . The inverted U-shape of the welfare results from the tradeoff between strong short-run and strong long-run responses to endogenous variables implied by our Taylor rule specification (26) since we hold the long-run responses to inflation, output gap and output growth rate constant in this experiment but, by raising $\rho_{1}+\rho_{2}$, decrease the short run response.

\section{Concluding remarks}

If nothing else, the Great Recession has taught monetary economists one lesson: the zero bound is not a theoretical curiosity of interest only to historians of the Great Depression or as a precautionary tale against overly cautious policy-makers such as the Japanese monetary and fiscal authorities in the early 1990s. Instead, the pervasiveness of the zero bound constraint among major industrial countries has demonstrated the necessity of incorporating this issue into modern macroeconomic models. Indeed, the recent interest in raising the inflation targets of central banks has resurrected a basic question for macroeconomists: what is the optimal inflation rate? Strikingly, New Keynesian models, with their pervasive reliance on the assumption of zero steady-state inflation, have been ill-equipped to answer this key question for central bankers.

We provide an integrated treatment of the effects of non-zero steady-state inflation in New Keynesian models. Most importantly, we derive an approximation to the utility function of the representative agent which incorporates the various dimensions along which steady-state inflation matters: the steady-state, the dynamics of the model, and the coefficients of the utility-function approximation. This allows us to study the optimal rate of inflation using a welfare criterion derived explicitly from the microfoundations of the model. Combining this with the zero-bound on nominal interest rates, we are then able to study the costs and benefits of steady-state inflation and quantify the optimal rate of inflation in the model. Our baseline result is that this optimal rate of inflation is fairly low: less than two percent a year. We show that this result is robust to a variety of parameter specifications and modifications of the model.

\footnotetext{
${ }^{16}$ Specifically, a Taylor rule with only PLT is observationally equivalent to a super-inertial Taylor rule that responds to contemporaneous inflation. More generally, a Taylor rule with "partial" PLT in which the central bank pushes prices only partly back to the initial target path is observationally equivalent to a Taylor rule with interest smoothing and a contemporaneous response to inflation. See Coibion and Gorodnichenko (2009) for more details.

${ }^{17}$ Billi (2009) similarly finds that higher interest smoothing lowers the optimal rate of inflation.
} 
Given that most central banks are targeting inflation rates between $1 \%$ and $3 \%$ a year, our results can be interpreted as supporting the current regimes and providing little evidence in favor of raising these targets to provide additional insurance against the zero-bound constraint on interest rates. However, from a normative point of view, we also show that welfare could be substantially improved by introducing price-level targeting. The latter helps stabilize economic fluctuations and significantly reduces the probability of hitting the zero-lower bound. As a result, the optimal inflation rate under a price-level targeting regime would be close to zero. In other words, optimal monetary policy, characterized as a combination of an inflation target and a systematic response to deviations of the price-level from its target, can be interpreted as being very close to the "price stability" enshrined in the legal mandates of most central banks.

\section{References}

Aruoba, S. Boragan, and Frank Schorfheide, 2009. "Sticky Prices versus Monetary Frictions: An Estimation of Policy Trade-offs," unpublished manuscript.

Ascari, Guido, and Tiziano Ropele, 2007. "Trend Inflation, Taylor Principle, and Indeterminacy," Journal of Money, Credit and Banking 48(1), 1557-1584.

Basu, Susanto, and John G. Fernald, 1997. "Returns to Scale in U.S. Production: Estimates and Implications," Journal of Political Economy 105, 249-283.

Billi, Roberto M., 2009, “Optimal Inflation for the US Economy?” Revised version of Research Working Paper 07-03, Federal Reserve Bank of Kansas City.

Bils, Mark, and Peter J. Klenow, 2004. "Some Evidence on the Importance of Sticky Prices," Journal of Political Economy 112(5), 947-985.

Bodenstein, Martin, Christopher J. Erceg, and Luca Guerrieri, 2009. "The effects of foreign shocks when interest rates are at zero," International Finance Discussion Papers 983, Board of Governors of the Federal Reserve System.

Boivin, Jean, 2006. "Has U.S. Monetary Policy Changed? Evidence from Drifting Coefficients and RealTime Data," Journal of Money, Credit and Banking 38(5), 1149-1173.

Burnside, Craig, 1996. "Production Function Regressions, Returns to Scale, and Externalities," Journal of Monetary Economics 37, 177-201.

Christiano, Lawrence J., Martin Eichenbaum, and Sergio Rebelo, 2009. "When is the government spending multiplier large?" NBER Working Paper 15394.

Clarida, Richard, Jordi Galí, and Mark Gertler, 1999. "The Science of Monetary Policy: A New Keynesian Perspective," Journal of Economic Literature 37(4), 1661-1707.

Clarida, Richard, Jordi Galí, and Mark Gertler, 2000. "Monetary Policy Rules and Macroeconomic Stability: Evidence and Some Theory," Quarterly Journal of Economics 115(1), 147-180.

Cogley, Timothy, and Argia Sbordone, 2008. "Trend Inflation, Indexation and Inflation Persistence in the New Keynesian Phillips Curve,” American Economic Review 98(5), 2101-2026.

Coibion, Olivier and Yuriy Gorodnichenko, 2009, "Monetary Policy, Trend Inflation, and the Great Moderation: An Alternative Interpretation" forthcoming in American Economic Review.

Cooley, Thomas F. and Gary D. Hansen, 1991. "The Welfare Costs of Moderate Inflations," Journal of Money, Credit and Banking 23(3) 483-503.

Dickens, William T., Lorenz Goette, Erica L. Groshen, Steinar Holden, Julian Messina, Mark E. Schweitzer, Jarkko Turunen, Melanie E. Ward, 2007. "How wages change: Micro evidence from the International Wage Flexibility Project," Journal of Economic Perspectives 21(2), 195-214. 
Dhyne, E., Alvarez, L.J., Le-Bihan, H., Veronese, G., Dias, D., Hoffmann, J., Jonker, N., Lunnemann, P., Rumler, F., Vilmunen, J.. 2005. "Price setting in the euro area: some stylized facts from individual consumer price data," European Central Bank, Working Paper 524.

Eggertsson, Gauti and Michael Woodford, 2004. "Policy Options in a Liquidity Trap," American Economic Review 94(2).

Friedman, Milton, 1969. The Optimum Quantity of Money, Macmillan.

Gagnon, Etienne, 2009, "Price Setting during Low and High Inflation: Evidence from Mexico," Quarterly Journal of Economics 124(3), 1221-1263.

Gali, Jordi and Mark Gertler, 1999. "Inflation Dynamics: A Structural Econometric Analysis," Journal of Monetary Economics 44(2) 195-222.

Gali, Jordi, 2008. Monetary Policy, Inflation, and the Business Cycle, Princeton University Press.

Gorodnichenko, Yuriy, and Matthew D. Shapiro, 2007. "Monetary Policy When Potential Output Is Uncertain: Understanding the Growth Gamble of the 1990s," Journal of Monetary Economics 54(4), 1132-1162.

Fuchi, Hitoshi, Nobuyuki Oda, and Hiroshi Ugai, 2008. "Optimal Inflation for Japan's Economy," Journal of the Japanese and International Economies 22(4) 439-475.

Justiniano, Alejandro and Giorgio Primiceri, 2008. "The Time-Varying Volatility of Macroeconomic Fluctuations," American Economic Review 98(3) 604-641.

Kiley, Michael E., 2007. "Is Moderate-to-High Inflation Inherently Unstable?" International Journal of Central Banking 3(2), 173-201.

Khan, Aubhik, Robert G. King and Alexander L. Wolman, 2003. "Optimal Monetary Policy," Review of Economic Studies 70(4) 825-860.

Kim, Jinill and Francisco J. Ruge-Marcia, 2009. "How much inflation is necessary to grease the wheels?" Journal of Monetary Economics 56(3), 365-377.

Lubik, Thomas A. and Frank Schorfheide, 2003. "Computing Sunspot Equilibria in Linear Rational Expectations Models," Journal of Economic Dynamics and Control 28(2), 273-285.

Nakamura, Emi, and Jón Steinsson, 2008. "Five Facts About Prices: A Reevaluation of Menu Cost Models," Quarterly Journal of Economics 123(4), 1415-1464.

Orphanides, Athanasios, and Simon van Norden, 2002. "The Unreliability of Output Gap Estimates in Real Time," Review of Economics and Statistics 84(4), 569-583.

Orphanides, Athanasios, 2003. "Historical Monetary Policy Analysis and the Taylor Rule," Journal of Monetary Economics 50(5), 983-1022.

Romer, David, 1990, "Staggered Price Setting with Endogenous Frequency of Adjustment," Economic Letters 32(3), 205-210.

Smets, Frank and Rafael Wouters, 2007. "Shocks and Frictions in US Business Cycles: A Bayesian DSGE Approach," American Economic Review 97(3) 586-606.

Schmitt-Grohe, Stephanie and Martin Uribe, 2007, "Optimal Inflation Stabilization in a Medium-Scale Macroeconomic Model" in Monetary Policy Under Inflation Targeting, edited by Klaus SchmidtHebbel and Rick Mishkin, Central Bank of Chile, Santiago, Chile, 2007, p. 125-186.

Schmitt-Grohe, Stephanie and Martin Uribe, 2010. "The Optimal Rate of Inflation" NBER Working Paper 16054.

Summers, Lawrence, 1991. "Price Stability: How Should Long-Term Monetary Policy Be Determined?" Journal of Money, Credit and Banking 23(3), 625-631.

Taylor, John B., 1977. "Staggered Wage Setting in a Macro Model." American Economic Review 69(2), 108-113.

Tobin, James, 1972. "Inflation and Unemployment," American Economic Review 62(1), 1-18.

Walsh, Carl E., 2009. "Using Monetary Policy to Stabilize Economic Activity," manuscript.

Williams, John C., 2009. "Heeding Deadalus: Optimal Inflation and the Zero Bound" Brookings Papers on Economic Activity 2009(2), 1-37.

Woodford, Michael, 2003. Interest and Prices: Foundations of a Theory of Monetary Policy. Princeton: Princeton University Press. 


\section{Table 1: Baseline Parameter Values}

\begin{tabular}{|c|c|c|c|}
\hline \multicolumn{2}{|l|}{ Parameters of Utility Function } & \multicolumn{2}{|l|}{ Steady-State Values } \\
\hline$\eta$ : Frisch Labor Elasticity & 1.00 & $\overline{g y}$ : Growth Rate of RGDP/cap & $\% 1.5$ p.a. \\
\hline$\beta$ : Steady-State Discount factor & 0.993 & $\overline{c_{y}}:$ Consumption Share of GDP & 0.80 \\
\hline$h$ : External Habit Formation & 0.00 & $\overline{g_{y}}:$ Government Share of GDP & 0.20 \\
\hline Pricing Parameters & & Shock Persistence & \\
\hline$\theta:$ Elasticity of substitution & 10 & $\rho_{g}$ : Government Spending Shocks & 0.97 \\
\hline$\lambda$ : Degree of Price Stickiness & 0.55 & $\rho_{m}:$ Cost-Push Shocks & 0.90 \\
\hline$\omega:$ Price indexation & 0.00 & $\rho_{b}$ : Discount Factor Shocks & 0.95 \\
\hline Taylor Rule Parameters & & $\underline{\text { Shock Volatility }}$ & \\
\hline$\phi_{\pi}:$ LR response to inflation & 2.50 & $\sigma_{g}:$ Government Spending Shocks & 0.0052 \\
\hline$\phi_{g y}:$ LR response to output growth & 1.50 & $\sigma_{m}:$ Cost-Push Shocks & 0.0024 \\
\hline$\phi_{x}:$ LR response to output gap & 0.43 & $\sigma_{b}$ : Discount Factor Shocks & 0.0031 \\
\hline$\rho_{I}:$ Interest smoothing & 1.05 & $\sigma_{a}:$ Technology Shocks & 0.0090 \\
\hline$\rho_{2}$ : Interest smoothing & -0.13 & $\sigma_{r}:$ Monetary Policy Shocks & 0.0043 \\
\hline
\end{tabular}

Note: The table presents the baseline parameter values assigned to the model in section 3.1 and used for solving for the optimal inflation rate in section 3.2. "p.a." means per annum. 
Figure 1. Frequency of being in the Zero Lower Bound and Steady-State Nominal Interest Rate

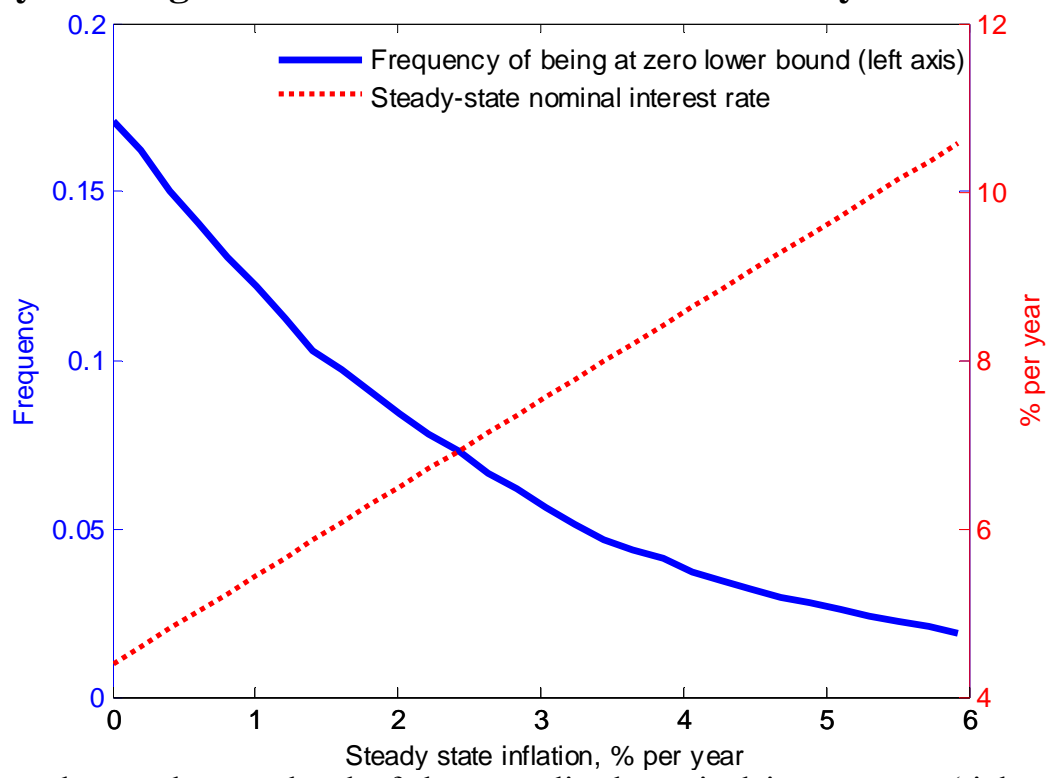

Note: The figure plots the steady-state level of the annualized nominal interest rate (right axis) implied by the baseline model of section 3 for different steady-state inflation rates. In addition, the figure plots the frequency of hitting the zero bound on nominal interest rates (left axis) from simulating the baseline model at different steadystate inflation rates. See section 3.2 for details.

Figure 2. Utility at Different Levels of Steady-State Inflation

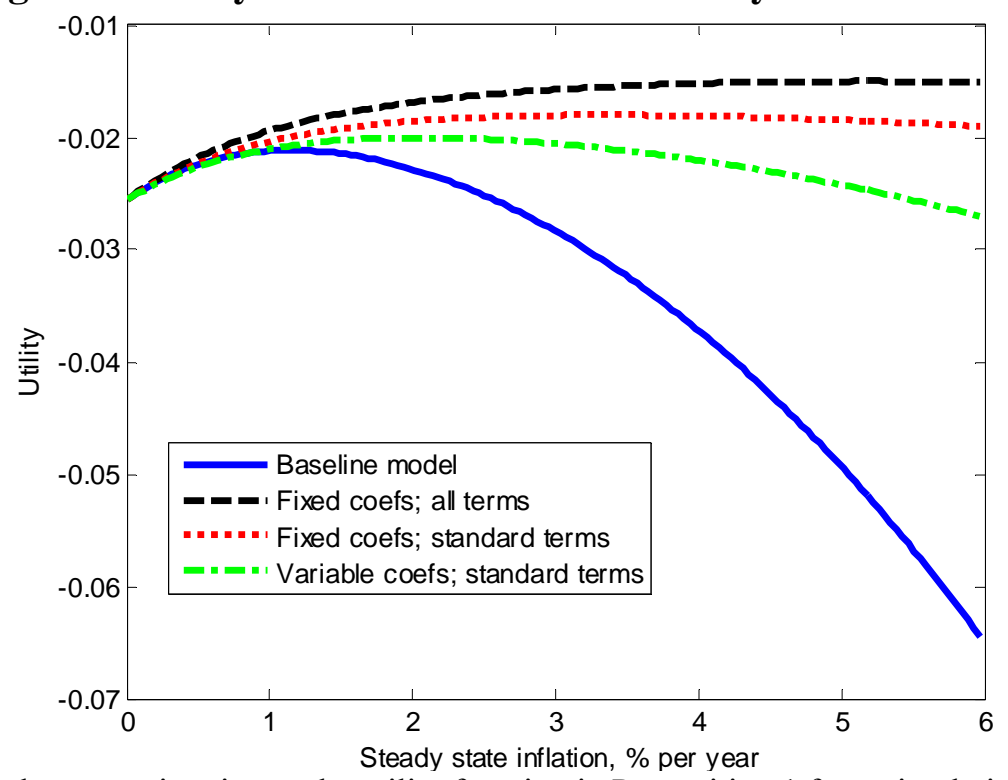

Note: The figure plots the approximation to the utility function in Proposition 1 from simulating the model subject to the zero bound on nominal interest rates for different levels of steady-state inflation using the baseline parameter values of the model. In addition, the figure plot levels of utility which include only the terms that apply under zero trend inflation ("standard terms") and levels of utility based on the coefficients evaluated only at zero steady-state inflation ("Fixed coefficients"). See section 3.2 for details. 
Figure 3. The Effect of steady-state Inflation on the Coefficients of the Utility Function Approximation

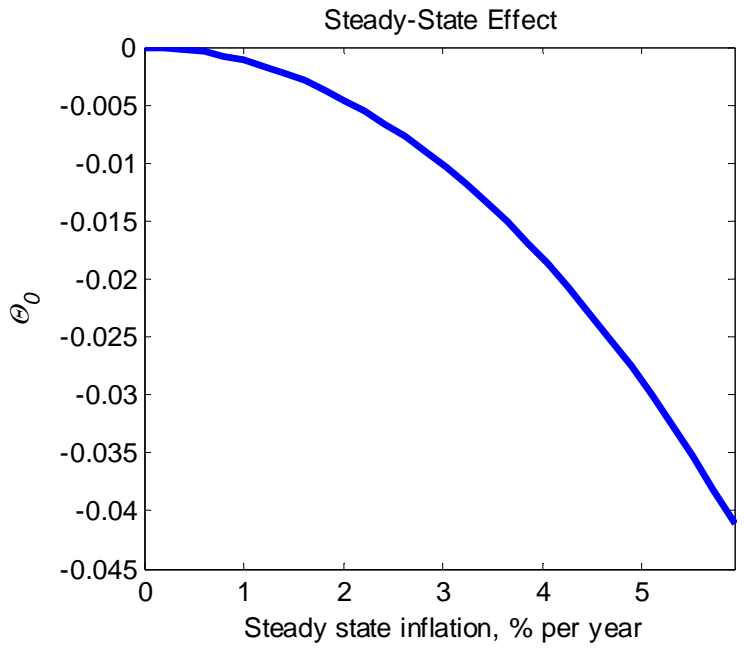

Coefficient on Output Variance
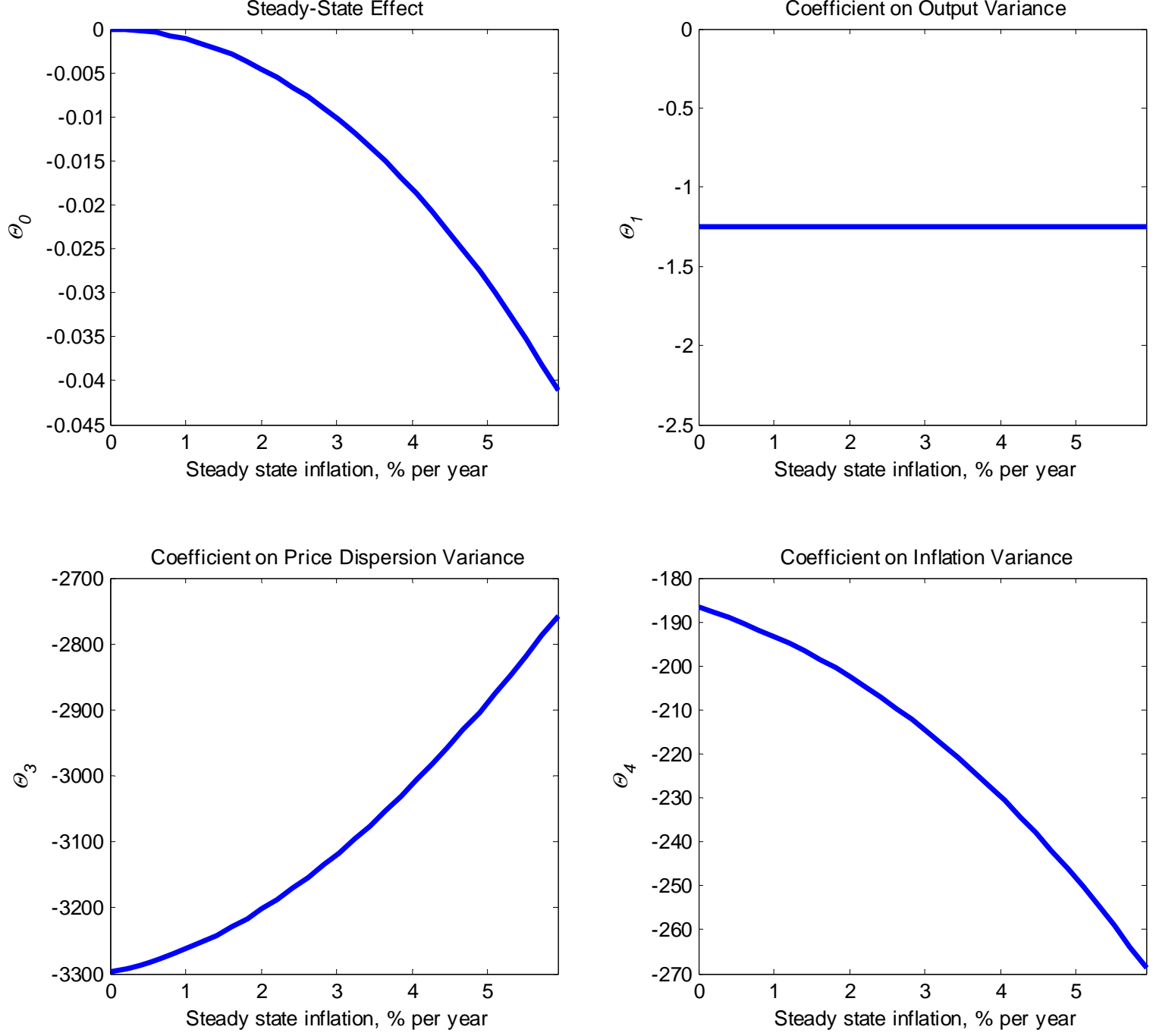

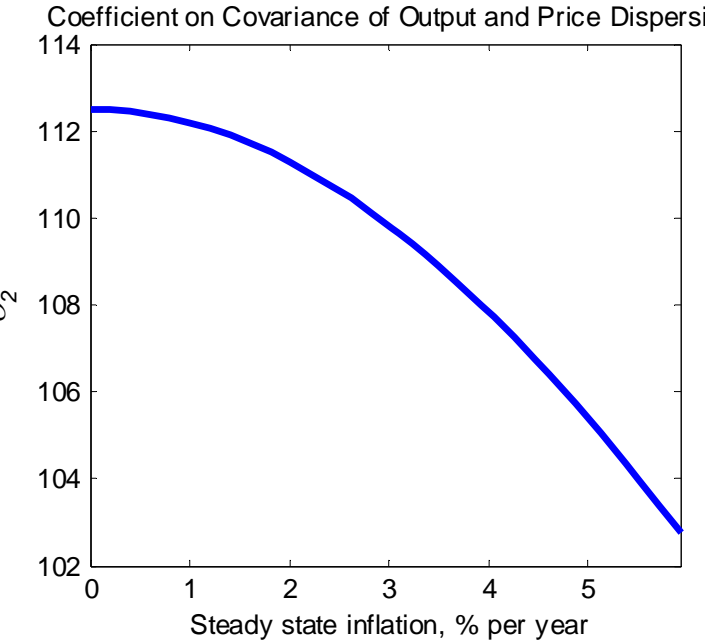

Note: The figure plots the coefficients of the approximation to the utility function from Proposition 1 for different levels of trend inflation using the baseline parameter values of the model. See section 3.2 for details. 


\section{Figure 4. The Effect of steady-state Inflation on the Moments of Macroeconomic Variables}
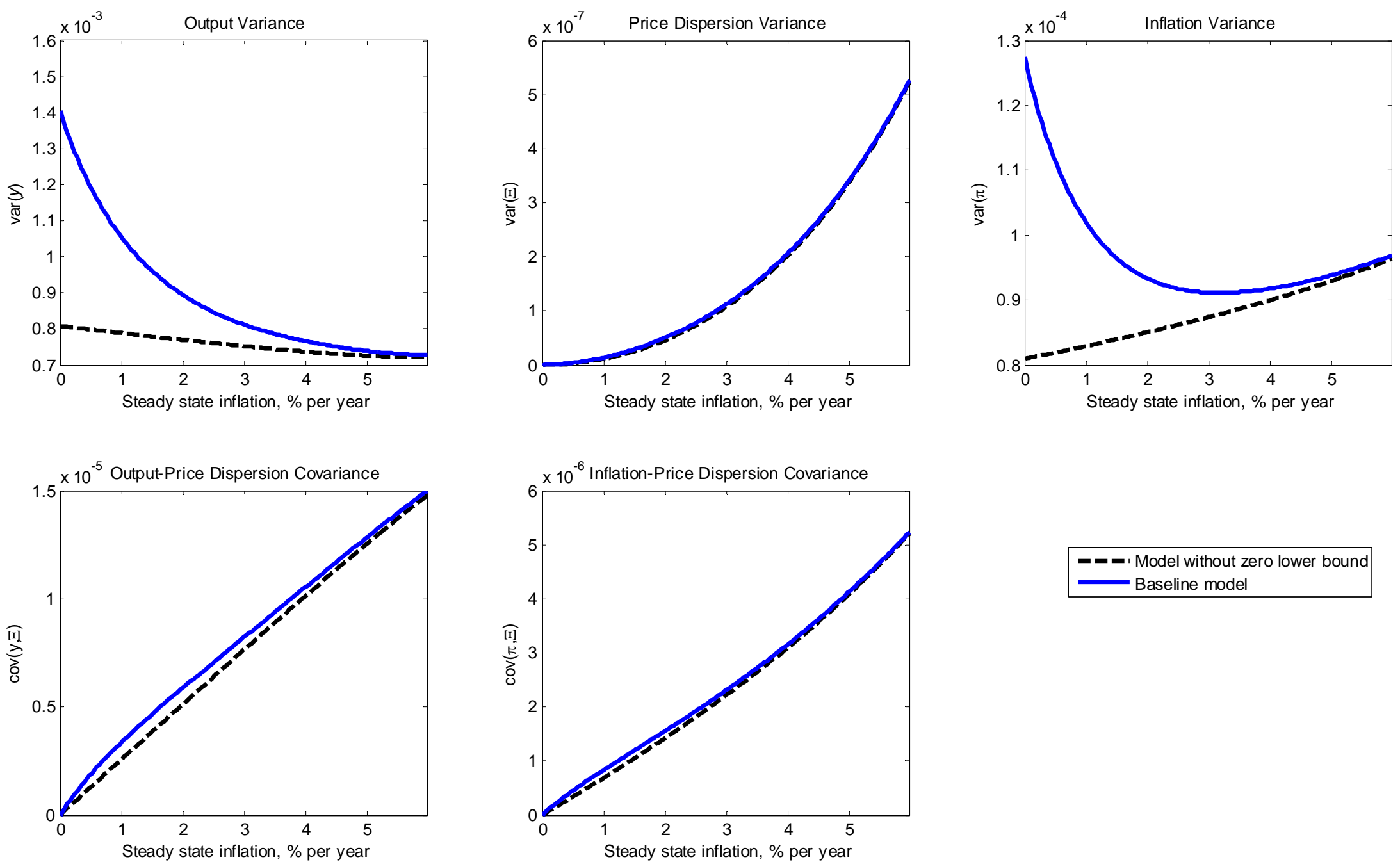

- Madel without zero lower bound
Badel

Note: The figure plots the variance and covariances of macroeconomic variables that enter the approximation to the utility function in Proposition 1 from simulating the model subject to the zero bound on nominal interest rates for different levels of steady-state inflation using the baseline parameter values of the model. The dashed black lines are the corresponding moments without the zero-bound on nominal interest rates. See section 3.2 for details. 
Figure 5. The Sources of Utility Costs of Inflation
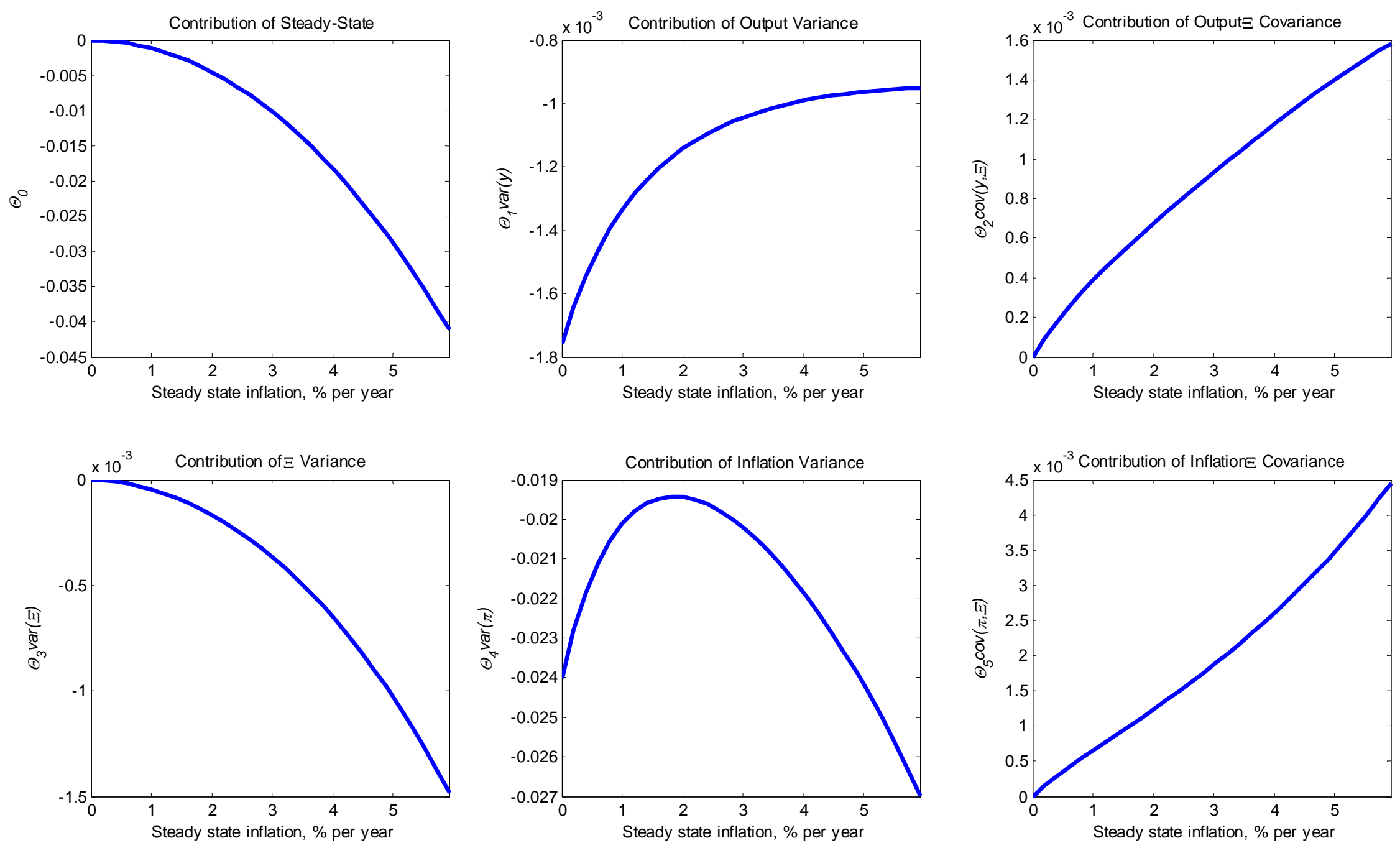

Note: The figure plots the contribution of the different components of the approximation to the utility function in Proposition 1 from simulating the model subject to the zero bound on interest rates for different levels of steady-state inflation using the baseline parameter values of the model. See section 3.2 for details. 
Figure 6. Robustness check: price setting parameters.
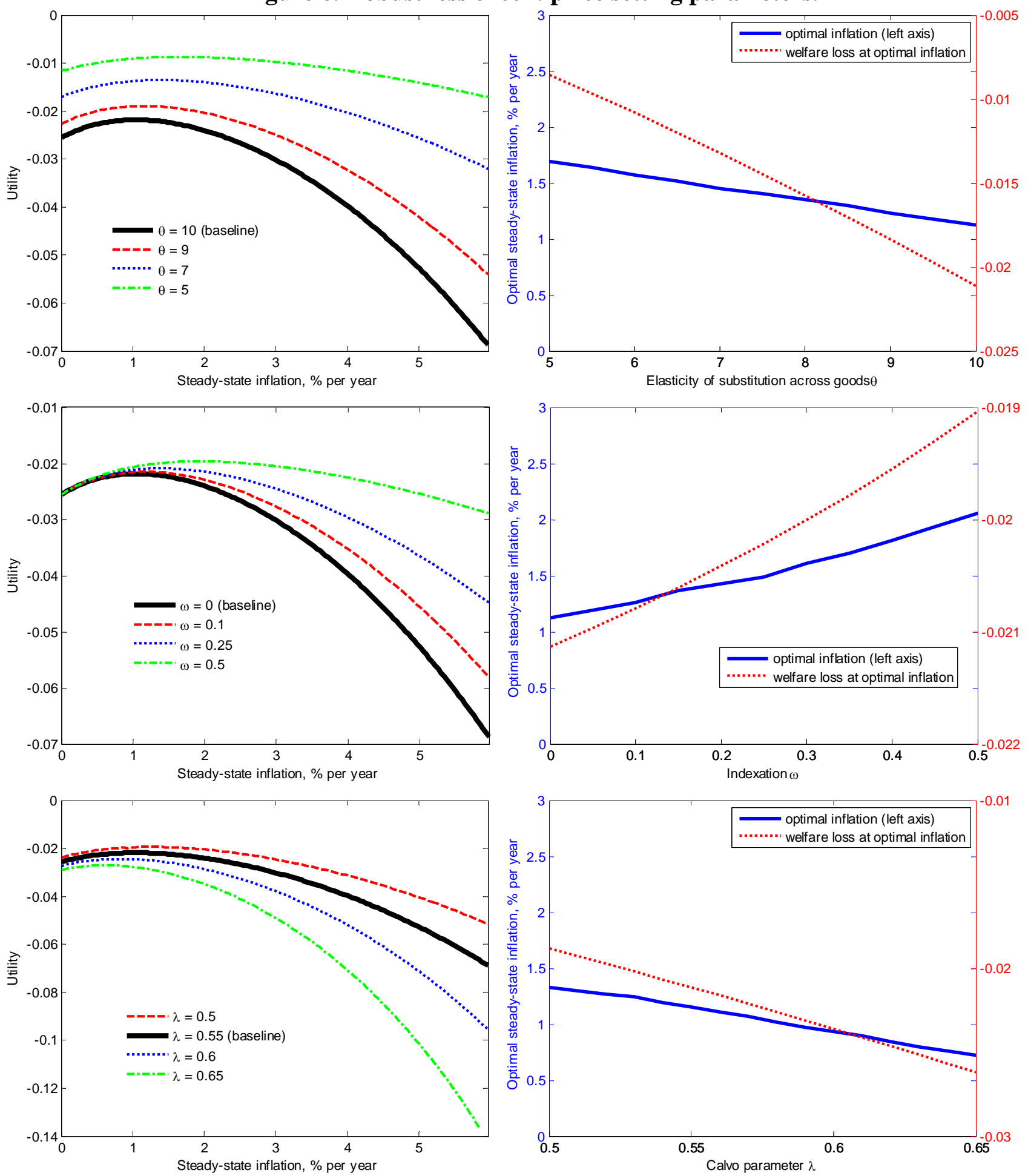

Note: Figures in the left column plot the welfare loss as a function of steady state inflation for alternative values of structural parameters. The solid thick back line corresponds to the baseline parameterization. Figures in the right column plot the optimal level of steady-state inflation and the welfare loss at the optimal steady state level of inflation as a function of a structural parameter. 
Figure 7. Robustness checks: Time preference parameters.
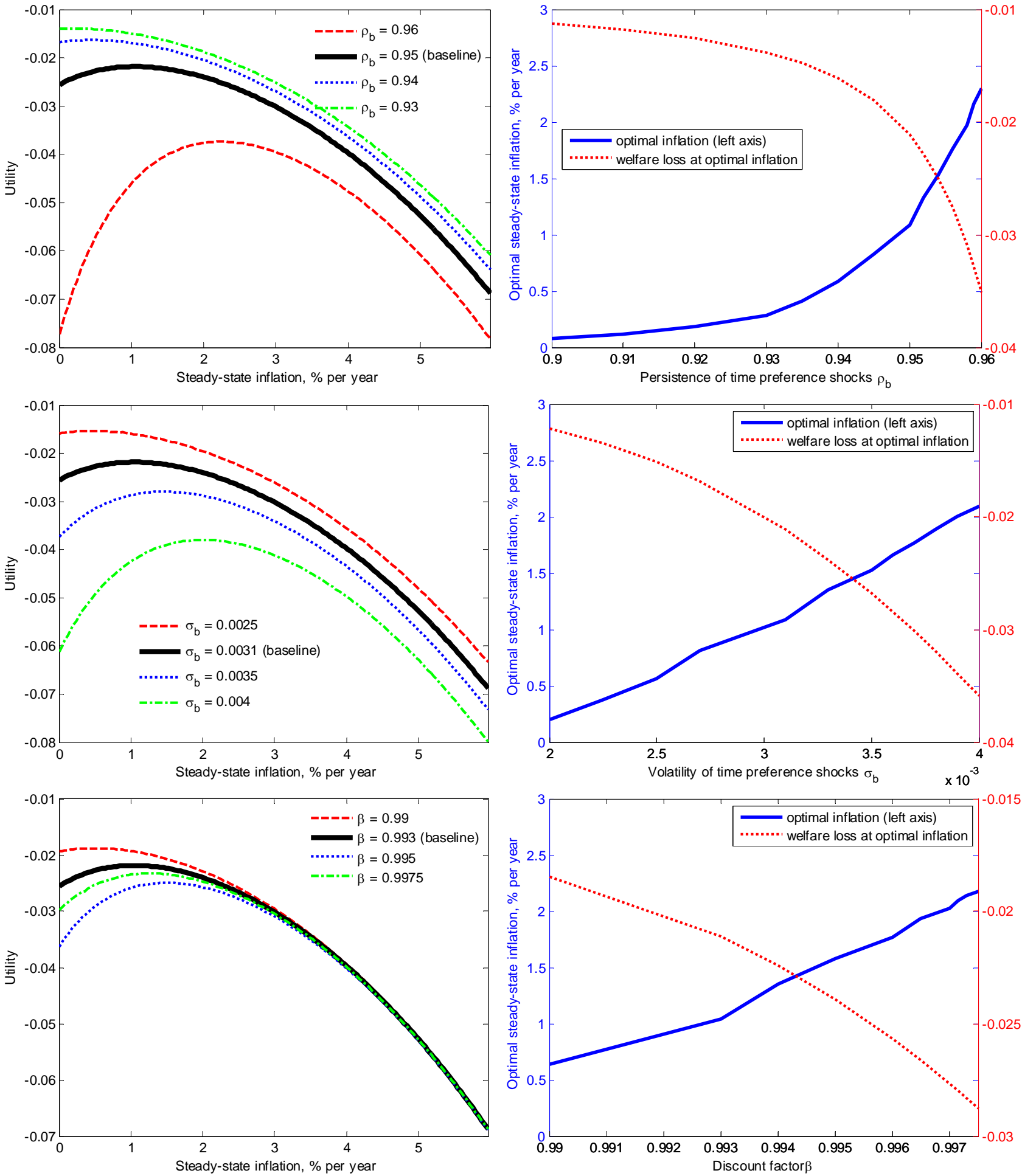

Note: Figures in the left column plot the welfare loss as a function of steady state inflation for alternative values of structural parameters. The solid thick back line corresponds to the baseline parameterization. Figures in the right column plot the optimal level of steady-state inflation and the welfare loss at the optimal steady state level of inflation as a function of a structural parameter. 
Figure 8. Sensitivity Analysis: Capital

Panel A: Welfare loss

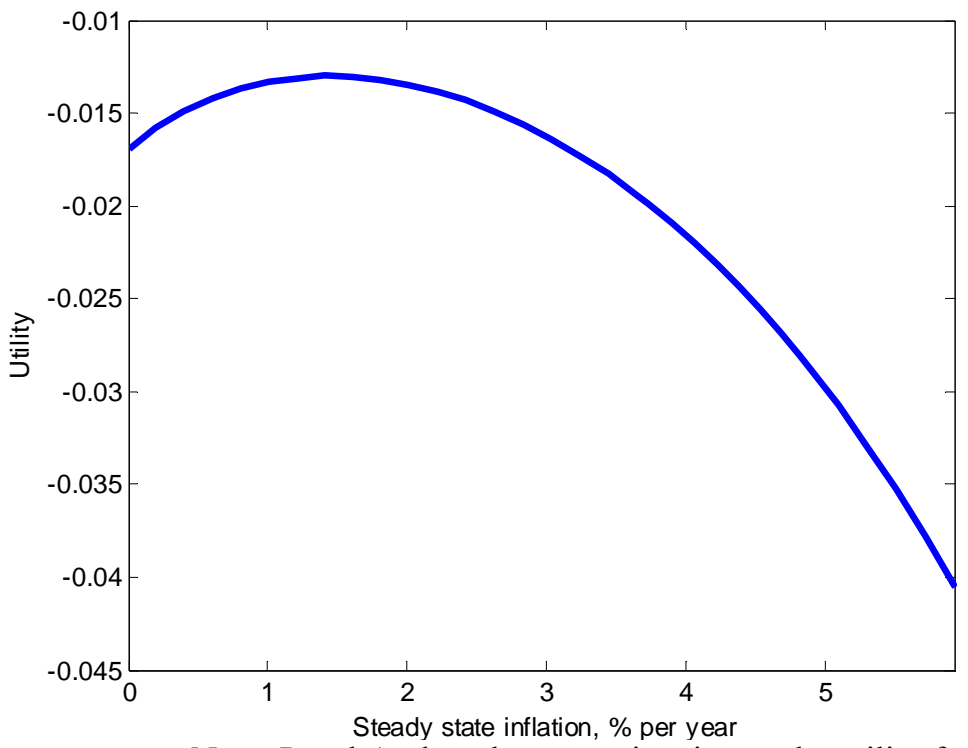

Panel B: Zero lower bound and nominal rate

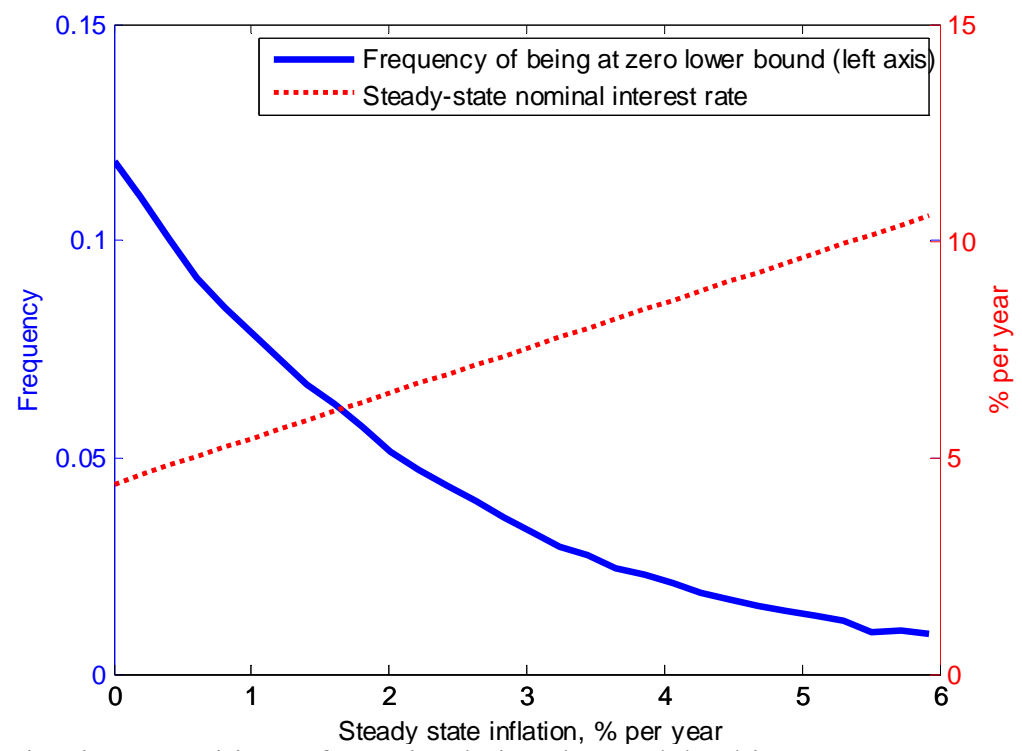

Note: Panel A plots the approximation to the utility function in Proposition 2 from simulating the model subject to the zero bound on nominal interest rates for different levels of steady-state inflation using the baseline parameter values of the model with capital. See section 5.1 for details. Panel B plots the frequency of hitting the zero bound on nominal interest rates (left axis) from simulating the baseline model with capital at different steady-state inflation rates. See section 5.1 for details.

Figure 9. Model Uncertainty

Panel A: Optimal Inflation Rate Panel

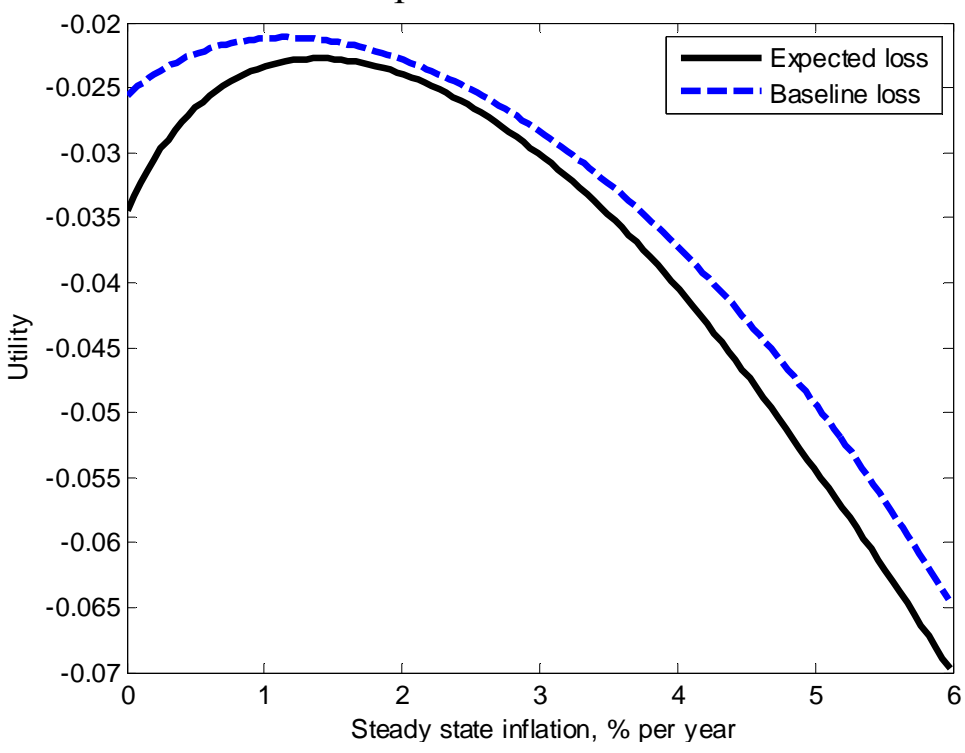

B: Distribution of Optimal Inflation Rates

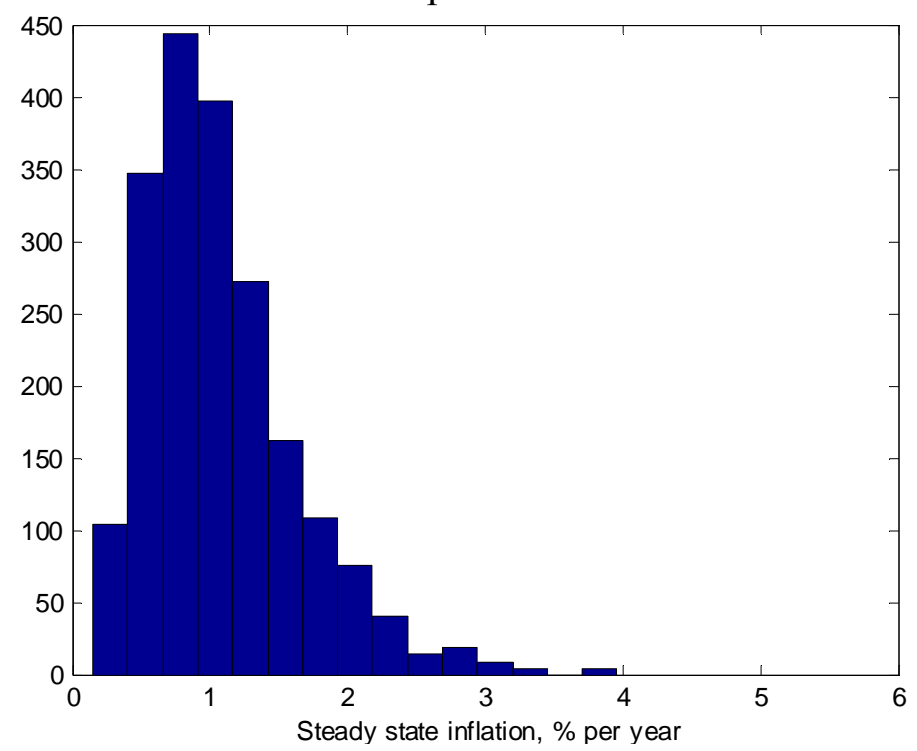

Note: Panel A plots the expected utility for different steady-state inflation rates under baseline parameter values as well as under model-uncertainty. Panel B plots the distribution of optimal inflation rates associated with different draws from the distribution of parameter values. See section 5.2 for details. 
Figure 10. Sensitivity Analysis: Endogenous Price Stickiness
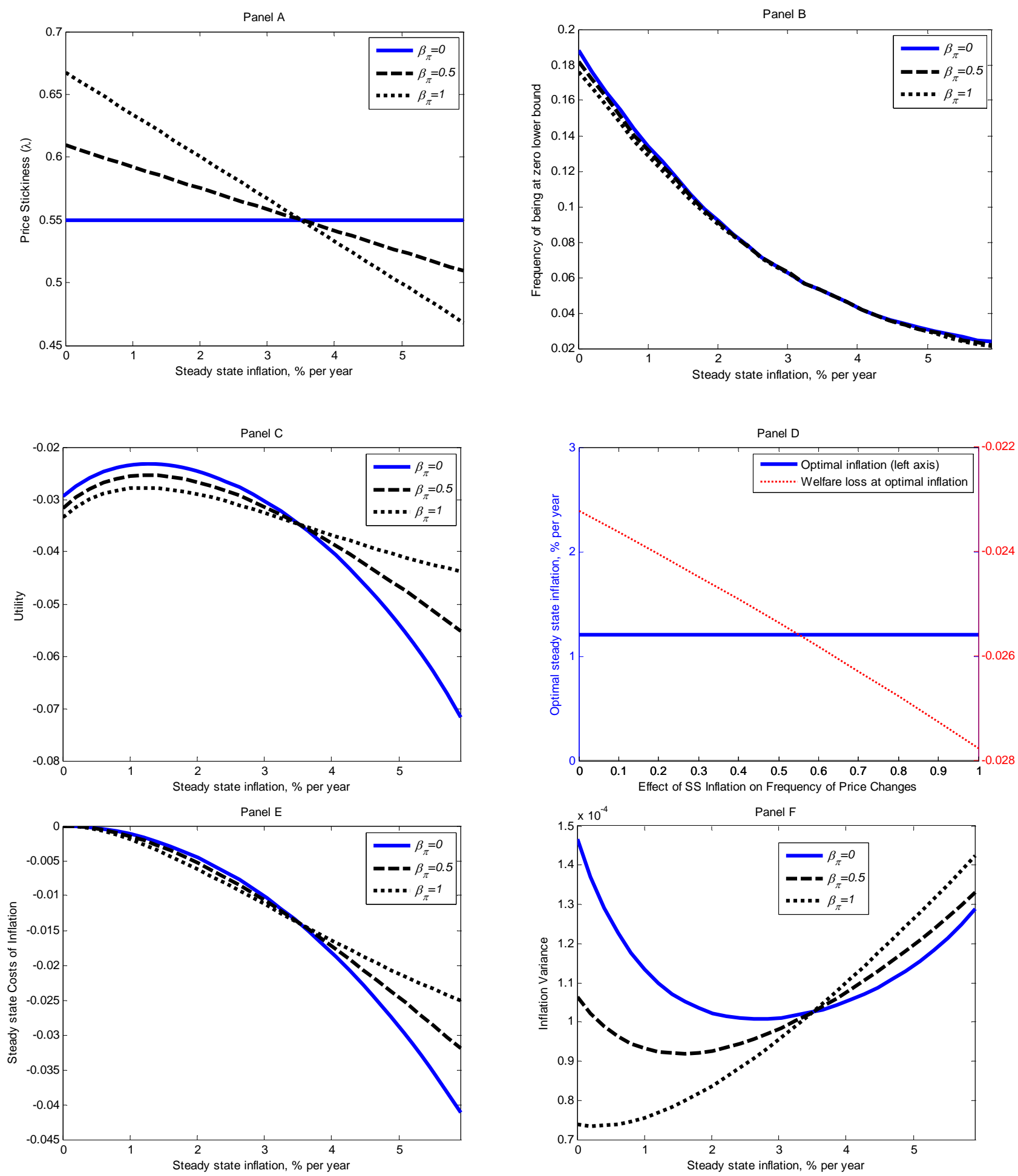

Note: The figures plot the implications of endogenous price stickiness on the model. $\beta_{\pi}$ is the effect of steady state inflation on the frequency of price changes, with $\beta_{\pi}=0$ being our baseline case of exogenous price stickiness. See section 5.3 for details. 
Figure 11. Sensitivity Analysis: Taylor pricing
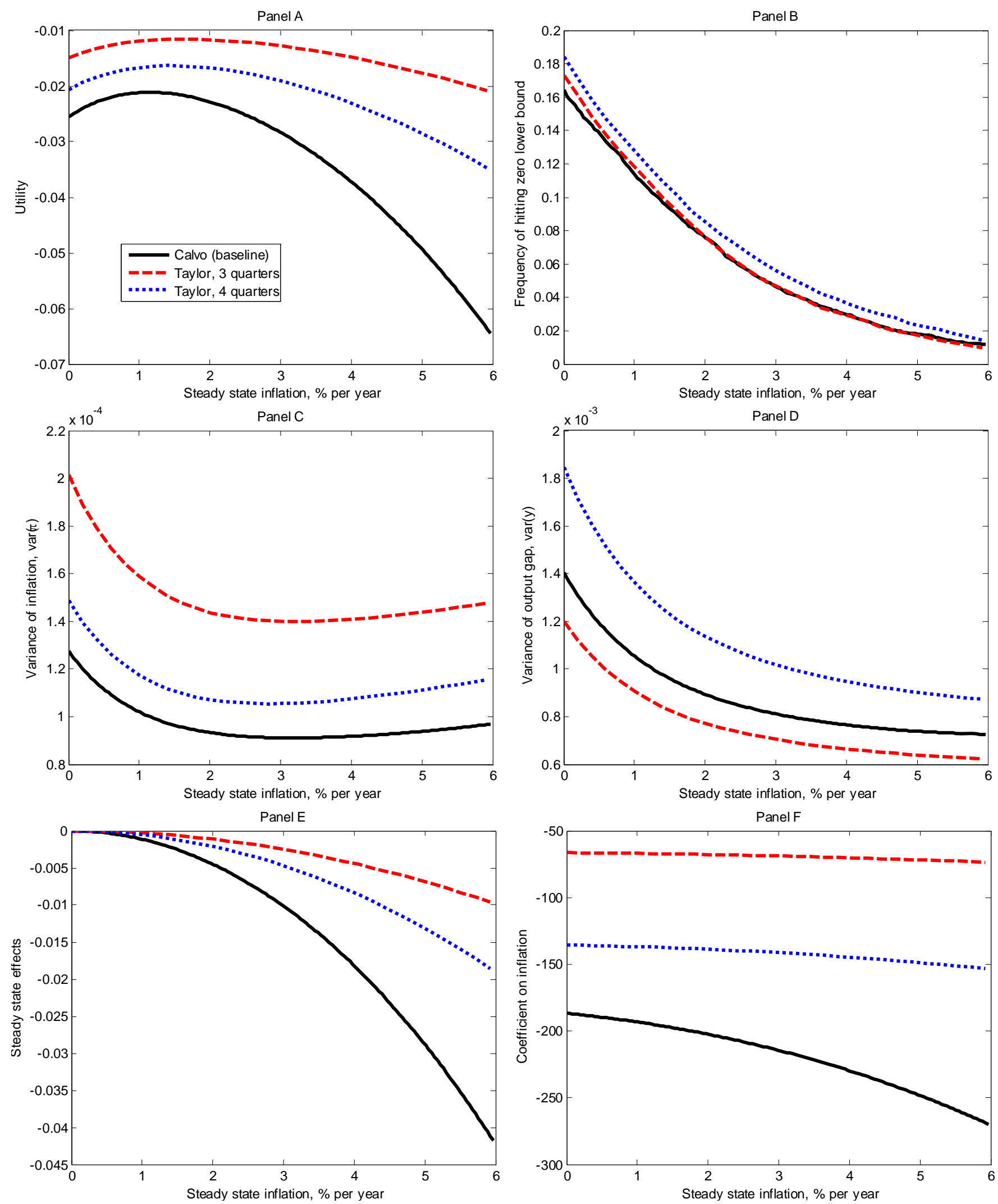

Note: The figures plot the implications of Calvo vs. Taylor price setting for welfare and optimal inflation. Taylor, X quarters corresponds to the duration of price contracts equal to $X$ quarters. See section 5.4 for details. 
Figure 12. Downward Wage Rigidity

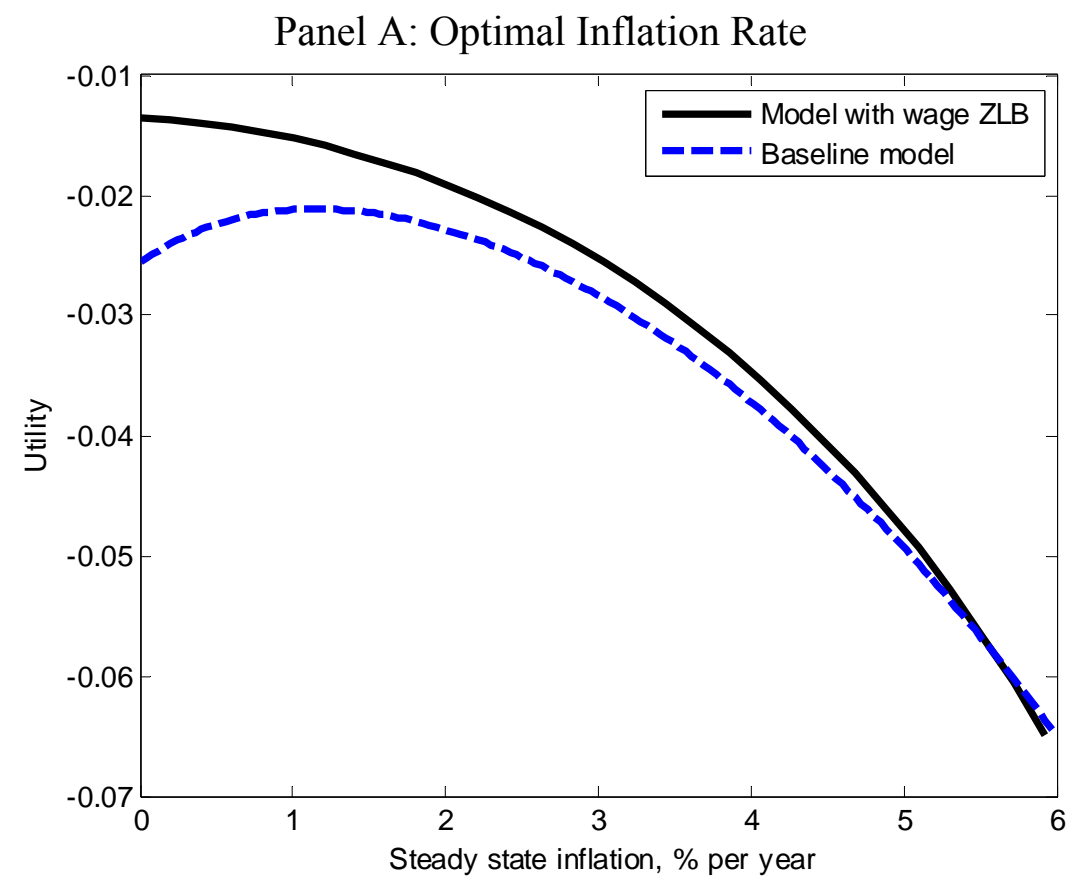

Panel B: Effects of Downward-Wage Rigidity
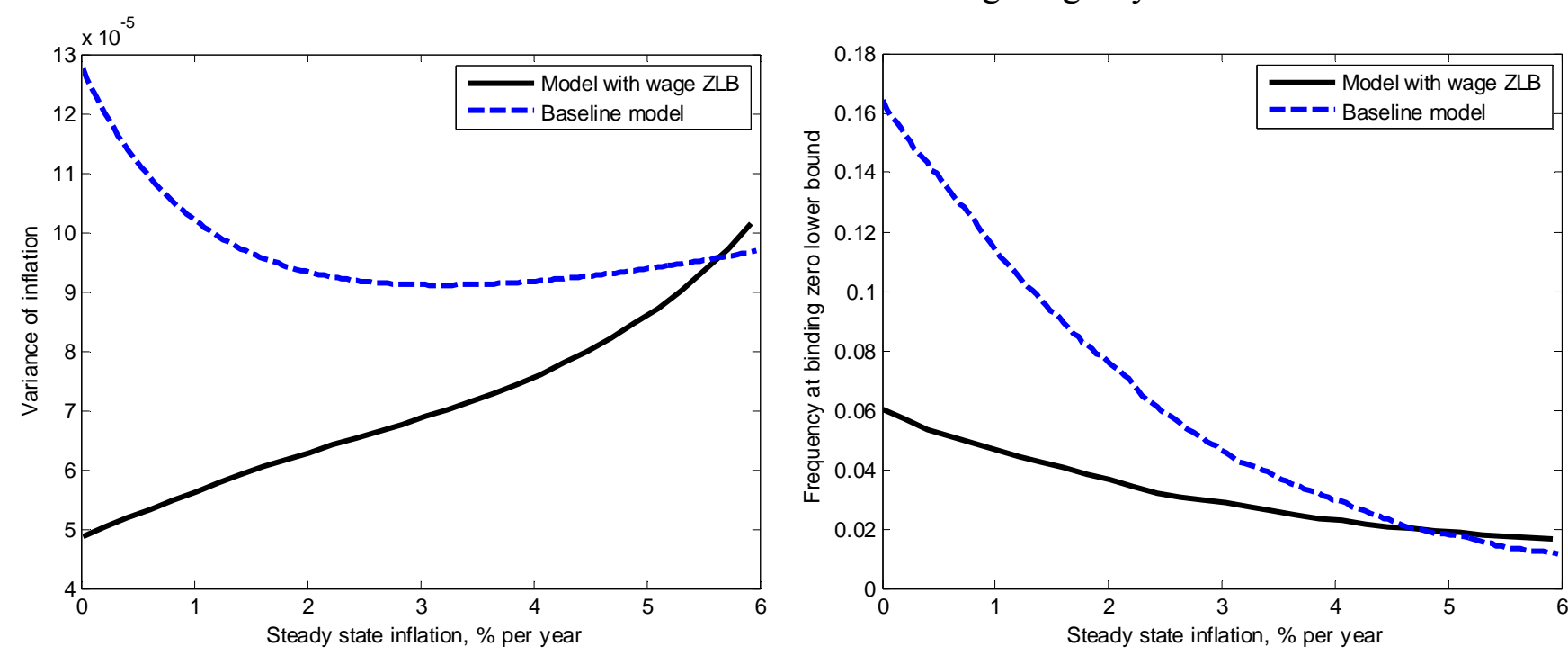

Note: Panel A plots the utility associated with different steady-state inflation rates under the baseline model as well as the model with downward nominal wage rigidity. Panel B figures plot the variance of inflation and the frequency of hitting the zero-bound on interest rates for different steady-state inflation rates using our baseline model and the model with downward nominal wage rigidity. See section 5.5 for details. 
Figure 13. Positive implication: parameters in the Taylor rule.
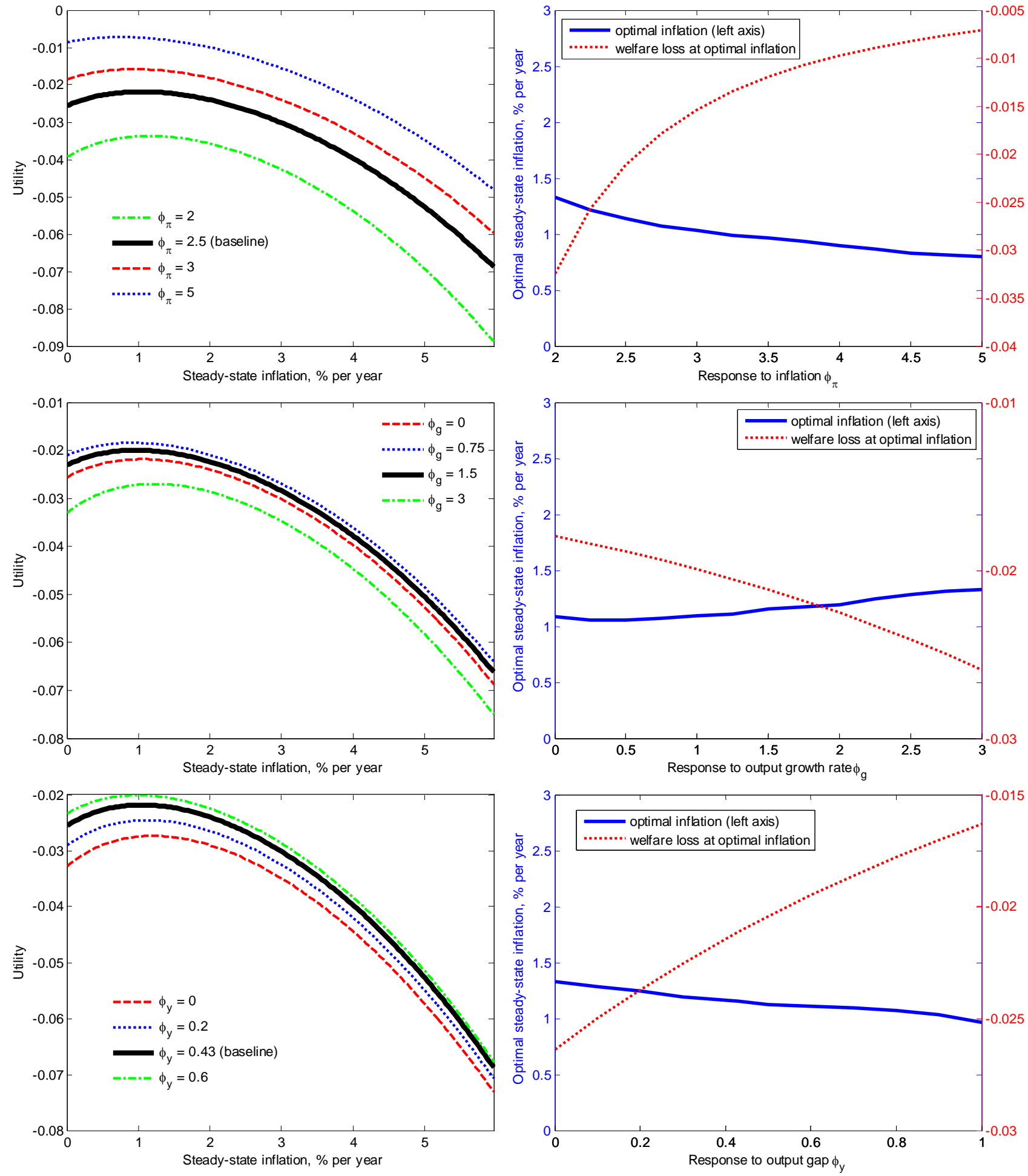

Note: Figures in the left column plot the welfare loss as a function of steady state inflation for alternative values of the monetary policy rule parameters. The solid thick back line corresponds to the baseline parameterization. Figures in the right column plot the optimal level of steady-state inflation and the welfare loss at the optimal steady state level of inflation as a function of the monetary policy rule parameters. $\phi_{\pi}$ is the long-run response of interest rates to inflation, $\phi_{g}$ is the response to output growth, and $\phi_{y}$ is the response to the output gap. See section 6.1 for details. 
Figure 14. Positive implications: price level targeting and interest rate smoothing.
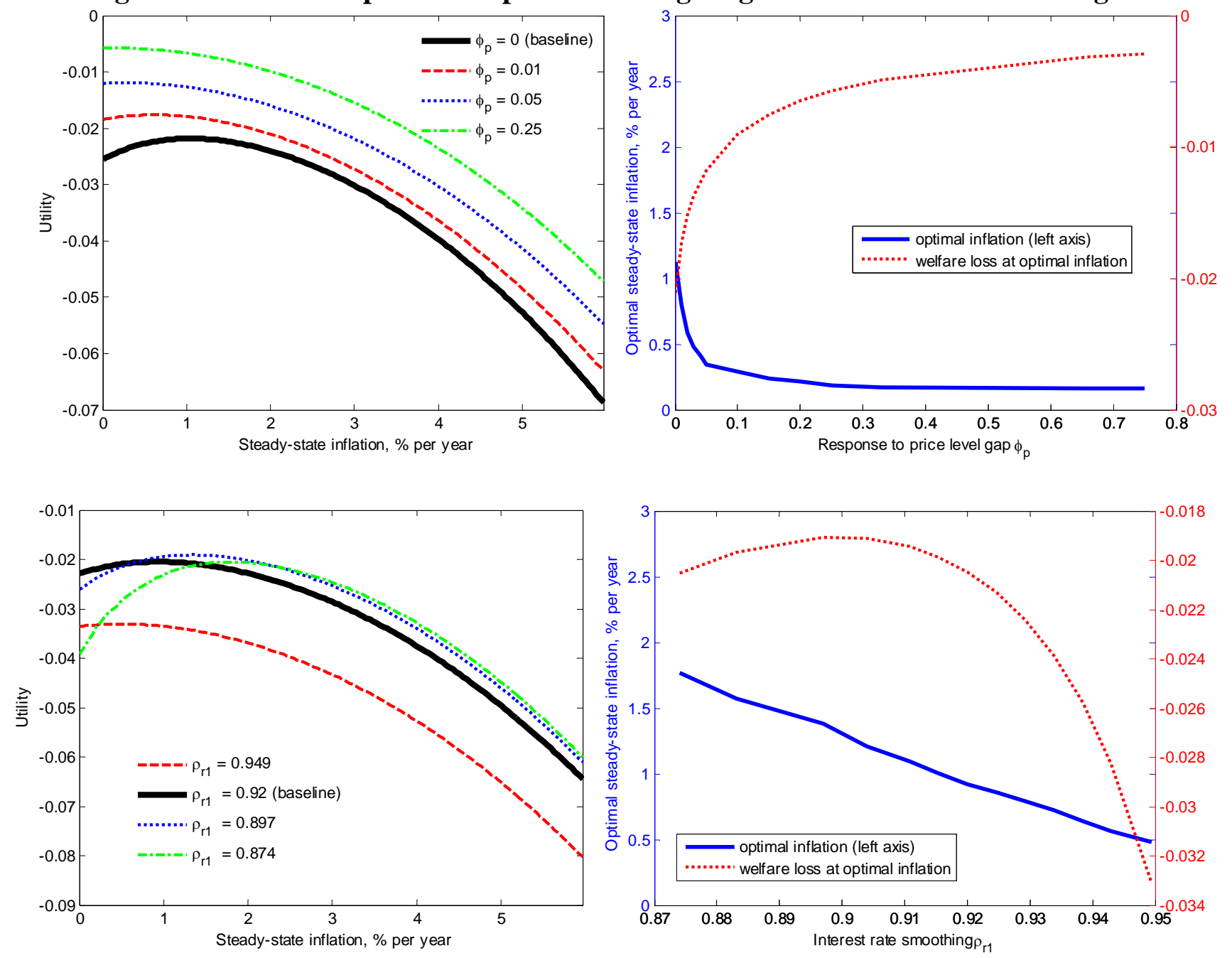

Note: Figures in the left column plot the welfare loss as a function of steady state inflation for alternative values of the monetary rule parameters. The solid thick back line corresponds to the baseline parameterization. Figures in the right column plot the optimal level of steady-state inflation and the welfare loss at the optimal steady state level of inflation as a function of the monetary policy rule parameters. $\phi_{p}$ is the response to the price-level gap while $\rho_{r 1}$ is the degree of interest smoothing. See section 6.2 for details. 


\section{Appendix A. Proofs for section 2.4.}

\section{Lemma 1.}

The expansion of the utility derived from consumption around flexible price steady state is

$$
\begin{aligned}
u\left(C_{t}\right)-h u\left(C_{t-1}\right)= & \underbrace{u\left(\bar{C}_{t}^{F}\right)-h u\left(\bar{C}_{t-1}^{F}\right)}_{t i p}+u_{\bar{C}_{t}^{F}}^{\prime}\left(C_{t}-\bar{C}_{t}^{F}\right)+\frac{1}{2} u_{\bar{C}_{t}^{F} \bar{C}_{t}^{F}}^{\prime \prime}\left(C_{t}-\bar{C}_{t}^{F}\right)^{2}-h u_{\bar{C}_{t-1}^{F}}^{\prime}\left(C_{t-1}-\bar{C}_{t-1}^{F}\right) \\
& \quad-\frac{1}{2} h u_{\bar{C}_{t-1}^{F} \bar{C}_{t-1}^{F}}^{\prime \prime}\left(C_{t-1}-\bar{C}_{t-1}^{F}\right)^{2}+h o t \\
= & \bar{C}_{t}^{F} u_{\bar{C}_{t}^{F}}^{\prime}\left(\tilde{c}_{t}+\frac{1}{2} \tilde{c}_{t}^{2}\right)+\frac{1}{2}\left(\bar{C}_{t}^{F}\right)^{2} u_{\bar{C}_{t}^{F} \bar{C}_{t}^{F}}^{\prime \prime} \tilde{c}_{t}^{2}-h \bar{C}_{t-1}^{F} u_{\bar{C}_{t-1}^{F}}^{\prime}\left(\tilde{c}_{t-1}+\frac{1}{2} \tilde{c}_{t-1}^{2}\right) \\
& \quad-\frac{1}{2} h\left(\bar{C}_{t-1}^{F}\right)^{2} u_{\bar{C}_{t-1}^{F} \bar{C}_{t-1}^{F}}^{\prime} \tilde{c}_{t-1}^{2}+h o t+t i p
\end{aligned}
$$

where $\sigma$ is the intertemporal elasticity of substitution for consumption, $\omega$ is the elasticity of real marginal cost with respect to own output, $\bar{C}_{t}^{F}$ is the flexible price level of consumption in the steady state. Tildes denote percent deviations from the flexible price level, tip stands for terms independent from policy, hot means higher order terms. We assume that utility is logarithmic, $u\left(C_{t}\right)=\log C_{t}, \bar{C}_{t}^{F} u_{\bar{C}_{t}^{F}}^{\prime}=1$ and $\sigma=1$ so that the expression becomes $u\left(C_{t}\right)-h u\left(C_{t-1}\right)=\tilde{c}_{t}-h \tilde{c}_{t-1}$.

\section{Lemma 3.}

Note that

$$
\ln P_{t}=\frac{1}{1-\theta} \log \left(\int_{0}^{1} P_{t}^{1-\theta}(i) d i\right)=\underbrace{\frac{1}{1-\theta} \int_{0}^{1} \log \left(P_{t}^{1-\theta}(i)\right) d i}_{\bar{P}_{t}}+\frac{1}{2} \frac{1}{1-\theta} \frac{1}{\left[E P_{t}^{1-\theta}(i)\right]^{2}} \operatorname{var}_{i}\left(P_{t}^{1-\theta}(i)\right)+h o t
$$

By the delta method, we have

$$
\begin{aligned}
\operatorname{var}_{i}\left(P_{t}^{1-\theta}(i)\right) & =\operatorname{var}_{i}\left(\exp \left\{(1-\theta) \log P_{t}(i)\right\}\right) \\
& \approx(1-\theta)^{2}\left[\exp \left\{(1-\theta) E \log P_{t}(i)\right\}\right]^{2} \operatorname{var}_{i}\left(\log P_{t}(i)\right) \\
& =(1-\theta)^{2}\left[\exp \left\{(1-\theta) \bar{P}_{t}\right\}\right]^{2} \Delta_{t}
\end{aligned}
$$

Now observe that

$$
\begin{aligned}
E P_{t}^{1-\theta}(i)= & E\left[\exp \left\{(1-\theta) \log P_{t}(i)\right\}\right] \approx \exp \left\{(1-\theta) E \log P_{t}(i)\right\} \\
& +\frac{1}{2}(1-\theta)^{2} \exp \left\{(1-\theta) E \log P_{t}(i)\right\} \underbrace{\operatorname{var}_{i}\left(\log P_{t}(i)\right)}_{\Delta_{t}} \\
= & \exp \left\{(1-\theta) \bar{P}_{t}\right\}+\frac{1}{2}(1-\theta)^{2} \exp \left\{(1-\theta) \bar{P}_{t}\right\} \Delta_{t}=\exp \left\{(1-\theta) \bar{P}_{t}\right\}\left[1+\frac{1}{2}(1-\theta)^{2} \Delta_{t}\right]
\end{aligned}
$$


Hence it follows that

$$
\begin{aligned}
\log P_{t} & =\bar{P}_{t}+\frac{1}{2} \frac{1}{1-\theta} \frac{(1-\theta)^{2}\left[\exp \left\{(1-\theta) \bar{P}_{t}\right\}\right]^{2} \Delta_{t}}{\left[\exp \left\{(1-\theta) \bar{P}_{t}\right\}\right]^{2}\left[1+\frac{1}{2}(1-\theta)^{2} \Delta_{t}\right]^{2}}+\text { hot } \\
& =\bar{P}_{t}+\frac{1}{2} \frac{(1-\theta) \Delta_{t}}{\left[1+\frac{1}{2}(1-\theta)^{2} \Delta_{t}\right]^{2}}+h o t \\
& =\bar{P}_{t}+\frac{1-\theta}{2} \frac{\bar{\Delta}}{\left[1+\frac{1}{2}(1-\theta)^{2} \bar{\Delta}\right]^{2}}+\frac{1-\theta}{2} \frac{1-\frac{1}{2}(1-\theta)^{2} \bar{\Delta}}{\left[1+\frac{1}{2}(1-\theta)^{2} \bar{\Delta}\right]^{3}} \Delta_{t}+h o t \\
& =\bar{P}_{t}+Q_{p}^{0}+\frac{1-\theta}{2} Q_{p}^{1}\left(\Delta_{t}-\bar{\Delta}\right)+h o t
\end{aligned}
$$

where $Q_{p}^{0}=\frac{\frac{1-\theta}{2} \bar{\Delta}}{\left[1+\frac{1}{2}(1-\theta)^{2} \bar{\Delta}\right]^{2}}$ and $Q_{p}^{1}=\frac{1-\frac{1}{2}(1-\theta)^{2} \bar{\Delta}}{\left[1+\frac{1}{2}(1-\theta)^{2} \bar{\Delta}\right]^{3}}$.

\section{Lemma 5.}

Consider the term $E_{i} \hat{y}_{t}(i)$. From the Dixit-Stiglitz aggregator we have

$$
Y_{t}=\left[\int_{0}^{1} Y_{t}(i)^{\frac{\theta-1}{\theta}}\right]^{\frac{\theta}{\theta-1}} \Rightarrow Y_{t} / \bar{Y}_{t}^{F}=\left[\int_{0}^{1}\left(Y_{t}(i) / \bar{Y}_{t}^{F}\right)^{\frac{\theta-1}{\theta}}\right]^{\frac{\theta}{\theta-1}}
$$

Note that

$$
\begin{aligned}
\log Y_{t} / \bar{Y}_{t}^{F} & =\frac{\theta}{\theta-1} \log \left(\int_{0}^{1}\left(Y_{t}(i) / \bar{Y}_{t}^{F}\right)^{\frac{\theta-1}{\theta}} d i\right)= \\
& =\frac{\theta}{\theta-1} \int_{0}^{1} \frac{\theta-1}{\theta} \log \left(Y_{t}(i) / \bar{Y}_{t}^{F}\right) d i+\frac{1}{2} \frac{\theta}{\theta-1} \frac{1}{\left[E\left(Y_{t}(i) / \bar{Y}_{t}^{F}\right)^{\frac{\theta-1}{\theta}}\right]^{2}} \operatorname{var}_{i}\left(\left(Y_{t}(i) / \bar{Y}_{t}^{F}\right)^{\frac{\theta-1}{\theta}}\right)+h o t \\
& =E_{i} \hat{y}_{t}(i)+\frac{1}{2} \frac{\theta}{\theta-1} \frac{1}{\left[E\left(Y_{t}(i) / \bar{Y}_{t}^{F}\right)^{\frac{\theta-1}{\theta}}\right]^{2}} \operatorname{var}_{i}\left(\left(Y_{t}(i) / \bar{Y}_{t}^{F}\right)^{\frac{\theta-1}{\theta}}\right)+h o t
\end{aligned}
$$

Using the delta method, we have

$$
\begin{aligned}
& \operatorname{var}_{i}\left(\left(Y_{t}(i) / \bar{Y}_{t}^{F}\right)^{\frac{\theta-1}{\theta}}\right)=\operatorname{var}_{i}\left(\exp \left\{\frac{\theta-1}{\theta} \log \left(Y_{t}(i) / \bar{Y}_{t}^{F}\right)\right\}\right) \\
& \quad \approx\left(\frac{\theta-1}{\theta}\right)^{2}\left[\exp \left\{\frac{\theta-1}{\theta} E \log \left(Y_{t}(i) / \bar{Y}_{t}^{F}\right)\right\}\right]^{2} \operatorname{var}_{i}\left(\log \left(Y_{t}(i) / \bar{Y}_{t}^{F}\right)\right)
\end{aligned}
$$

Also observe that

$$
\begin{aligned}
& E\left(Y_{t}(i) / \bar{Y}_{t}^{F}\right)^{\frac{\theta-1}{\theta}}=E\left[\exp \left\{\frac{\theta-1}{\theta} \log \left(Y_{t}(i) / \bar{Y}_{t}^{F}\right)\right\}\right] \\
& \begin{array}{l}
\approx \exp \left\{\frac{\theta-1}{\theta} E \log \left(Y_{t}(i) / \bar{Y}_{t}^{F}\right)\right\} \\
\quad+\frac{1}{2}\left(\frac{\theta-1}{\theta}\right)^{2} \exp \left\{\frac{\theta-1}{\theta} E \log \left(Y_{t}(i) / \bar{Y}_{t}^{F}\right)\right\} \operatorname{var}_{i}\left(\log \left(Y_{t}(i) / \bar{Y}_{t}^{F}\right)\right) \\
=\exp \left\{\frac{\theta-1}{\theta} E \log \left(Y_{t}(i) / \bar{Y}_{t}^{F}\right)\right\}\left[1+\frac{1}{2}\left(\frac{\theta-1}{\theta}\right)^{2} \operatorname{var}_{i}\left(\log \left(Y_{t}(i) / \bar{Y}_{t}^{F}\right)\right)\right]
\end{array}
\end{aligned}
$$

Combine (A.7) and (A.8) to re-write (A.6) as follows 


$$
\begin{aligned}
\tilde{y}_{t}=\ln Y_{t} / \bar{Y}_{t}^{F} & =E_{i} \tilde{y}_{t}(i)+\frac{1}{2} \frac{\theta}{\theta-1} \frac{\left(\frac{\theta-1}{\theta}\right)^{2} \operatorname{var}_{i}\left(\log \left(Y_{t}(i) / \bar{Y}_{t}^{F}\right)\right)}{\left[1+\frac{1}{2}\left(\frac{\theta-1}{\theta}\right)^{2} \operatorname{var}_{i}\left(\log \left(Y_{t}(i) / \bar{Y}_{t}^{F}\right)\right)\right]^{2}}+h o t \\
& =E_{i} \tilde{y}_{t}(i)+\frac{1}{2} \frac{\theta-1}{\theta} \operatorname{var}_{i}\left(\log \left(y_{t}(i) / \bar{Y}_{t}^{F}\right)\right)+h o t \\
& =E_{i} \tilde{y}_{t}(i)+\frac{1}{2} \frac{\theta-1}{\theta} \frac{\bar{\Upsilon}}{\left[1+\frac{1}{2}\left(\frac{\theta-1}{\theta}\right)^{2} \bar{\Upsilon}\right]^{2}}+\frac{1}{2} \frac{\theta-1}{\theta} \frac{1-\frac{1}{2}\left(\frac{\theta-1}{\theta}\right)^{2} \bar{\Upsilon}}{\left[1+\frac{1}{2}\left(\frac{\theta-1}{\theta}\right)^{2} \bar{\Upsilon}\right]^{3}}\left[\Upsilon_{t}-\bar{\Upsilon}\right]+h o t \\
& =E_{i} \tilde{y}_{t}(i)+Q_{y}^{0}+\frac{1}{2} \frac{\theta-1}{\theta} Q_{y}^{1}\left(\Upsilon_{t}-\bar{\Upsilon}\right)+h o t
\end{aligned}
$$

where $Q_{y}^{1}=\frac{1-\frac{1}{2}\left(\frac{\theta-1}{\theta}\right)^{2} \bar{\Upsilon}}{\left[1+\frac{1}{2}\left(\frac{\theta-1}{\theta}\right)^{2} \bar{\Upsilon}\right]^{3}}$ and $Q_{y}^{0}=\frac{\frac{1}{2} \frac{\theta-1}{\theta} \bar{\Upsilon}}{\left[1+\frac{1}{2}\left(\frac{\theta-1}{\theta}\right)^{2} \bar{\Upsilon}\right]^{2}}$

\section{Lemma 4.}

Recall that $b_{t}=\log \left(B_{t} / P_{t}\right)$ (note that in our notation $b_{t}$ is the price relative to current price level) and $\bar{P}_{t}=E_{i} \log P_{t}(i)$, and $P_{t}=\left(\int_{0}^{1} P_{t}^{1-\theta}(i) d i\right)^{1 /(1-\theta)}$. Also keep in mind that the fraction of firms that do not change their price index it to a fraction $0 \leq \omega \leq 1$ of steady-state inflation, $P_{t}(i)=P_{t-1}(i) \bar{\Pi}^{\omega}$. Then

$$
\begin{aligned}
& \Delta_{t} \quad \equiv \operatorname{var}_{i}\left(\log P_{t}(i)\right)=\int_{0}^{1}\left[\log P_{t}(i)-\bar{P}_{t}\right]^{2} d i=\underbrace{\int_{0}^{1-\lambda}\left[\log P_{t}(i)-\bar{P}_{t}\right]^{2} d i}_{\text {price change }}+\underbrace{\int_{1-\lambda}^{1}\left[\log P_{t}(i)-\bar{P}_{t}\right]^{2} d i}_{\text {indexed price }} \\
&= \int_{0}^{1-\lambda}\left[\log P_{t}(i)-\log P_{t}\right]^{2} d i+2 \int_{0}^{1-\lambda}\left[\log P_{t}(i)-\log P_{t}\right]\left[\log P_{t}-\bar{P}_{t}\right] d i+\int_{0}^{1-\lambda}\left[\log P_{t}-\bar{P}_{t}\right]^{2} d i \\
& \quad \int_{1-\lambda}^{1}\left[\log P_{t-1}(i)-\bar{P}_{t}+\omega \bar{\pi}\right]^{2} d i \\
&= \int_{0}^{1-\lambda}\left[\log P_{t}(i)-\log P_{t}\right]^{2} d i+2 \int_{0}^{1-\lambda}\left[\log P_{t}(i)-\log P_{t}\right]\left[\log P_{t}-\bar{P}_{t}\right] d i+\int_{0}^{1-\lambda}\left[\log P_{t}-\bar{P}_{t}\right]^{2} d i \\
& \quad+\int_{1-\lambda}^{1}\left[\log P_{t-1}(i)-\bar{P}_{t-1}\right]^{2} d i+2 \int_{1-\lambda}^{1}\left[\log P_{t-1}(i)-\bar{P}_{t-1}\right]\left[\bar{P}_{t-1}-\bar{P}_{t}+\omega \bar{\pi}\right] d i+\int_{1-\lambda}^{1}\left[\bar{P}_{t-1}-\bar{P}_{t}+\omega \bar{\pi}\right]^{2} d i \\
&=(1-\lambda) b_{t}^{2}+2(1-\lambda) b_{t}\left[\log P_{t}-\bar{P}_{t}\right]+(1-\lambda)\left[\log P_{t}-\bar{P}_{t}\right]^{2} \\
& \quad+\lambda \Delta_{t-1}+2\left[\bar{P}_{t-1}-\bar{P}_{t}+\omega \bar{\pi}\right] \int_{=0}^{\int_{1-\lambda}^{1}\left[\log P_{t-1}(i)-\bar{P}_{t-1}\right] d i}+\lambda\left[\bar{P}_{t}-\bar{P}_{t-1}+\omega \bar{\pi}\right]^{2}
\end{aligned}
$$

So that$$
\Delta_{t}=(1-\lambda) b_{t}^{2}+2(1-\lambda) b_{t}\left[\log P_{t}-\bar{P}_{t}\right]+(1-\lambda)\left[\log P_{t}-\bar{P}_{t}\right]^{2}+\lambda \Delta_{t-1}+\lambda\left[\bar{P}_{t}-\bar{P}_{t-1}-\omega \bar{\pi}\right]^{2}
$$

From Lemma 3 we have

$$
\log P_{t}-\bar{P}_{t} \approx Q_{p}^{0}+\frac{1-\theta}{2} Q_{p}^{1}\left(\Delta_{t}-\bar{\Delta}\right) .
$$

Also from equation (21) in the paper we have that

$$
\pi_{t}-\bar{\pi}=\frac{1-\lambda \bar{\Pi}^{(\theta-1)(1-\omega)}}{\lambda \bar{\Pi}^{(\theta-1)(1-\omega)}}\left(b_{t}-\bar{b}\right) \Rightarrow b_{t}=\bar{b}+\frac{\lambda \bar{\Pi}^{(\theta-1)(1-\omega)}}{1-\lambda \bar{\Pi}^{(\theta-1)(1-\omega)}}\left(\pi_{t}-\bar{\pi}\right)=\bar{b}+M\left(\pi_{t}-\bar{\pi}\right) .
$$


While solving for the dispersion of prices, we need to be mindful that steady-state inflation generates price dispersion of first order. We use a guess and verify procedure to address this issue. In particular, we posit that if the deviation of cross-sectional price dispersion from its non-stochastic steady state level $\bar{\Delta}$ is $\Xi_{t} \equiv \Delta_{t}-\bar{\Delta}$ then

$$
\Xi_{t}=K_{Q}\left(\pi_{t}-\bar{\pi}\right)+Z_{1, Q}\left(\pi_{t}-\bar{\pi}\right)^{2}+F_{Q} \Xi_{t-1}+G_{Q}\left(\pi_{t}-\bar{\pi}\right) \Xi_{t-1}+H_{Q} \Xi_{t-1}^{2}
$$

Note that the first term on the right hand side is of first order. Plug (A.12) and (A.11) into (A.10) and using the guess (A.13) yields,

$$
\begin{aligned}
& \Delta_{t} \quad=(1-\lambda)\left[\bar{b}+M\left(\pi_{t}-\bar{\pi}\right)\right]^{2}+2(1-\lambda)\left[\bar{b}+M\left(\pi_{t}-\bar{\pi}\right)\right]\left[Q_{p}^{0}+\frac{1-\theta}{2} Q_{p}^{1} \Xi_{t}\right] \\
& +(1-\lambda)\left[Q_{p}^{0}+\frac{1-\theta}{2} Q_{p}^{1} \Xi_{t}\right]^{2}+\lambda \Delta_{t-1} \\
& +\lambda\left[\left(\ln P_{t}-\ln P_{t-1}-\omega \bar{\pi}\right)-\left(\ln P_{t}-\bar{P}_{t}\right)+\left(\ln P_{t-1}-\bar{P}_{t-1}\right)\right]^{2} \\
& =(1-\lambda) \bar{b}^{2}+(1-\lambda) M^{2}\left(\pi_{t}-\bar{\pi}\right)^{2}+2(1-\lambda) \bar{b} M\left(\pi_{t}-\bar{\pi}\right) \\
& +2(1-\lambda) \bar{b} Q_{p}^{0}+(1-\lambda)(1-\theta) \bar{b} Q_{p}^{1} \Xi_{t}+2(1-\lambda) Q_{p}^{0} M\left(\pi_{t}-\bar{\pi}\right) \\
& +(1-\lambda)(1-\theta) M Q_{p}^{1} K_{Q}\left(\pi_{t}-\bar{\pi}\right)^{2}+(1-\lambda)(1-\theta) M Q_{p}^{1} F_{Q}\left(\pi_{t}-\bar{\pi}\right) \Xi_{t-1} \\
& +(1-\lambda)\left[Q_{p}^{0}\right]^{2}+(1-\lambda)(1-\theta) Q_{p}^{0} Q_{p}^{1} \Xi_{t} \\
& +(1-\lambda) \frac{(1-\theta)^{2}}{4}\left[Q_{p}^{1}\right]^{2} K_{Q}{ }^{2}\left(\pi_{t}-\bar{\pi}\right)^{2}+(1-\lambda) \frac{(1-\theta)^{2}}{2}\left[Q_{p}^{1}\right]^{2} F_{Q} K_{Q}\left(\pi_{t}-\bar{\pi}\right) \Xi_{t-1} \\
& +(1-\lambda) \frac{(1-\theta)^{2}}{4}\left[Q_{p}^{1}\right]^{2} F_{Q}^{2} \Xi_{t-1}^{2}+\lambda \Delta_{t-1} \\
& +\lambda\left(\pi_{t}-\bar{\pi}\right)^{2}+\lambda(1-\omega)^{2} \bar{\pi}^{2}+2 \lambda(1-\omega) \bar{\pi}\left(\pi_{t}-\bar{\pi}\right) \\
& +\lambda \frac{(1-\theta)^{2}}{4}\left[Q_{p}^{1}\right]^{2} K_{Q}^{2}\left(\pi_{t}-\bar{\pi}\right)^{2}+\lambda \frac{(1-\theta)^{2}}{2}\left[Q_{p}^{1}\right]^{2} F_{Q} K_{Q}\left(\pi_{t}-\bar{\pi}\right) \Xi_{t-1} \\
& +\lambda \frac{(1-\theta)^{2}}{2}\left[Q_{p}^{1}\right]^{2} F_{Q}{ }^{2} \Xi_{t-1}^{2}+\lambda\left[Q_{p}^{0}\right]^{2}+\lambda(1-\theta) Q_{p}^{0} Q_{p}^{1} \Xi_{t} \\
& +\lambda \frac{(1-\theta)^{2}}{4}\left[Q_{p}^{1}\right]^{2} \Xi_{t-1}^{2}+\lambda\left[Q_{p}^{0}\right]^{2}+\lambda(1-\theta) Q_{p}^{0} Q_{p}^{1} \Xi_{t-1} \\
& -\lambda(1-\theta) Q_{p}^{1} K_{Q}\left(\pi_{t}-\bar{\pi}\right)^{2}-\lambda(1-\theta) Q_{p}^{1} F_{Q}\left(\pi_{t}-\bar{\pi}\right) \Xi_{t-1} \\
& -2 \lambda Q_{p}^{0}\left(\pi_{t}-\bar{\pi}\right)-2 \lambda(1-\omega) \bar{\pi} Q_{p}^{0}-\lambda(1-\theta)(1-\omega) \bar{\pi} Q_{p}^{1} \Xi_{t} \\
& +\lambda(1-\theta) Q_{p}^{1}\left(\pi_{t}-\bar{\pi}\right) \Xi_{t-1}+2 \lambda Q_{p}^{0}\left(\pi_{t}-\bar{\pi}\right)+2 \lambda(1-\omega) \bar{\pi} Q_{p}^{0}+\lambda(1-\theta)(1-\omega) \bar{\pi} Q_{p}^{1} \Xi_{t-1} \\
& -\lambda \frac{(1-\theta)^{2}}{2}\left[Q_{p}^{1}\right]^{2} K_{Q}\left(\pi_{t}-\bar{\pi}\right) \Xi_{t-1}-\lambda \frac{(1-\theta)^{2}}{2}\left[Q_{p}^{1}\right]^{2} F_{Q} \Xi_{t-1}^{2} \\
& -2 \lambda\left[Q_{p}^{0}\right]^{2}-\lambda(1-\theta) Q_{p}^{0} Q_{p}^{1} \Xi_{t-1}-\lambda(1-\theta) Q_{p}^{0} Q_{p}^{1} \Xi_{t}+\text { hot. }
\end{aligned}
$$

The non-stochastic steady state value is given by

$$
\bar{\Delta}=(1-\lambda) \bar{b}^{2}+2(1-\lambda) \bar{b} Q_{0}^{p}+(1-\lambda)\left[Q_{0}^{p}\right]^{2}+\lambda \bar{\Delta}+\lambda(1-\omega)^{2} \bar{\pi}^{2}=\left(\bar{b}+Q_{0}^{p}\right)^{2}+\frac{\lambda(1-\omega)^{2}}{(1-\lambda)} \bar{\pi}^{2}
$$

So we can solve for deviations from steady state dispersion $\Xi_{t} \equiv \Delta_{t}-\bar{\Delta}$ 


$$
\begin{aligned}
\Xi_{t} & =\left(\pi_{t}-\bar{\pi}\right)\left\{2(1-\lambda) \bar{b} M+2(1-\lambda) Q_{p}^{0} M+2 \lambda(1-\omega) \bar{\pi}\right\} \\
& +\left(\pi_{t}-\bar{\pi}\right)^{2}\left\{(1-\lambda) M^{2}+\lambda+\frac{(1-\theta)^{2}}{4}\left[Q_{p}^{1}\right]^{2} K_{Q}^{2}+(1-\lambda)(1-\theta) M Q_{p}^{1} K_{Q}-\lambda(1-\theta) Q_{p}^{1} K_{Q}\right\} \\
& +\Xi_{t}\left\{(1-\lambda)(1-\theta) \bar{b} Q_{p}^{1}+(1-\lambda)(1-\theta) Q_{p}^{0} Q_{p}^{1}-\lambda(1-\theta)(1-\omega) \bar{\pi} Q_{p}^{1}\right\} \\
& +\left(\pi_{t}-\bar{\pi}\right) \Xi_{t-1}\left\{(1-\lambda)(1-\theta) M Q_{p}^{1} F_{Q}+(1-\lambda)(1-\theta) Q_{p}^{1}\left(1-F_{Q}\right)+\frac{(1-\theta)^{2}}{2}\left[Q_{p}^{1}\right]^{2} K_{Q}\left(F_{Q}-\lambda\right)\right\} \\
& +\Xi_{t-1}^{2}\left\{\frac{(1-\theta)^{2}}{4}\left[Q_{p}^{1}\right]^{2}\left[F_{Q}^{2}+\lambda\left(1-2 F_{Q}\right)\right]\right\}+\Xi_{t-1}\left\{\lambda+\lambda(1-\theta)(1-\omega) \bar{\pi} Q_{p}^{1}\right\}+\text { hot. }
\end{aligned}
$$

Note that the form of (A.15) is the same as the form of our guess in (A.13). Let $\Gamma_{0}=\left\{1+(\theta-1) Q_{1}^{p}\left[(1-\lambda)\left(\bar{b}+Q_{0}^{p}\right)-\lambda(1-\omega) \bar{\pi}\right]\right\}^{-1}$ and $\Gamma_{1}=\left[1-(\theta-1)(1-\omega) Q_{1}^{p} \bar{\pi}\right] \Gamma_{0}$. Then matching coefficients with the guess and verify equation (A.13), we have $\Gamma_{2}=2\left\{(1-\lambda) M\left(\bar{b}+Q_{p}^{0}\right)+\lambda(1-\omega) \bar{\pi}\right\} \Gamma_{0}$ which confirms the guess for the functional form of $\Delta_{t}-\bar{\Delta}$ with $F_{Q}=\lambda \Gamma_{1}$. Hence

$$
\begin{aligned}
\Xi_{t}= & \Gamma_{2}\left(\pi_{t}-\bar{\pi}\right)+\lambda \Gamma_{1} \Xi_{t-1}+\Xi_{t-1}^{2} \Gamma_{0}\left\{\frac{(1-\theta)^{2}}{4}\left[Q_{p}^{1}\right]^{2}\left[\left(\lambda \Gamma_{1}\right)^{2}+\lambda\left(1-2 \lambda \Gamma_{1}\right)\right]\right\} \\
& +\left(\pi_{t}-\bar{\pi}\right)^{2} \Gamma_{0}\left\{(1-\lambda) M^{2}+\lambda+\frac{(1-\theta)^{2}}{4}\left[Q_{p}^{1}\right]^{2} \Gamma_{2}^{2}+(1-\lambda)(1-\theta) M Q_{p}^{1} \Gamma_{2}-\lambda(1-\theta) Q_{p}^{1} \Gamma_{2}\right\} \\
& +\left(\pi_{t}-\bar{\pi}\right) \Xi_{t-1} \Gamma_{0}\left\{(1-\lambda)(1-\theta) Q_{p}^{1}\left[M \lambda \Gamma_{1}+\left(1-\lambda \Gamma_{1}\right)\right]+\frac{(1-\theta)^{2}}{2}\left[Q_{p}^{1}\right]^{2} \Gamma_{2} \lambda\left(\Gamma_{1}-1\right)\right\}+\text { h.o.t. }
\end{aligned}
$$

which completes the proof.

\section{Corollary 1.}

Up to a first order approximation, the deviation of price dispersion from its steady state evolves according to $\Xi_{t}=\Gamma_{2}\left(\pi_{t}-\bar{\pi}\right)+\lambda \Gamma_{1} \Xi_{t-1}$, which reduces to Proposition 6.3 in Woodford (2003) when $\bar{\pi}=0$.

\section{Proposition 1.}

From Lemma 5, we have $E_{i} \tilde{y}_{t}(i)=\tilde{y}_{t}-Q_{y}^{0}-\frac{1}{2} \frac{\theta-1}{\theta} Q_{y}^{1}\left(\operatorname{var}_{i} \hat{y}_{t}(i)-\bar{\Upsilon}\right)+$ hot . Therefore, we can express the approximation from the disutility of labor supply given in Lemma 2 as follows:

$$
\begin{aligned}
\int_{0}^{1} \tilde{v}\left(Y_{t}(i)\right) d i \quad \approx & \bar{Y}_{t}^{F} \tilde{v}_{\bar{Y}_{t}^{F}}^{\prime}\left\{E_{i} \tilde{y}_{t}(i)+\frac{1}{2}\left(1+\eta^{-1}\right) \int_{0}^{1} \tilde{y}_{t}^{2}(i) d i\right\} \\
= & \bar{Y}_{t}^{F} \tilde{v}_{\bar{Y}_{t}^{F}}^{\prime}\left\{E_{i} \tilde{y}_{t}(i)+\frac{1}{2}\left(1+\eta^{-1}\right)\left(\operatorname{var}_{i} \hat{y}_{t}(i)+\left[E_{i} \tilde{y}_{t}(i)\right]^{2}\right)\right\} \\
= & \bar{Y}_{t}^{F} \tilde{v}_{\bar{Y}_{t}^{F}}^{\prime}\left\{\left(1-\left(1+\eta^{-1}\right) Q_{y}^{0}\right) \tilde{y}_{t}\right. \\
& +\frac{1}{2}\left[Q_{y}^{1} \theta^{-1}-Q_{y}^{1}+\left(1+\eta^{-1}\right)\left(1+\frac{\theta-1}{\theta} Q_{y}^{0} Q_{y}^{1}\right)\right] \operatorname{var}_{i} \hat{y}_{t}(i)+ \\
& +\frac{1}{2}\left(1+\eta^{-1}\right)\left(\frac{1}{4}\left(\frac{\theta-1}{\theta}\right)^{2}\left[Q_{y}^{1}\left(\operatorname{var}_{i} \hat{y}_{t}(i)-\bar{\Upsilon}\right)\right]^{2}-\frac{\theta-1}{\theta} x_{t} Q_{y}^{1}\left[\operatorname{var}_{i} \hat{y}_{t}(i)-\bar{\Upsilon}\right]\right) \\
& \left.+\frac{1}{2}\left(1+\eta^{-1}\right) \tilde{y}_{t}^{2}+\left(1+\eta^{-1}\right)\left[Q_{y}^{0}\right]^{2}-Q_{y}^{0}+\frac{\theta-1}{\theta} Q_{y}^{1}\left[\frac{1}{2}-\left(1+\eta^{-1}\right) Q_{y}^{0}\right] \bar{\Upsilon}\right\}+ \text { hot tip }
\end{aligned}
$$

As Woodford (2003) shows, $\tilde{v}_{\bar{Y}_{t}^{F}}^{\prime}=(1-\beta h) u_{\bar{C}_{t}^{F}}^{\prime}(1-\Phi)$, where (with $\log$ utility) $\Phi=-\ln \left(\frac{\theta-1}{\theta}\right)$ which follows from the intra-temporal condition for labor supply. Hence,

$\int_{0}^{1} \tilde{v}\left(Y_{t}(i)\right) d i=(1-\beta h)\left(1-\bar{g}_{y}\right)^{-1} \hat{C}_{t}^{F} u_{\hat{C}_{t}^{F}}^{\prime}(1-\Phi)\left\{\left(1-\left(1+\eta^{-1}\right) Q_{y}^{0}\right) \tilde{y}_{t}+\frac{1}{2}\left(1+\eta^{-1}\right) \tilde{y}_{t}^{2}+\right.$ 


$$
\begin{aligned}
& +\frac{1}{2}\left[Q_{y}^{1} \theta^{-1}-Q_{y}^{1}+\left(1+\eta^{-1}\right)\left(1+\frac{\theta-1}{\theta} Q_{y}^{0} Q_{y}^{1}\right)\right] \operatorname{var}_{i} \hat{y}_{t}(i) \\
& +\frac{1}{2}\left(1+\eta^{-1}\right)\left(\frac{1}{4}\left(\frac{\theta-1}{\theta}\right)^{2}\left[Q_{y}^{1}\left(\operatorname{var}_{i} \hat{y}_{t}(i)-\bar{\Upsilon}\right)\right]^{2}-\frac{\theta-1}{\theta} x_{t} Q_{y}^{1}\left[\operatorname{var}_{i} \hat{y}_{t}(i)-\bar{\Upsilon}\right]\right) \\
& \left.+\left(1+\eta^{-1}\right)\left[Q_{y}^{0}\right]^{2}-Q_{y}^{0}+\frac{\theta-1}{\theta} Q_{y}^{1}\left[\frac{1}{2}-\left(1+\eta^{-1}\right) Q_{y}^{0}\right] \bar{\Upsilon}\right\}+ \text { hot }+ \text { tip }
\end{aligned}
$$

As in Lemma 1, $\hat{C}_{t}^{F} u_{\hat{C}_{t}^{F}}^{\prime}=1$. Using equation (39) from the derivations in the paper and Lemma 4, we replace the cross-section dispersion of output in (A.17) with the cross-sectional dispersion of prices.

Using Corollary 1 and $E\left(\pi_{t}-\bar{\pi}\right)=0$, we compute the expected value of $\Xi_{t}$ :

$$
E\left(\Xi_{t}\right)=\Gamma_{3} \operatorname{var}\left(\hat{\pi}_{t}\right)+\Gamma_{4} \operatorname{cov}\left(\hat{\pi}_{t}, \Xi_{t-1}\right)+\Gamma_{5} \operatorname{var}\left(\Xi_{t-1}\right)
$$

where

$$
\begin{aligned}
& \Gamma_{3}=\frac{\Gamma_{0}}{1-\lambda \Gamma_{1}}\left\{(1-\lambda) M^{2}+\lambda+\frac{(1-\theta)^{2}}{4}\left[Q_{p}^{1}\right]^{2} \Gamma_{2}^{2}+(1-\lambda)(1-\theta) M Q_{p}^{1} \Gamma_{2}-\lambda(1-\theta) Q_{p}^{1} \Gamma_{2}\right\}, \\
& \Gamma_{4}=\frac{\Gamma_{0}}{1-\lambda \Gamma_{1}}\left\{(1-\lambda)(1-\theta) Q_{p}^{1}\left[M \lambda \Gamma_{1}+\left(1-\lambda \Gamma_{1}\right)\right]+\frac{(1-\theta)^{2}}{2}\left[Q_{p}^{1}\right]^{2} \Gamma_{2} \lambda\left(\Gamma_{1}-1\right)\right\}, \\
& \Gamma_{5}=\frac{\Gamma_{0}}{1-\lambda \Gamma_{1}}\left\{\frac{(1-\theta)^{2}}{4}\left[Q_{p}^{1}\right]^{2}\left[\left(\lambda \Gamma_{1}\right)^{2}+\lambda\left(1-2 \lambda \Gamma_{1}\right)\right]\right\} .
\end{aligned}
$$

Note that from the definition of $\Xi_{t}$, we have

$$
E\left(\Delta_{t}\right)=E\left(\Xi_{t}\right)+\bar{\Delta}
$$

Since all variables are stationary and $\hat{y}_{t}=\tilde{y}_{t}-\log (\bar{X})$, we can compute the expected per period utility as follows

$$
\begin{aligned}
E U_{t} \quad \approx & E\left\{\left(\tilde{c}_{t}-h \tilde{c}_{t-1}\right)\right. \\
- & (1-\beta h)(1-g)^{-1}(1-\Phi)\left(1-\left(1+\eta^{-1}\right) Q_{y}^{0}\right) \tilde{y}_{t}-\frac{1}{2}(1-\beta h)(1-g)^{-1}(1-\Phi)\left(1+\eta^{-1}\right) \tilde{y}_{t}^{2} \\
& -\frac{1}{2}(1-\beta h)(1-g)^{-1}\left[Q_{y}^{1} \theta^{-1}-Q_{y}^{1}+\left(1+\eta^{-1}\right)\left(1+\frac{\theta-1}{\theta} Q_{y}^{0} Q_{y}^{1}\right)\right] \theta^{2} \Delta_{t} \\
& -\frac{1}{8}(1-\beta h)(1-g)^{-1}\left(1+\eta^{-1}\right)\left(\frac{\theta-1}{\theta}\right)^{2}\left[Q_{y}^{1}\right]^{2} \theta^{2} \Xi_{t}^{2}+\frac{1}{2}(1-\beta h)(1-g)^{-1}\left(1+\eta^{-1}\right) \frac{\theta-1}{\theta} Q_{y}^{1} \theta^{2} \tilde{y}_{t} \Xi_{t} \\
& \left.-(1-\beta h)(1-g)^{-1}(1-\Phi)\left[\left(1+\eta^{-1}\right)\left[Q_{y}^{0}\right]^{2}-Q_{y}^{0}+\frac{\theta-1}{\theta} Q_{y}^{1}\left[\frac{1}{2}-\left(1+\eta^{-1}\right) Q_{y}^{0}\right] \bar{\Upsilon}\right]\right\}+h o t+t i p \\
= & {\left[1-h-(1-\beta h)(1-g)^{-1}(1-\Phi)\left(1-\left(1+\eta^{-1}\right) Q_{y}^{0}\right)\right] \log (\bar{X}) } \\
& -(1-\beta h)(1-g)^{-1}(1-\Phi)\left[\left(1+\eta^{-1}\right)\left[Q_{y}^{0}\right]^{2}-Q_{y}^{0}+\frac{\theta-1}{\theta} Q_{y}^{1}\left[\frac{1}{2}-\left(1+\eta^{-1}\right) Q_{y}^{0}\right] \bar{\Upsilon}\right] \\
& -\frac{1}{2}(1-\beta h)(1-g)^{-1}\left(1+\eta^{-1}\right)\left\{(1-\Phi)[\log (\bar{X})]^{2}+\operatorname{var}\left(\hat{y}_{t}\right)\right\} \\
& -\frac{1}{2}(1-\beta h)(1-g)^{-1}\left[Q_{y}^{1} \theta^{-1}-Q_{y}^{1}+\left(1+\eta^{-1}\right)\left(1+\frac{\theta-1}{\theta} Q_{y}^{0} Q_{y}^{1}\right)\right] \theta^{2} E\left(\Delta_{t}\right) \\
& -\frac{1}{8}(1-\beta h)(1-g)^{-1}\left(1+\eta^{-1}\right)\left(\frac{\theta-1}{\theta}\right)^{2}\left[Q_{y}^{1}\right]^{2} \theta^{4} \operatorname{var}\left(\Xi_{t}\right) \\
& +\frac{1}{2}(1-\beta h)(1-g)^{-1}\left(1+\eta^{-1}\right) \frac{\theta-1}{\theta} Q_{y}^{1} \theta^{2} \operatorname{cov}\left(\hat{y}_{t}, \Xi_{t}\right)+ \\
& +\frac{1}{2}(1-\beta h)(1-g)^{-1}\left(1+\eta^{-1}\right) \frac{\theta-1}{\theta} Q_{y}^{1} \theta^{2} \log (\bar{X}) E\left(\Xi_{t}\right) \\
& +h o t+t i p
\end{aligned}
$$

After using (A.18) and (A.22) and collecting terms, one arrives at equation (41). 


\section{Appendix B: Model with Capital}

The representative consumer aims to maximize the present discount value of the utility stream from consumption and leisure

$$
\max E_{t} \sum_{j=0}^{\infty}\left[\prod_{s=0}^{j} \beta_{t+s}\right]\left\{\ln C_{t+j}-h \ln C_{t+j-1}-\frac{\eta}{\eta+1} \int_{0}^{1} N_{t+j}(i)^{1+\eta^{-1}} d i\right\}
$$

where $C$ is consumption of the final good, $N_{t}(i)$ is labor supplied to individual industry $i, h$ is the degree of external habit formation, $\eta$ is the Frisch labor supply elasticity and $\beta_{t}$ is the time-varying discount factor. The budget constraint each period is given by

$$
\begin{aligned}
\xi_{t+j}: C_{t+j}+\frac{S_{t+j}}{P_{t+j}} & +I_{t+j}+\frac{\psi}{2}\left(\frac{I_{t+j}}{K_{t+j-1}}-\delta-\overline{G Y}+1\right)^{2} K_{t+j-1} \\
\leq & \int_{0}^{1} \frac{n_{t+j}(i) W_{t+j}(i)}{P_{t+j}} d i+\frac{S_{t+j} R_{t+j-1}}{P_{t+j}}+\frac{K_{t+j-1} R_{t+j}^{k}}{P_{t+j}}+T_{t+j}
\end{aligned}
$$

where $S$ is the stock of one-period bonds held by the consumer, $R$ is the gross nominal interest rate, $P$ is the price of the final good, $W(i)$ is the nominal wage earned from labor in industry $i, K$ is capital owned by the representative consumer, $R^{k}$ is the nominal rental rate on capital, $T$ is transfers and profits from ownership of firms, and $\xi$ is the shadow value of wealth. The fourth term on the left hand side is a quadratic adjustment cost to the stock of capital held by the consumer, where $\psi$ measures the strength of the adjustment cost. Capital can be accumulated according to the law of motion

$$
\mu_{t+j}: K_{t+j}=(1-\delta) K_{t+j-1}+I_{t+j}
$$

The first order conditions from this utility-maximization problem are then:

$$
\begin{aligned}
& C_{t+j}^{-1}-h \beta_{t+j+1} C_{t+j}^{-1}=\xi_{t+j} \\
& N_{t+j}(i)^{1 / \eta}=\xi_{t+j} \frac{W_{t+j}(i)}{P_{t+j}} \\
& \frac{\xi_{t+j}}{P_{t+j}}=E_{t+j} \beta_{t+j+1} \xi_{t+j+1} \frac{R_{t+j+1}}{P_{t+j+1}} \\
& q_{t+j}=1+\psi\left(\frac{I_{t+j}}{K_{t+j-1}}-\delta-\overline{G Y}+1\right) \\
& 0=E_{t+j} \beta_{t+j} \lambda_{t+j+1}\left[\tilde{R}_{t+j+1}^{k}-\frac{\psi}{2}\left(\frac{I_{t+j+1}}{K_{t+j}}-\delta-\overline{G Y}+1\right)^{2}+\psi \frac{I_{t+j+1}}{K_{t+j}}\left(\frac{I_{t+j+1}}{K_{t+j}}-\delta-\overline{G Y}+1\right)\right] \\
& \quad+(1-\delta) E_{t+j} \beta_{t+j} \mu_{t+j+1}+\mu_{t+j}
\end{aligned}
$$

where $q_{t}=\lambda_{t+j} / \mu_{t+j}$ is Tobin's q and $\tilde{R}_{t+j}^{k}=R_{t+j}^{k} / P_{t+j}$ is the real rental rate of capital.

Production of the final good is done by a perfectly competitive sector which combines a continuum of intermediate goods into a final good per the following aggregator

$$
Y_{t}=\left[\int_{0}^{1} Y_{t}(i)^{\frac{\theta-1}{\theta}} d i\right]^{\frac{\theta}{\theta-1}}
$$

where $Y_{t}$ is the final good and $Y(i)$ is intermediate good $i$, while $\theta$ denotes the elasticity of substitution across intermediate goods, yielding the following demand curve for goods of intermediate sector $i$

$$
Y_{t}(i)=Y_{t}\left(P_{t}(i) / P_{t}\right)^{-\theta}
$$


and the following expression for the aggregate price level

$$
P_{t}=\left[\int_{0}^{1} P_{t}(i)^{1-\theta} d i\right]^{\frac{1}{1-\theta}}
$$

The production of each intermediate good is done by a monopolist facing a Cobb-Douglas production function with capital share $\alpha$

$$
Y_{t}(i)=K_{t+j-1}(i)^{\alpha}\left(A_{t+j} N_{t+j}(i)\right)^{1-\alpha}
$$

where $A$ denotes the level of technology, common across firms. We assume that capital is perfectly mobile across firms,

$$
K_{t+j-1}=\int_{0}^{1} K_{t+j-1}(i) d i
$$

Each intermediate good producer has sticky prices, modeled as in Calvo (1983) where $1-\lambda$ is the probability that each firm will be able to reoptimize its price each period. We allow for indexation of prices to steady-state inflation by firms who do not reoptimize their prices each period, with $\omega$ representing the degree of indexation ( 0 for no indexation to 1 for full indexation). Denoting the optimal reset price of firm $i$ by $B(i)$, re-optimizing firms solve the following profit-maximization problem

$$
\max E_{t} \sum_{j=0}^{\infty} \lambda^{j} Q_{t, t+j} y_{t+j}(i)\left[B_{t}(i) \bar{\Pi}^{\omega j}-W_{t+j}(i) N_{t+j}(i)\right]
$$

where $Q$ is the stochastic discount factor and $\bar{\Pi}$ is the gross steady-state level of inflation. The optimal relative reset price is then given by

$$
\frac{B_{t}(i)}{P_{t}}=\frac{\theta}{\theta-1} \frac{\sum_{j=0}^{\infty} \lambda^{j} Q_{t, t+j} Y_{t+j}\left(P_{t+j} / P_{t}\right)^{\theta+1} \bar{\Pi}^{-\omega \theta}\left(M C(i)_{t+j} / P_{t+j}\right)}{\sum_{j=0}^{\infty} \lambda^{j} Q_{t, t+j} Y_{t+j}\left(P_{t+j} / P_{t}\right)^{\theta} \bar{\Pi}^{-\omega(\theta-1)}}
$$

where firm-specific marginal costs can be related to aggregate variables using

$$
\begin{aligned}
\frac{M C_{t+j}(i)}{P_{t+j}}= & \left(\frac{C_{t+j}}{\left(1-h \beta_{t+j+1}\right) A_{t+j}}\right)^{\frac{(1-\alpha) \eta}{\eta+\alpha}}\left(\frac{Y_{t+j}}{A_{t+j}}\right)^{\frac{1-\alpha}{\eta+\alpha}}\left(\frac{R_{t+j}^{k}}{P_{t+j}}\right)^{\frac{\alpha(\eta+1)}{\eta+\alpha}} \times \\
& \times\left(\frac{B_{t}(i)}{P_{t}}\right)^{-\frac{\theta(1-\alpha)}{\eta+\alpha}}\left(\frac{P_{t+j}}{\bar{\Pi}^{\omega} P_{t}}\right)^{\frac{\theta(1-\alpha)}{\eta+\alpha}}\left[\alpha^{\alpha}(1-\alpha)^{1-\alpha}\right]^{-\frac{\eta+1}{\eta+\alpha}} .
\end{aligned}
$$

Firm-specific marginal cost remain a function of aggregate variables and the reset price only because full capital mobility implies that all firms have the same (adjusted) capital labor ratio. The first order condition for the firms' input usage is

$$
\frac{\alpha}{1-\alpha} \frac{n_{t}(i)}{k_{t-1}(i)}=\frac{R_{t}^{k}}{W_{t}(i)}
$$

which we combine with the first order condition for labor supply to get

$$
\frac{\alpha}{1-\alpha} \frac{n_{t}(i)^{1+\eta^{-1}}}{k_{t-1}(i)}=\frac{R_{t}^{k}}{P_{t+j}} \xi_{t+j}
$$

Since the right hand side consists of aggregate variables only, the left hand side must be identical across firms.

Give these price-setting assumptions, the dynamics of the price level are governed by

$$
P_{t}^{1-\theta}=(1-\lambda) B_{t}^{1-\theta}+\lambda P_{t-1}^{1-\theta} \bar{\Pi}^{\omega(1-\theta)}
$$

We allow for government consumption of final goods $\left(G_{t}\right)$, so the goods market clearing condition for the economy is 


$$
Y_{t}=C_{t}+G_{t}+I_{t}
$$

We define the aggregate labor input as

$$
N_{t+j}=\left[\int_{0}^{1} n_{t+j}(i)^{1+\eta^{-1}}\right]^{1 /\left(1+\eta^{-1}\right)} .
$$

Note that this definition of labor input differs from the labor only model. We make different assumptions to simplify our aggregation problems.

\section{Log-linearization}

In the model with capital the goods market clearing condition becomes

$$
\hat{y}_{t}=\bar{c}_{y} \hat{c}_{t}+\bar{g}_{y} \hat{g}_{t}+\bar{i}_{y} \hat{i}_{t}
$$

where $\bar{c}_{y}, \bar{g}_{y}$, and $\bar{i}_{y}$ are the steady-state ratios of consumption, government and investment to output respectively.

Lemma 6. Let $\bar{c}_{y}, \bar{g}_{y}$, and $\bar{i}_{y}$ be the steady-state ratios of consumption, government and investment to output respectively. Then

$$
\begin{aligned}
& \bar{c}_{y}=\left(1-\bar{g}_{y}\right)-\frac{\theta-1}{\theta} \frac{\alpha \beta(\delta+\overline{G Y}-1)}{\overline{G Y}-\beta(1-\delta)}, \\
& \bar{i}_{y}=\frac{\theta-1}{\theta} \frac{\alpha \beta(\delta+\overline{G Y}-1)}{\overline{G Y}-\beta(1-\delta)},
\end{aligned}
$$

Proof: See Appendix C.

Also, integrating over firm-specific production functions and log-linearizing yields the aggregate production function:

Lemma 7. Let lower case letters denote the deviations from steady state values. Then the aggregate production function up to a first order approximation is given by

$$
y_{t}=\alpha k_{t}+(1-\alpha) n_{t}+\Psi \Xi_{t},
$$

where

$$
\Psi=\frac{1}{2} \frac{\theta(\theta-1)\left\{1-\frac{1}{2}\left[\frac{\eta+\alpha}{\eta} \frac{\theta-1}{\theta}\right]^{2} \bar{\Upsilon}\right\}}{\left\{1+\frac{1}{2}\left[\frac{\eta+\alpha}{\eta} \frac{\theta-1}{\theta}\right]^{2} \bar{\Upsilon}\right\}^{3}},
$$

Proof: See Appendix C.

Allowing for capital also changes the steady state effects of positive trend inflation. For example, the steady-state level of the output gap (which is defined as the deviation of output from its flexible price level counterpart) is given by 


$$
\bar{X}^{\frac{(1-\alpha)(\eta+1)}{\eta+\alpha}}=\frac{\left.1-\left[1-\lambda \beta^{-1} \bar{\Pi}^{(1-\omega) \theta}\right]\left(\frac{1-\lambda \bar{\Pi}^{(1-\omega)(\theta-1)}}{1-\lambda}\right)\right)^{\frac{\eta+\alpha+\theta(1-\alpha)}{(\eta+\alpha)(\theta-1)}}}{\lambda \beta^{-1} \bar{\Pi}^{\frac{(1-\omega) \theta(\eta+1)}{\eta+\alpha}}}
$$

Note that the steady-state level of the gap is again equal to one when steady-state inflation is zero (i.e., $\bar{\Pi}=1$ ) or when the degree of price indexation is exactly equal to one.

Lemma 8. The expansion of the utility part that corresponds to disutility from labor supply in the capital model is given by

$$
\begin{aligned}
\int_{0}^{1} v\left(n_{t}(i)\right) d i= & \bar{N}_{t}^{F} v_{\bar{N}_{t}^{F}}^{\prime}\left\{\left(1-\left(\frac{\eta+1}{\eta}\right) Q_{n}^{0}\right) \hat{n}_{t}+\frac{1}{2}\left[\left(\frac{\eta+1}{\eta}\right)\left(1-Q_{n}^{1}+\frac{\eta+1}{\eta} Q_{n}^{0} Q_{n}^{1}\right)\right] \operatorname{var}_{i} \hat{n}_{t}(i)+\right. \\
& +\frac{1}{8}\left(\frac{\eta+1}{\eta}\right)^{3}\left[Q_{n}^{1}\left(\operatorname{var}_{i} \hat{n}_{t}(i)-\bar{\Upsilon}\right)\right]^{2}-\frac{1}{2}\left(\frac{\eta+1}{\eta}\right)^{2} \hat{n}_{t} Q_{n}^{1}\left(\operatorname{var}_{i} \hat{n}_{t}(i)-\bar{\Upsilon}\right)+ \\
& \left.+\frac{1}{2}\left(\frac{\eta+1}{\eta}\right) \hat{n}_{t}^{2}-Q_{n}^{0}+\left(\frac{\eta+1}{\eta}\right)\left[Q_{n}^{0}\right]^{2}+\frac{\eta+1}{\eta} Q_{n}^{1}\left[\frac{1}{2}-\left(\frac{\eta+1}{\eta}\right) Q_{n}^{0}\right] \bar{\Upsilon}\right\}+ \text { hot }+ \text { tip }
\end{aligned}
$$

where $Q_{n}^{1}=\frac{1-\frac{1}{2}\left(\frac{\eta+1}{\eta}\right)^{2} \bar{\Upsilon}}{\left[1+\frac{1}{2}\left(\frac{\eta+1}{\eta}\right)^{2} \bar{\Upsilon}\right]^{3}} \leq 1$ and $Q_{n}^{0}=\frac{1}{2} \frac{\eta+1}{\eta} \frac{\bar{\Upsilon}}{\left[1+\frac{1}{2}\left(\frac{\eta+1}{\eta}\right)^{2} \bar{\Upsilon}\right]^{2}}$ and $\bar{\Upsilon}$ is the steady state dispersion of labor supply.

Proof: See Appendix C.

Lemma 9. The cross sectional variations in labor input and prices are proportional,

$$
\operatorname{var}_{i} \hat{n}_{t}(i)=\left(\frac{\theta}{1+\alpha \eta^{-1}}\right)^{2} \operatorname{var}_{i} \ln p_{t}(i)
$$

Proof: See Appendix C.

Before we proceed with Proposition 2 we write the inter-temporal condition for labor supply as,

$$
\frac{v_{\bar{N}_{t}^{F}}^{\prime} \bar{N}_{t}^{F}}{(1-\beta h) u_{\bar{C}_{t}^{F}}^{\prime}}=\bar{N}_{t}^{F} \frac{W_{t}}{P_{t}}
$$

The right hand side of this expression is simply total labor income. Because of the distortion due to monopolistic competition it is equal to

$$
\frac{v_{\bar{N}_{t}^{F}}^{\prime} \bar{N}_{t}^{F}}{(1-\beta h) u_{\bar{C}_{t}^{F}}^{\prime}}=(1-\Phi)(1-\alpha) \bar{Y}_{t}^{F}
$$

where $1-\Phi=(\theta-1) / \theta$. Since we assume log utility this expression further simplifies to

$$
v_{\bar{N}_{t}^{F}}^{\prime} \bar{N}_{t}^{F}=(1-\beta h)(1-\Phi)(1-\alpha)\left(\bar{c}_{y}^{F}\right)^{-1}
$$

where $\bar{c}_{y}^{F}$ is the share of consumption in output at the flexible price steady state.

Woodford argues that $\Phi$ is of the same order as the shocks and thus can be ignored on second order terms. However, as we show in appendix G, trend inflation generates first order cross sectional dispersion in output and prices. We therefore cannot yet ignore $\Phi$ in any terms in Lemma 8 so that 


$$
\begin{aligned}
\int_{0}^{1} v\left(n_{t}(i)\right) d i= & (1-\beta h)(1-\alpha)\left(c_{y}^{F}\right)^{-1}(1-\Phi)\left\{\left(1-\left(\frac{\eta+1}{\eta}\right) Q_{n}^{0}\right) \hat{n}_{t}+\frac{1}{2}\left[\left(\frac{\eta+1}{\eta}\right)\left(1-Q_{n}^{1}+\frac{\eta+1}{\eta} Q_{n}^{0} Q_{n}^{1}\right)\right] \operatorname{var}_{i} \hat{n}_{t}(i)+\right. \\
& +\frac{1}{8}\left(\frac{\eta+1}{\eta}\right)^{3}\left[Q_{n}^{1}\left(\operatorname{var}_{i} \hat{n}_{t}(i)-\bar{\Upsilon}\right)\right]^{2}-\frac{1}{2}\left(\frac{\eta+1}{\eta}\right)^{2} \hat{n}_{t} Q_{n}^{1}\left(\operatorname{var}_{i} \hat{n}_{t}(i)-\bar{\Upsilon}\right)+ \\
& \left.+\frac{1}{2}\left(\frac{\eta+1}{\eta}\right) \hat{n}_{t}^{2}-Q_{n}^{0}+\left(\frac{\eta+1}{\eta}\right)\left[Q_{n}^{0}\right]^{2}+\frac{\eta+1}{\eta} Q_{n}^{1}\left[\frac{1}{2}-\left(\frac{\eta+1}{\eta}\right) Q_{n}^{0}\right] \bar{\Upsilon}\right\}+ \text { hot }+ \text { tip }
\end{aligned}
$$

Proposition 2. In the model for capital, the second order approximation to utility (1) is

$\Omega_{0}+\Omega_{1} \operatorname{var}\left(\hat{y}_{t}\right)+\Omega_{2} \operatorname{cov}\left(\hat{y}_{t}, \Xi_{t}\right)+\Omega_{3} \operatorname{var}\left(\Xi_{t}\right)+\Omega_{4} \operatorname{var}\left(\hat{\pi}_{t}\right)+\Omega_{5} \operatorname{cov}\left(\hat{\pi}_{t}, \Xi_{t-1}\right)$

where $\Xi_{t}$ is the deviation of price dispersion from non-stochastic steady state and parameters $\Omega_{i}, i=0, \ldots, 5$ depend on the steady state inflation $\bar{\pi}$ and are given by

$$
\begin{aligned}
\Omega_{0}= & (1-h) \log (\bar{X})-\frac{1}{2}(1-\alpha)\left(\bar{c}_{y}\right)^{-1}(1-\Phi)\left[\frac{\eta+1}{\eta}\left[Q_{n}^{0}\right]^{2}-Q_{n}^{0}+Q_{n}^{1} \frac{\eta+1}{\eta}\left[\frac{1}{2}-\left(\frac{\eta+1}{\eta}\right) Q_{n}^{0}\right] \frac{\theta^{2}}{\left(1+\alpha \eta^{-1}\right)^{2}} \bar{\Delta}\right] \\
& -\frac{1}{2}(1-\alpha)\left(\bar{c}_{y}\right)^{-1}(1-\Phi)\left[\left(\frac{\eta+1}{\eta}\right)\left(1-Q_{n}^{1}+\frac{\eta+1}{\eta} Q_{n}^{0} Q_{n}^{1}\right)\right] \frac{\theta^{2}}{\left(1+\alpha \eta^{-1}\right)^{2}} \bar{\Delta}, \\
\Omega_{1}= & -\frac{1}{2}\left(\overline{c_{y}}\right)^{-1}(1-\beta h)\left(1+\frac{1}{\eta}\right), \\
\Omega_{2}= & \frac{1}{2}(1-\alpha)\left(\bar{c}_{y}\right)^{-1}\left(\frac{\eta+1}{\eta}\right)^{2} Q_{n}^{1} \frac{\theta^{2}}{\left(1+\alpha \eta^{-1}\right)^{2}}, \\
\Omega_{3}= & -\frac{1}{2}(1-\alpha)\left(c_{y}^{F}\right)^{-1}\left[\left(\frac{\eta+1}{\eta}\right)\left(1-Q_{n}^{1}+\frac{\eta+1}{\eta} Q_{n}^{0} Q_{n}^{1}\right)\right] \frac{\theta^{2}}{\left(1+\alpha \eta^{-1}\right)^{2}} \Gamma_{5}, \\
\Omega_{4}= & -\frac{1}{2}(1-\alpha)\left(c_{y}^{F}\right)^{-1}\left[\left(\frac{\eta+1}{\eta}\right)\left(1-Q_{n}^{1}+\frac{\eta+1}{\eta} Q_{n}^{0} Q_{n}^{1}\right)\right] \frac{\theta^{2}}{\left(1+\alpha \eta^{-1}\right)^{2}} \Gamma_{3}-\frac{1}{8}(1-\alpha)\left(c_{y}^{F}\right)^{-1}\left(\frac{\eta+1}{\eta}\right)^{3}\left[Q_{n}^{1}\right]^{2}\left(\frac{\theta^{2}}{\left(1+\alpha \eta^{-1}\right)^{2}}\right)^{2}, \\
\Omega_{5}= & -\frac{1}{2}(1-\alpha)\left(c_{y}^{F}\right)^{-1}\left[\left(\frac{\eta+1}{\eta}\right)\left(1-Q_{n}^{1}+\frac{\eta+1}{\eta} Q_{n}^{0} Q_{n}^{1}\right)\right] \frac{\theta^{2}}{\left(1+\alpha \eta^{-1}\right)^{2}} \Gamma_{4}, \\
Q_{n}^{1}= & \frac{1-\frac{1}{2}\left(\frac{\eta+1}{\eta}\right)^{2} \bar{\Upsilon}}{\left[1+\frac{1}{2}\left(\frac{\eta+1}{\eta}\right)^{2} \bar{\Upsilon}\right]^{3}} \\
Q_{n}^{0}= & \frac{1}{2} \frac{\eta+1}{\eta} \frac{\bar{\Upsilon}}{\left[1+\frac{1}{2}\left(\frac{\eta+1}{\eta}\right)^{2} \bar{\Upsilon}\right]^{2}} \\
\bar{\Upsilon}= & \left(\frac{\theta}{1+\alpha \eta}\right)^{2} \bar{\Delta} \\
\bar{X} & \lambda \beta^{-1} \bar{\Pi}^{\frac{(1-\omega) \theta(\eta+1)}{\eta+\alpha}} \\
\Phi=-\theta^{-1} . & 1-\left[1-\lambda \beta^{-1} \bar{\Pi}^{(1-\omega) \theta}\right]\left(\frac{1-\lambda \bar{\Pi}^{(1-\omega)(\theta-1)}}{1-\lambda}\right)
\end{aligned}
$$

Proof: See Appendix C. 


\section{Appendix C: Proofs for model with capital}

\section{Lemma 6}

From the first order condition for the use of capital we know that capital for a firm that reset its price at time $t$ evolves as follows

$$
k_{t+j-1}(i)=G Y_{t}^{j} \bar{\Pi}^{j(1-\omega)(\theta-1)} \underbrace{\frac{\theta-1}{\theta} Y_{t} \alpha \frac{1}{\tilde{R}_{t}^{k}}\left(\frac{\bar{B}}{P}\right)^{1-\theta}}_{k_{t-1}^{R}}
$$

where $k_{t}^{R}$ is the optimal reset stock of capital at time $t$. Due to Calvo pricing the aggregate capital stock today is an aggregate of an infinite sum of past capital stocks, adjusted for their growth rate in the interim

$$
\begin{aligned}
K_{t-1} & =\int_{0}^{1} k_{t-1}(i)=\sum_{j=0}^{\infty}(1-\lambda) \lambda^{j} k_{t-j-1}^{R} G Y_{t}^{j} \bar{\Pi}^{j(1-\omega)(\theta-1)} \\
& =\sum_{j=0}^{\infty}(1-\lambda) \lambda^{j} \frac{\theta-1}{\theta} Y_{t-j} \alpha \frac{1}{\tilde{R}^{k}}\left(\frac{\bar{B}}{P}\right)^{1-\theta} G Y_{t}^{j} \bar{\Pi}^{j(1-\omega)(\theta-1)} \\
& =Y_{t} \frac{\theta-1}{\theta} \alpha \frac{1}{\tilde{R}^{k}} \frac{1-\lambda}{1-\lambda \bar{\Pi}^{(1-\omega)(\theta-1)}}\left(\frac{\bar{B}}{P}\right)^{1-\theta}=Y_{t} \frac{\theta-1}{\theta} \frac{\alpha \beta}{\overline{G Y}-\beta(1-\delta)} \\
& =Y_{t} \bar{k}_{y}
\end{aligned}
$$

Thus, the ratio of capital to output $\bar{k}_{y}$. From the capital accumulation equation we know that in the steady state the share of output going to investment is equal to

$$
\overline{i_{y}}=\frac{\theta-1}{\theta} \frac{\alpha \beta(\delta+\overline{G Y}-1)}{\overline{G Y}-\beta(1-\delta)},
$$

The conclusion for $\bar{c}_{y}$ then follows directly from the resource constraint.

\section{Lemma 7}

We first rewrite the individual production function as

$$
y_{t}(i)=A_{t}^{1-\alpha} n_{t}(i)^{1+\alpha \eta^{-1}}\left(\frac{k_{t-1}(i)}{n_{t}(i)^{1+\eta^{-1}}}\right)^{\alpha}
$$

From the first order condition for labor supply and the optimal capital labor ratio, we know that the term in parentheses is the same across firms. Integrating this equation then yields,

$$
Y_{t}=A_{t}^{1-\alpha}\left[\int_{0}^{1} n_{t}(i)^{\left(1+\alpha \eta^{-1}\right)(\theta-1) / \theta}\right]^{\frac{\theta}{\theta-1}}\left(\frac{K_{t-1}}{N_{t}^{1+\eta^{-1}}}\right)^{\alpha}
$$

We then take logs of this expression and consider a first order approximation to the integral,

$$
\begin{aligned}
\frac{\theta}{\theta-1} \ln & {\left[\int_{0}^{1} n_{t}(i)^{\left(1+\alpha \eta^{-1}\right)(\theta-1) / \theta}\right] \approx } \\
& \approx \frac{\eta+\alpha}{\eta+1}\left[\int_{0}^{1} \ln n_{t}(i)^{\left(1+\eta^{-1}\right)}\right]+\frac{1}{2} \frac{\theta}{\theta-1} \frac{\left[\frac{\eta+\alpha}{\eta} \frac{\theta-1}{\theta}\right]^{2} \operatorname{var}_{i}\left(\ln n_{t}(i)\right)}{\left\{1+\frac{1}{2}\left[\frac{\eta+\alpha}{\eta} \frac{\theta-1}{\theta}\right]^{2} \operatorname{var}_{i}\left(\ln n_{t}(i)\right)\right\}^{2}}
\end{aligned}
$$




$$
\begin{aligned}
& \approx \ln N_{t}^{1+\alpha \eta^{-1}}+\underbrace{\frac{1}{2} \frac{\theta}{\theta-1} \frac{\left[\frac{\eta+\alpha}{\eta} \frac{\theta-1}{\theta}\right]^{2} \bar{\Upsilon}}{\left\{1+\frac{1}{2}\left[\frac{\eta+\alpha}{\eta} \frac{\theta-1}{\theta}\right]^{2} \bar{\Upsilon}\right\}^{2}}}_{Z_{n}^{0}}+\underbrace{\frac{1}{2} \frac{\theta}{\theta-1} \frac{\left[\frac{\eta+\alpha}{\eta} \frac{\theta-1}{\theta}\right]^{2}\left\{1-\frac{1}{2}\left[\frac{\eta+\alpha}{\eta} \frac{\theta-1}{\theta}\right]^{2} \bar{\Upsilon}\right\}}{\left\{1+\frac{1}{2}\left[\frac{\eta+\alpha}{\eta} \frac{\theta-1}{\theta}\right]^{2} \bar{\Upsilon}\right\}^{3}}}_{Z_{n}^{1}}\left(\Upsilon_{t}-\bar{\Upsilon}\right) \\
& =\ln N_{t}^{1+\alpha \eta^{-1}}+Z_{n}^{0}+Z_{n}^{1} \frac{\theta^{2}}{\left(1+\alpha \eta^{-1}\right)^{2}}\left(\bar{\Delta}_{t}-\bar{\Delta}\right)+h o t \\
& =\ln N_{t}^{1+\alpha \eta^{-1}}+Z_{n}^{0}+Z_{n}^{1} \frac{\theta^{2}}{\left(1+\alpha \eta^{-1}\right)^{2}} \Xi_{t}+h o t
\end{aligned}
$$

where the last line follows from Corollary 1 (Appendix A).

\section{Lemma 8}

Note that

$$
v\left(n_{t}(i)\right) d i \approx \bar{N}_{t}^{F} v_{\bar{N}_{t}^{F}}^{\prime}\left\{\hat{n}_{t}(i)+\frac{1}{2}\left(1+\eta^{-1}\right) \hat{n}_{t}^{2}(i)\right\}+t i p
$$

where $\hat{n}_{t}(i)=\log \left(n_{t}(i) / \bar{N}_{t}^{F}\right)$ is the deviation of firm $i$ 's labor input from flexible price level of labor input $\bar{N}_{t}^{F}$ and $\eta$ is the Frisch elasticity of labor supply. Because of our definition of labor input in the capital model the flexible price steady state labor input and the Calvo-pricing steady state labor input are the same, $\bar{N}_{t}=\bar{N}_{t}^{F} \Rightarrow \hat{n}_{t}=\tilde{n}_{t}$. Compute the average across firms

$$
\int_{0}^{1} v\left(n_{t}(i)\right) d i=\bar{N}_{t}^{F} v_{\bar{N}_{t}^{F}}^{\prime}\left\{E_{i} \hat{n}_{t}(i)+\frac{1}{2}\left(1+\eta^{-1}\right) \int_{0}^{1} \hat{n}_{t}^{2}(i) d i\right\}+h o t
$$

Consider the first term $E_{i} \hat{n}_{t}(i)$. We define aggregate labor input as

$$
N_{t}=\left[\int_{0}^{1} n_{t}(i)^{1+\eta^{-1}}\right]^{\frac{1}{1+\eta^{-1}}} \Rightarrow N_{t} / \bar{N}_{t}^{F}=\left[\int_{0}^{1}\left(n_{t}(i) / \bar{N}_{t}^{F}\right)^{1+\eta^{-1}}\right]^{\frac{1}{1+\eta^{-1}}}
$$

Note that

$$
\begin{aligned}
\ln N_{t} / \bar{N}_{t}^{F} & =\frac{\eta}{\eta+1} \ln \left(\int_{0}^{1}\left(\frac{n_{t}(i)}{\bar{N}_{t}^{F}}\right)^{\frac{\eta+1}{\eta}} d i\right)=\frac{\eta}{\eta+1} \int_{0}^{1} \frac{\eta+1}{\eta} \ln \left(\frac{n_{t}(i)}{\bar{N}_{t}^{F}}\right) d i+\frac{1}{2} \frac{\eta}{\eta+1} \frac{1}{\left[E\left(\frac{n_{t}(i)}{\bar{N}_{t}^{F}}\right)^{\frac{\eta+1}{\eta}}\right]^{2}} \operatorname{var}_{i}\left(\left(\frac{n_{t}(i)}{\bar{N}_{t}^{F}}\right)^{\frac{\eta+1}{\eta}}\right)+h o t \\
& =E_{i} \hat{n}_{t}(i)+\frac{1}{2} \frac{\eta}{\eta+1} \frac{1}{\left[E\left(\frac{n_{t}(i)}{\bar{N}_{t}^{F}}\right)^{\frac{\eta+1}{\eta}}\right]^{2}} \operatorname{var}_{i}\left(\left(\frac{n_{t}(i)}{\bar{N}_{t}^{F}}\right)^{\frac{\eta+1}{\eta}}\right)+h o t
\end{aligned}
$$

Using the delta method, we have

$$
\operatorname{var}_{i}\left(\left(n_{t}(i) / \bar{N}_{t}^{F}\right)^{\frac{\eta+1}{\eta}}\right)=\operatorname{var}_{i}\left(\exp \left\{\frac{\eta+1}{\eta} \ln \left(\frac{n_{t}(i)}{\bar{N}_{t}^{F}}\right)\right\}\right) \approx\left(\frac{\eta+1}{\eta}\right)^{2}\left[\exp \left\{\frac{\eta+1}{\eta} E \ln \left(\frac{n_{t}(i)}{\bar{N}_{t}^{F}}\right)\right\}\right]^{2} \operatorname{var}_{i}\left(\ln \left(\frac{n_{t}(i)}{\bar{N}_{t}^{F}}\right)\right)
$$

Also observe that

$$
\begin{aligned}
E\left(n_{t}(i)\right. & \left./ \bar{N}_{t}^{F}\right)^{\frac{\eta+1}{\eta}}=E\left[\exp \left\{\frac{\eta+1}{\eta} \ln \left(n_{t}(i) / \bar{N}_{t}^{F}\right)\right]\right. \\
& \approx \exp \left\{\frac{\eta+1}{\eta} E \ln \left(n_{t}(i) / \bar{N}_{t}^{F}\right)\right\}+\frac{1}{2}\left(\frac{\eta+1}{\eta}\right)^{2} \exp \left\{\frac{\eta+1}{\eta} E \ln \left(n_{t}(i) / \bar{N}_{t}^{F}\right)\right\} \operatorname{var}_{i}\left(\ln \left(n_{t}(i) / \bar{N}_{t}^{F}\right)\right) \\
& =\exp \left\{\frac{\eta+1}{\eta} E \ln \left(n_{t}(i) / \bar{N}_{t}^{F}\right)\right\}\left[1+\frac{1}{2}\left(\frac{\eta+1}{\eta}\right)^{2} \operatorname{var}_{i}\left(\ln \left(n_{t}(i) / \bar{N}_{t}^{F}\right)\right)\right]
\end{aligned}
$$

Combine (C.11) and (C.12) to re-write (C.10) as follows 


$$
\ln N_{t} / \bar{N}_{t}^{F}=E_{i} \hat{n}_{t}(i)+\frac{1}{2} \frac{\eta}{\eta+1} \frac{\left(\frac{\eta+1}{\eta}\right)^{2} \operatorname{var}_{i}\left(\ln \left(\frac{n_{t}(i)}{\bar{N}_{t}^{F}}\right)\right)}{\left[1+\frac{1}{2}\left(\frac{\eta+1}{\eta}\right)^{2} \operatorname{var}_{i}\left(\ln \left(\frac{n_{t}(i)}{\bar{N}_{t}^{F}}\right)\right)\right]^{2}}+h o t
$$

We use Taylor series expansion of the second term,

$$
\ln N_{t} / \bar{N}_{t}^{F}=E_{i} \hat{n}_{t}(i)+\frac{1}{2} \frac{\eta+1}{\eta} \frac{\bar{\Upsilon}}{\left[1+\frac{1}{2}\left(\frac{\eta+1}{\eta}\right)^{2} \bar{\Upsilon}\right]^{2}}+\frac{1}{2} \frac{\eta+1}{\eta} \frac{1-\frac{1}{2}\left(\frac{\eta+1}{\eta}\right)^{2} \bar{\Upsilon}}{\left[1+\frac{1}{2}\left(\frac{\eta+1}{\eta}\right)^{2} \bar{\Upsilon}\right]^{3}}\left[\Upsilon_{t}-\bar{\Upsilon}\right]+\text { hot }
$$

where $\Upsilon_{t}=\operatorname{var}_{i}\left(\ln \left(n_{t}(i) / \bar{N}_{t}^{F}\right)\right)$ and $\bar{\Upsilon}=E \Upsilon_{t}$. We can consider a modification where

$$
\ln N_{t} / \bar{N}_{t}^{F}=E_{i} \hat{n}_{t}(i)+Q_{n}^{0}+\frac{1}{2} \frac{\eta+1}{\eta} Q_{n}^{1}\left(\Upsilon_{t}-\bar{\Upsilon}\right)+h o t
$$

where $Q_{n}^{1}=\frac{1-\frac{1}{2}\left(\frac{\eta+1}{\eta}\right)^{2} \bar{\Upsilon}}{\left[1+\frac{1}{2}\left(\frac{\eta+1}{\eta}\right)^{2} \bar{\Upsilon}\right]^{3}} \leq 1$ and $Q_{n}^{0}=\frac{1}{2} \frac{\eta+1}{\eta} \frac{\bar{\Upsilon}}{\left[1+\frac{1}{2}\left(\frac{\eta+1}{\eta}\right)^{2} \bar{\Upsilon}\right]^{2}}$.

It then follows from (C.14),

$$
\hat{n}_{t}=\ln N_{t} / \bar{N}_{t}=\ln N_{t} / \bar{N}_{t}^{F}=E_{i} \hat{n}_{t}(i)+Q_{n}^{0}+\frac{1}{2} \frac{\eta+1}{\eta} Q_{n}^{1}\left[\operatorname{var}_{i}\left(\ln \left(n_{t}(i) / \bar{N}_{t}^{F}\right)\right)-\bar{\Upsilon}\right]+h o t
$$

which implies that the first order term in (C.8) is equal to

$$
E_{i} \hat{n}_{t}(i)=\hat{n}_{t}-Q_{n}^{0}-\frac{1}{2} \frac{\eta+1}{\eta} Q_{n}^{1}\left[\operatorname{var}_{i}\left(\ln \left(\frac{n_{t}(i)}{\bar{N}_{t}^{F}}\right)\right)-\bar{\Upsilon}\right]+h o t=\hat{n}_{t}-Q_{n}^{0}-\frac{1}{2} \frac{\eta+1}{\eta} Q_{n}^{1}\left[\operatorname{var}_{i} \hat{n}_{t}(i)-\bar{\Upsilon}\right]+h o t
$$

Now consider the second term in (C.8):

$$
\int_{0}^{1} \hat{n}_{t}^{2}(i) d i=\int_{0}^{1}\left[\hat{n}_{t}(i)-E_{i} \hat{n}_{t}(i)+E_{i} \hat{n}_{t}(i)\right]^{2} d i=\operatorname{var}_{i} \hat{n}_{t}(i)+\left[E_{i} \hat{n}_{t}(i)\right]^{2}
$$

Using (C.16), we can re-write (C.17) as follows

$$
\begin{aligned}
\int_{0}^{1} \hat{n}_{t}^{2}(i) d i & =\operatorname{var}_{i} \hat{n}_{t}(i)+\left[\hat{n}_{t}-Q_{n}^{0}-\frac{1}{2} \frac{\eta+1}{\eta} Q_{n}^{1}\left(\operatorname{var}_{i} \hat{n}_{t}(i)-\bar{\Upsilon}\right)\right]^{2} \\
& =\operatorname{var}_{i} \hat{n}_{t}(i)+\hat{n}_{t}^{2}+\frac{1}{4}\left(\frac{\eta+1}{\eta}\right)^{2}\left[Q_{n}^{1}\left(\operatorname{var}_{i} \hat{n}_{t}(i)-\bar{\Upsilon}\right)\right]^{2}-\frac{\eta+1}{\eta} \hat{n}_{t} Q_{n}^{1}\left(\operatorname{var}_{i} \hat{n}_{t}(i)-\bar{\Upsilon}\right)+ \\
& +\left[Q_{n}^{0}\right]^{2}-2 Q_{n}^{0} \hat{n}_{t}+\frac{\eta+1}{\eta} Q_{n}^{0} Q_{n}^{1}\left(\operatorname{var}_{i} \hat{n}_{t}(i)-\bar{\Upsilon}\right)
\end{aligned}
$$

Now we combine (C.18) and (C.16) to finally get the part which corresponds to the second-order approximation of utility due to the disutility of labor supply (C.8):

$$
\begin{aligned}
& \int_{0}^{1} v\left(n_{t}(i)\right) d i=\bar{N}_{t}^{F} v_{\bar{N}_{t}^{F}}^{\prime}\left\{E_{i} \hat{n}_{t}(i)+\frac{1}{2}\left(1+\eta^{-1}\right) \int_{0}^{1} \hat{n}_{t}^{2}(i) d i\right\}+h o t \\
& =\bar{N}_{t}^{F} v_{\bar{N}_{t}^{F}}^{\prime}\left\{\hat{n}_{t}-Q_{n}^{0}-\frac{1}{2} \frac{\eta+1}{\eta} Q_{n}^{1}\left[\operatorname{var}_{i} \hat{n}_{t}(i)-\bar{\Upsilon}\right]\right. \\
& +\frac{1}{2}\left(1+\eta^{-1}\right)\left(\left[1+\frac{\eta+1}{\eta} Q_{n}^{0} Q_{n}^{1}\right] \operatorname{var}_{i} \hat{n}_{t}(i)+\hat{n}_{t}^{2}-2 Q_{n}^{0} \hat{N}_{t}\right) \\
& +\frac{1}{8}\left(1+\eta^{-1}\right)\left(\frac{\eta+1}{\eta}\right)^{2}\left[Q_{n}^{1}\left(\operatorname{var}_{i} \hat{n}_{t}(i)-\bar{\Upsilon}\right)\right]^{2} \\
& -\frac{1}{2}\left(1+\eta^{-1}\right) \frac{\eta+1}{\eta} \hat{n}_{t} Q_{n}^{1}\left(\operatorname{var}_{i} \hat{n}_{t}(i)-\bar{\Upsilon}\right)+\left(1+\eta^{-1}\right)\left[Q_{n}^{0}\right]^{2} \\
& \left.-\left(1+\eta^{-1}\right) \frac{\eta+1}{\eta} Q_{n}^{0} Q_{n}^{1} \bar{\Upsilon}\right\}+ \text { hot }+ \text { tip } \\
& =\bar{N}_{t}^{F} v_{\bar{N}_{t}^{F}}^{\prime}\left\{\left(1-\left(\frac{\eta+1}{\eta}\right) Q_{n}^{0}\right) \hat{N}_{t}+\frac{1}{2}\left[\left(\frac{\eta+1}{\eta}\right)\left(1-Q_{n}^{1}+\frac{\eta+1}{\eta} Q_{n}^{0} Q_{n}^{1}\right)\right] \operatorname{var}_{i} \hat{n}_{t}(i)+\right. \\
& +\frac{1}{8}\left(\frac{\eta+1}{\eta}\right)^{3}\left[Q_{n}^{1}\left(\operatorname{var}_{i} \hat{n}_{t}(i)-\bar{\Upsilon}\right)\right]^{2}-\frac{1}{2}\left(\frac{\eta+1}{\eta}\right)^{2} \hat{n}_{t} Q_{n}^{1}\left(\operatorname{var}_{i} \hat{n}_{t}(i)-\bar{\Upsilon}\right)+ \\
& \left.+\frac{1}{2}\left(\frac{\eta+1}{\eta}\right) \hat{n}_{t}^{2}-Q_{n}^{0}+\left(\frac{\eta+1}{\eta}\right)\left[Q_{n}^{0}\right]^{2}+\frac{\eta+1}{\eta} Q_{n}^{1}\left[\frac{1}{2}-\left(\frac{\eta+1}{\eta}\right) Q_{n}^{0}\right] \bar{\Upsilon}\right\}+ \text { hot }+ \text { tip. }
\end{aligned}
$$




\section{Lemma 9}

We first note that,

$$
\operatorname{var}_{i}\left(\hat{n}_{t}(i)\right)=\operatorname{var}_{i}\left(\ln n_{t}(i)-\ln N_{t}^{F}\right)=\operatorname{var}_{i}\left(\ln n_{t}(i)\right)
$$

To replace variability of $\log$ labor with variability of $\log$ prices we will use the market firms' first order conditions for inputs and combine it with the agents first order condition for labor supply,

$$
\frac{(1-\alpha)}{\alpha} \frac{k_{t}(i)}{n_{t}(i)}=\frac{W_{t}(i)}{R_{t}^{k}}=\frac{P_{t} C_{t} n_{t}(i)^{1 / \eta}}{R_{t}^{k}}
$$

This implies that the idiosyncrasy in the capital-labor ratio is proportional to log labor input across firms,

$$
\ln \frac{k_{t}(i)}{n_{t}(i)}=\frac{1}{\eta} \ln n_{t}(i)+\text { aggregate terms }
$$

This then allows us to calculate the cross sectional variation in output,

$$
\begin{aligned}
\operatorname{var}_{i}\left(\ln y_{t}(i)\right) & =\operatorname{var}_{i}\left(\ln n_{t}(i)^{1+\alpha \eta^{-1}}+\alpha \ln \frac{k_{t}(i)}{n_{t}(i)^{1+\alpha \eta^{-1}}}+\ln A_{t}\right) \\
& =\operatorname{var}_{i}\left[\left(1+\alpha \eta^{-1}\right) \ln n_{t}(i)+\text { aggregate terms }\right]=\left(1+\alpha \eta^{-1}\right)^{2} \operatorname{var}_{i}\left(\ln n_{t}(i)\right)
\end{aligned}
$$

Finally, using the demand curve for each variety, we have

$$
\operatorname{var}_{i}\left(\ln y_{t}(i)\right)=\operatorname{var}_{i}\left(\ln Y_{t}-\theta\left(\ln p_{t}(i)-\ln P_{t}\right)\right)=\theta^{2} \operatorname{var}_{i}\left(\ln p_{t}(i)\right)
$$

and it follows that the cross-sectional variation in labor input is proportional to the cross-sectional variation in prices.

$$
\operatorname{var}_{i} \hat{n}_{t}(i)=\left(\frac{\theta}{1+\alpha / \eta}\right)^{2} \operatorname{var}_{i} \ln p_{t}(i)
$$

\section{Proposition 2.}

Combine Lemmas 8-9 with Lemma 1 and Lemma 4 to get

$$
\begin{aligned}
E U_{t}= & (1-h) \log (\bar{X}) \\
& -\frac{1}{2}(1-\beta h)(1-\alpha)\left(c_{y}^{F}\right)^{-1}\left(\frac{\eta+1}{\eta}\right) \operatorname{var}\left(\hat{n}_{t}\right) \\
& -\frac{1}{2}(1-\beta h)(1-\alpha)\left(c_{y}^{F}\right)^{-1}\left[\left(\frac{\eta+1}{\eta}\right)\left(1-Q_{n}^{1}+\frac{\eta+1}{\eta} Q_{n}^{0} Q_{n}^{1}\right)\right] \frac{\theta^{2}}{\left(1+\alpha \eta^{-1}\right)^{2}} \Gamma_{3} \operatorname{var}\left(\hat{\pi}_{t}\right) \\
& \left\{-\frac{1}{8}(1-\beta h)(1-\alpha)\left(c_{y}^{F}\right)^{-1}\left(\frac{\eta+1}{\eta}\right)^{3}\left[Q_{n}^{1}\right]^{2}\left(\frac{\theta^{2}}{\left(1+\alpha \eta^{-1}\right)^{2}}\right)^{2}\right. \\
& \left.-\frac{1}{2}(1-\beta h)(1-\alpha)\left(c_{y}^{F}\right)^{-1}\left[\left(\frac{\eta+1}{\eta}\right)\left(1-Q_{n}^{1}+\frac{\eta+1}{\eta} Q_{n}^{0} Q_{n}^{1}\right)\right] \Gamma_{5}\right\} \operatorname{var}\left(\Xi_{t}\right) \\
& -\frac{1}{2}(1-\beta h)(1-\alpha)\left(c_{y}^{F}\right)^{-1}\left[\left(\frac{\eta+1}{\eta}\right)\left(1-Q_{n}^{1}+\frac{\eta+1}{\eta} Q_{n}^{0} Q_{n}^{1}\right)\right] \Gamma_{4} \operatorname{cov}\left(\hat{\pi}_{t}, \Xi_{t-1}\right) \\
& +\frac{1}{2}(1-\beta h)(1-\alpha)\left(c_{y}^{F}\right)^{-1}\left(\frac{\eta+1}{\eta}\right)^{2} Q_{n}^{1} \frac{\theta^{2}}{\left(1+\alpha \eta^{-1}\right)^{2}} \operatorname{cov}\left(\hat{n}_{t}, \Xi_{t}\right) \\
& -\frac{1}{2}(1-\beta h)(1-\alpha)\left(c_{y}^{F}\right)^{-1}(1-\Phi)\left[\frac{\eta+1}{\eta}\left[Q_{n}^{0}\right]^{2}-Q_{n}^{0}+Q_{n}^{1} \frac{\eta+1}{\eta}\left[\frac{1}{2}-\left(\frac{\eta+1}{\eta}\right) Q_{n}^{0}\right] \frac{\theta^{2}}{\left(1+\alpha \eta^{-1}\right)^{2}} \bar{\Delta}\right] \\
& -\frac{1}{2}(1-\beta h)(1-\alpha)\left(c_{y}^{F}\right)^{-1}(1-\Phi)\left[\left(\frac{\eta+1}{\eta}\right)\left(1-Q_{n}^{1}+\frac{\eta+1}{\eta} Q_{n}^{0} Q_{n}^{1}\right)\right] \frac{\theta^{2}}{\left(1+\alpha \eta^{-1}\right)^{2}} \bar{\Delta} \\
& +h o t+\text { tip. } \mathbf{}
\end{aligned}
$$




\section{Appendix C: Taylor-pricing model with 3-quarter length contracts}

In the Taylor-pricing model with 3-quarter length contracts, in each period one third of all firms can change their price. This price will then have to last for 3 quarters before it can be reset. The model is otherwise identical to the baseline model.

The firms maximization problem is now given by

$$
\max E_{t} \sum_{j=0}^{2} Q_{t, t+j} y_{t+j}(i)\left[B_{t}(i) \bar{\Pi}^{\omega j}-W_{t+j}(i) N_{t+j}(i)\right]
$$

since the price is only fixed for 3 quarters. The first order condition from this optimization problem is

$$
\frac{B_{t}(i)}{P_{t}}=\frac{\theta}{\theta-1} \frac{\sum_{j=0}^{2} Q_{t, t+j} Y_{t+j}\left(P_{t+j} / P_{t}\right)^{\theta+1} \bar{\Pi}^{-\omega \theta}\left(M C(i)_{t+j} / P_{t+j}\right)}{\sum_{j=0}^{2} Q_{t, t+j} Y_{t+j}\left(P_{t+j} / P_{t}\right)^{\theta} \bar{\Pi}^{-\omega(\theta-1)}}
$$

Substituting the equations for the discount factor and the firm-specific marginal cost from the baseline model yields,

$$
\left(\frac{B_{t}}{P_{t}}\right)^{1+\theta \eta^{-1}}=\frac{\theta}{\theta-1} \frac{\sum_{j=0}^{2}\left[\prod_{i=1}^{j} R_{t+i-1}^{-1} G Y_{t+i} \Pi_{t+i}^{1+\theta\left(1+\eta^{-1}\right)}\right]\left(\frac{C_{t+j}}{A_{t+j}}\right)\left(\frac{Y_{t+j}}{A_{t+j}}\right)^{\eta^{-1}}}{\sum_{j=0}^{2}\left[\prod_{i=1}^{j} R_{t+i-1}^{-1} G Y_{t+i} \Pi_{t+i}^{\theta-1}\right]}
$$

Given these price-setting assumptions, the dynamics of the price level are governed by

$$
P_{t}^{1-\theta}=\frac{1}{3}\left[B_{t}^{1-\theta}+B_{t-1}^{1-\theta}+B_{t-2}^{1-\theta}\right]
$$

The remaining equations are as in the baseline model.

\section{Steady State:}

The steady state real reset price is then equal to

$$
\left(\frac{\bar{B}}{P}\right)=\left[\frac{1+\bar{\Pi}^{\theta-1}+\bar{\Pi}^{2(\theta-1)}}{3}\right]^{\frac{1}{\theta-1}}
$$

which is greater than one for positive trend inflation. This implies that the output gap is equal to

$$
\bar{X}=\left\{\left(\frac{\bar{B}}{P}\right)^{1+\theta \eta^{-1}} \frac{\sum_{j=0}^{2}\left[\beta^{-1} \bar{\Pi}^{\theta-1}\right]^{j}}{\sum_{j=0}^{2}\left[\beta^{-1} \bar{\Pi}^{\theta\left(1+\eta^{-1}\right)}\right]^{j}}\right\}^{\frac{1}{1+\eta^{-1}}}
$$

In the steady state, the cross sectional mean of prices is given by

$$
\bar{P}_{t}(i)=E_{i} \log P_{t}(i)=\frac{1}{3}\left[B_{t}+B_{t-1}+B_{t-2}\right]=\bar{b}+\log P_{t}-\log (\bar{\Pi})
$$


This implies that the cross sectional variance of prices in the steady state is equal to

$$
\bar{\Delta}=\operatorname{var}_{i}\left(\log P_{t}(i)\right)=\frac{1}{3} \bar{\pi}^{2}+0+\frac{1}{3} \bar{\pi}^{2}=\frac{2}{3} \bar{\pi}^{2}
$$

\section{Dynamic Equations:}

With staggered pricing the log-linearized equations are now as follows. For equation (D.4),

$$
\hat{b}_{t}=\left(\bar{\Pi}^{\theta-1}\right)\left(\hat{\pi}_{t}-\hat{b}_{t-1}\right)+\left(\bar{\Pi}^{2(\theta-1)}\right)\left(\hat{\pi}_{t}+\hat{\pi}_{t-1}-\hat{b}_{t-2}\right)
$$

and for equation (D.3)

$$
\begin{aligned}
\left(1+\frac{\theta}{\eta}\right) \hat{b}_{t} & =G_{2}^{-1}\left(\hat{c}_{t}+\gamma_{2} \hat{c}_{t+1}+\gamma_{2} \hat{c}_{t+2}\right)+G_{2}^{-1} \eta^{-1}\left(\hat{y}_{t}+\gamma_{2} \hat{y}_{t+1}+\gamma_{2} \hat{y}_{t+2}\right) \\
& +\left(\widehat{g y}_{t+1}-\hat{r}_{t}\right)\left(G_{2}^{-1}\left(\gamma_{2}+\gamma_{2}^{2}\right)-G_{1}^{1}\left(\gamma_{1}+\gamma_{1}^{2}\right)\right)+\left(\widehat{g y}_{t+2}-\hat{r}_{t+1}\right)\left(G_{2}^{-1} \gamma_{2}^{2}-G_{1}^{-1} \gamma_{1}^{2}\right) \\
& +\hat{\pi}_{t+1}\left[\left(1+\theta\left(1+\theta \eta^{-1}\right)\right)\left(\gamma_{2}+\gamma_{2}^{2}\right) G_{2}^{-1}-\theta G_{1}^{-1}\left(\gamma_{1}+\gamma_{1}^{2}\right)\right] \\
& +\hat{\pi}_{t+2}\left[\left(1+\theta\left(1+\theta \eta^{-1}\right)\right)\left(\gamma_{2}^{2}\right) G_{2}^{-1}-\theta G_{1}^{-1}\left(\gamma_{1}^{2}\right)\right]
\end{aligned}
$$

where $\gamma_{1}=\bar{R}^{-1} \overline{G Y} \bar{\Pi}^{\theta}, \gamma_{2}=\gamma_{1} \bar{\Pi}^{1+\theta \eta^{-1}}, G_{2}=1+\gamma_{2}+\gamma_{2}^{2}, G_{1}=1+\gamma_{1}+\gamma_{1}^{2}$.

\section{Lemma 4 in Taylor model:}

In the baseline model, we derived the cross-sectional price dispersion up to a second order approximation. Because, the pricing contracts are different in the Taylor model, this section derives an equivalent Lemma for the Taylor model.

\section{Lemma 4 (Taylor):}

Let $\Xi_{t} \equiv \Delta_{t}-\bar{\Delta}$ be the deviation of cross-section price dispersion from its non-stochastic steady state level $\bar{\Delta}$. Then

$$
\begin{aligned}
\Delta_{t}-\bar{\Delta} & =\frac{1}{3} \Gamma_{1}\left[\left(b_{t}-\bar{b}\right)^{2}+2 \bar{b}\left(b_{t}-\bar{b}\right)\right. \\
& +\left(b_{t-1}-\bar{b}\right)^{2}+\left(\pi_{t}-\bar{\pi}\right)^{2}-2\left(b_{t-1}-\bar{b}\right)\left(\pi_{t}-\bar{\pi}\right)+2\left(b_{t-1}-\bar{b}\right)(\bar{b}-\bar{\pi})-2\left(\pi_{t}-\bar{\pi}\right)(\bar{b}-\bar{\pi}) \\
& +\left(b_{t-2}-\bar{b}\right)^{2}+\left(\pi_{t}-\bar{\pi}\right)^{2}+\left(\pi_{t-1}-\bar{\pi}\right)^{2}-2\left(b_{t-2}-\bar{b}\right)\left(\pi_{t}-\bar{\pi}\right)-2\left(b_{t-2}-\bar{b}\right)\left(\pi_{t-1}-\bar{\pi}\right) \\
& \left.+2\left(\pi_{t}-\bar{\pi}\right)\left(\pi_{t-1}-\bar{\pi}\right)+2\left(b_{t-2}-\bar{b}\right)(\bar{b}-\bar{\pi})-2\left(\pi_{t}-\bar{\pi}\right)(\bar{b}-\bar{\pi})-2\left(\pi_{t-1}-\bar{\pi}\right)(\bar{b}-\bar{\pi})\right] \\
& +\frac{2}{3} \Gamma_{1}\left[\left(b_{t}-\bar{b}\right)+\left(b_{t-1}-\bar{b}\right)+\left(b_{t-2}-\bar{b}\right)-2\left(\pi_{t}-\bar{\pi}\right)-\left(\pi_{t-1}-\bar{\pi}\right)\right]\left[Q_{p}^{0}\right] \\
& +\frac{2}{3} \Gamma_{1}\left[\left(b_{t}-\bar{b}\right)+\left(b_{t-1}-\bar{b}\right)+\left(b_{t-2}-\bar{b}\right)-2\left(\pi_{t}-\bar{\pi}\right)-\left(\pi_{t-1}-\bar{\pi}\right)\right]\left[\frac{1-\theta}{2} Q_{p}^{1}\left(\Delta_{t}-\bar{\Delta}\right)\right] \\
& +\Gamma_{1} \frac{(1-\theta)^{2}}{4}\left[Q_{p}^{1}\right]^{2}\left(\Delta_{t}-\bar{\Delta}\right)^{2}
\end{aligned}
$$

where

$$
\Gamma_{1}=\left[1+(\theta-1) Q_{p}^{1}\left(\bar{b}-\bar{\pi}+Q_{p}^{0}\right)\right]^{-1} .
$$




\section{Proof:}

At any given time the cross sectional dispersion is given by

$\Delta_{t} \quad=\operatorname{var}_{i}\left(\log P_{t}(i)\right)=\int_{0}^{1}\left[\log P_{t}(i)-\bar{P}_{t}\right]$

$$
\begin{aligned}
= & \frac{1}{3}\left[b_{t}+\log P_{t}-\bar{P}_{t}\right]^{2}+\frac{1}{3}\left[b_{t-1}+\log P_{t-1}-\bar{P}_{t}\right]^{2}+\frac{1}{3}\left[b_{t-2}+\log P_{t-2}-\bar{P}_{t}\right]^{2} \\
= & \frac{1}{3}\left[b_{t}+\left(\log P_{t}-\bar{P}_{t}\right)\right]^{2}+\frac{1}{3}\left[b_{t-1}-\pi_{t}+\left(\log P_{t}-\bar{P}_{t}\right)\right]^{2}+\frac{1}{3}\left[b_{t-2}-\pi_{t}-\pi_{t-1}+\left(\log P_{t}-\bar{P}_{t}\right)\right]^{2} \\
= & \frac{1}{3}\left[b_{t}^{2}+\left(b_{t-1}-\pi_{t}\right)^{2}+\left(b_{t-2}-\pi_{t}-\pi_{t-1}\right)^{2}\right]+\frac{2}{3}\left[b_{t}+\left(b_{t-1}-\pi_{t}\right)+\left(b_{t-2}-\pi_{t}-\pi_{t-1}\right)\right]\left(\log P_{t}-\bar{P}_{t}\right) \\
& +\left(\log P_{t}-\bar{P}_{t}\right)^{2} \\
= & \frac{1}{3}\left[b_{t}^{2}+\left(b_{t-1}-\pi_{t}\right)^{2}+\left(b_{t-2}-\pi_{t}-\pi_{t-1}\right)^{2}\right] \\
& \quad+\frac{2}{3}\left[b_{t}+\left(b_{t-1}-\pi_{t}\right)+\left(b_{t-2}-\pi_{t}-\pi_{t-1}\right)\right]\left[Q_{p}^{0}+\frac{1-\theta}{2} Q_{p}^{1}\left(\Delta_{t}-\bar{\Delta}\right)\right] \\
& +\left[Q_{p}^{0}\right]^{2}+(1-\theta) Q_{p}^{0} Q_{p}^{1}\left(\Delta_{t}-\bar{\Delta}\right)+\frac{(1-\theta)^{2}}{4}\left[Q_{p}^{1}\right]^{2}\left(\Delta_{t}-\bar{\Delta}\right)^{2} \\
= & \frac{1}{3}\left[\left(b_{t}-\bar{b}\right)^{2}+2 \bar{b} b_{t}-\bar{b}^{2}\right. \\
& +\left(b_{t-1}-\bar{b}\right)^{2}+\left(\pi_{t}-\bar{\pi}\right)^{2}-2\left(b_{t-1}-\bar{b}\right)\left(\pi_{t}-\bar{\pi}\right)+2\left(b_{t-1}-\bar{b}\right)(\bar{b}-\bar{\pi})-2\left(\pi_{t}-\bar{\pi}\right)(\bar{b}-\bar{\pi})+(\bar{b}-\bar{\pi})^{2} \\
& +\left(b_{t-2}-\bar{b}\right)^{2}+\left(\pi_{t}-\bar{\pi}\right)^{2}+\left(\pi_{t-1}-\bar{\pi}\right)^{2}-2\left(b_{t-2}-\bar{b}\right)\left(\pi_{t}-\bar{\pi}\right)-2\left(b_{t-2}-\bar{b}\right)\left(\pi_{t-1}-\bar{\pi}\right) \\
& \left.+2\left(\pi_{t}-\bar{\pi}\right)\left(\pi_{t-1}-\bar{\pi}\right)+2\left(b_{t-2}-\bar{b}\right)(\bar{b}-\bar{\pi})-2\left(\pi_{t}-\bar{\pi}\right)(\bar{b}-\bar{\pi})-2\left(\pi_{t-1}-\bar{\pi}\right)(\bar{b}-\bar{\pi})+(\bar{b}-\bar{\pi})^{2}\right] \\
& +\frac{2}{3}\left[\left(b_{t}-\bar{b}\right)+\left(b_{t-1}-\bar{b}\right)+\left(b_{t-2}-\bar{b}\right)-2\left(\pi_{t}-\bar{\pi}\right)-\left(\pi_{t-1}-\bar{\pi}\right)+3 \bar{b}-3 \bar{\pi}\right]\left[Q_{p}^{0}+\frac{1-\theta}{2} Q_{p}^{1}\left(\Delta_{t}-\bar{\Delta}\right)\right] \\
& +\left[Q_{p}^{0}\right]^{2}+(1-\theta) Q_{p}^{0} Q_{p}^{1}\left(\Delta_{t}-\bar{\Delta}\right)+\frac{(1-\theta)^{2}}{4}\left[Q_{p}^{1}\right]^{2}\left(\Delta_{t}-\bar{\Delta}\right)^{2}
\end{aligned}
$$

The deviation from the steady state is then equal to

$$
\begin{aligned}
\Delta_{t}-\bar{\Delta}=\frac{1}{3} \Gamma_{1}[( & \left.b_{t}-\bar{b}\right)^{2}+2 \bar{b}\left(b_{t}-\bar{b}\right) \\
& +\left(b_{t-1}-\bar{b}\right)^{2}+\left(\pi_{t}-\bar{\pi}\right)^{2}-2\left(b_{t-1}-\bar{b}\right)\left(\pi_{t}-\bar{\pi}\right)+2\left(b_{t-1}-\bar{b}\right)(\bar{b}-\bar{\pi})-2\left(\pi_{t}-\bar{\pi}\right)(\bar{b}-\bar{\pi}) \\
& +\left(b_{t-2}-\bar{b}\right)^{2}+\left(\pi_{t}-\bar{\pi}\right)^{2}+\left(\pi_{t-1}-\bar{\pi}\right)^{2}-2\left(b_{t-2}-\bar{b}\right)\left(\pi_{t}-\bar{\pi}\right)-2\left(b_{t-2}-\bar{b}\right)\left(\pi_{t-1}-\bar{\pi}\right) \\
& \left.+2\left(\pi_{t}-\bar{\pi}\right)\left(\pi_{t-1}-\bar{\pi}\right)+2\left(b_{t-2}-\bar{b}\right)(\bar{b}-\bar{\pi})-2\left(\pi_{t}-\bar{\pi}\right)(\bar{b}-\bar{\pi})-2\left(\pi_{t-1}-\bar{\pi}\right)(\bar{b}-\bar{\pi})\right] \\
& +\frac{2}{3} \Gamma_{1}\left[\left(b_{t}-\bar{b}\right)+\left(b_{t-1}-\bar{b}\right)+\left(b_{t-2}-\bar{b}\right)-2\left(\pi_{t}-\bar{\pi}\right)-\left(\pi_{t-1}-\bar{\pi}\right)\right]\left[Q_{p}^{0}\right] \\
& +\frac{2}{3} \Gamma_{1}\left[\left(b_{t}-\bar{b}\right)+\left(b_{t-1}-\bar{b}\right)+\left(b_{t-2}-\bar{b}\right)-2\left(\pi_{t}-\bar{\pi}\right)-\left(\pi_{t-1}-\bar{\pi}\right)\right]\left[\frac{1-\theta}{2} Q_{p}^{1}\left(\Delta_{t}-\bar{\Delta}\right)\right] \\
& +\Gamma_{1} \frac{(1-\theta)^{2}}{4}\left[Q_{p}^{1}\right]^{2}\left(\Delta_{t}-\bar{\Delta}\right)^{2}
\end{aligned}
$$


where

$$
\Gamma_{1}=\left[1+(\theta-1) Q_{p}^{1}\left(\bar{b}-\bar{\pi}+Q_{p}^{0}\right)\right]^{-1} .
$$

\section{Corollary 1 (Taylor).}

Up to a first order approximation, the deviation of price dispersion from its steady state evolves according to $\Xi_{t}=\frac{1}{3} \Gamma_{1}\left[2\left(\bar{b}+Q_{p}^{0}\right) \hat{b}_{t}+2\left(\bar{b}-\bar{\pi}+Q_{p}^{0}\right)\left(\hat{b}_{t-1}+\hat{b}_{t-2}-2 \hat{\pi}_{t}-\hat{\pi}_{t-1}\right)\right]$.

\section{Proposition 2 (Taylor) in the Taylor model}

Given Lemmas 1-5 for the Taylor model, the second order approximation to utility is

$\Theta_{0}+\Theta_{1} \operatorname{var}\left(\hat{y}_{t}\right)+\Theta_{2} \operatorname{cov}\left(\hat{y}_{t}, \Xi_{t}\right)+\Theta_{3} \operatorname{var}\left(\Xi_{t}\right)+\Theta_{4} \operatorname{var}\left(\hat{\pi}_{t}\right)+\Theta_{5} \operatorname{var}\left(\hat{b}_{t}\right)+\Theta_{6} \operatorname{cov}\left(\hat{b}_{t-1}, \hat{\pi}_{t}\right)$

$+\Theta_{7} \operatorname{cov}\left(\hat{b}_{t-2}, \hat{\pi}_{t}\right)+\Theta_{8} \operatorname{cov}\left(\hat{\pi}_{t}, \hat{\pi}_{t-1}\right)+\Theta_{9} \operatorname{cov}\left(\hat{b}_{t}, \Xi_{t}\right)+\Theta_{10} \operatorname{cov}\left(\hat{b}_{t-1}, \Xi_{t}\right)+\Theta_{11} \operatorname{cov}\left(\hat{b}_{t-2}, \Xi_{t}\right)$

$+\Theta_{12} \operatorname{cov}\left(\hat{\pi}_{t}, \Xi_{t}\right)+\Theta_{13} \operatorname{cov}\left(\hat{\pi}_{t-1}, \Xi_{t}\right)$

where $\Xi_{t}$ is the deviation of price dispersion from non-stochastic steady state and parameters $\Theta_{i}, i=0, \ldots, 5$ depend on the steady state inflation $\bar{\pi}$ and are given by

$$
\begin{aligned}
\Theta_{0}=[1-h- & \left.(1-\beta h)(1-\Phi)\left(1-\left(1+\frac{1}{\eta}\right) Q_{y}^{0}\right)\right] \log (\bar{X}) \\
& -\frac{(1-\beta h)(1-\Phi)}{\left(1-\bar{g}_{y}\right)}\left[\left(1+\frac{1}{\eta}\right)\left[Q_{y}^{0}\right]^{2}-Q_{y}^{0}+\frac{\theta-1}{\theta} Q_{y}^{1}\left[\frac{1}{2}-\left(1+\frac{1}{\eta}\right) Q_{y}^{0}\right] \bar{\Upsilon}\right] \\
& -\frac{1}{2} \frac{(1-\beta h)\left(1+\frac{1}{\eta}\right)(1-\Phi)}{\left(1-\bar{g}_{y}\right)}[\log (\bar{X})]^{2} \\
& -\frac{1}{2} \frac{(1-\beta h)}{\left(1-\bar{g}_{y}\right)}\left[Q_{y}^{1}\left(\frac{1}{\theta}-1\right)-Q_{y}^{1}+\left(1+\frac{1}{\eta}\right)\left(1+\frac{\theta-1}{\theta} Q_{y}^{0} Q_{y}^{1}\right)\right] \theta^{2} \bar{\Delta},
\end{aligned}
$$

$\Theta_{1}=-\frac{1}{2} \frac{(1-\beta h)\left(1+\frac{1}{\eta}\right)}{\left(1-\bar{g}_{y}\right)}$,

$\Theta_{2}=\frac{1}{2} \frac{(1-\beta h)\left(1+\frac{1}{\eta}\right)}{\left(1-\bar{g}_{y}\right)} \frac{\theta-1}{\theta} Q_{y}^{1} \theta^{2}$

$\Theta_{3}=-\frac{1}{8} \frac{(1-\beta h)\left(1+\frac{1}{\eta}\right)}{\left(1-\bar{g}_{y}\right)}\left(\frac{\theta-1}{\theta}\right)^{2}\left[Q_{y}^{1}\right]^{2} \theta^{4}$

$$
-\frac{1}{2} \frac{(1-\beta h)}{\left(1-\bar{g}_{y}\right)} \theta^{2}\left\{\left[Q_{y}^{1}\left(\frac{1}{\theta}-1\right)+\left(1+\frac{1}{\eta}\right)\left(1+\frac{\theta-1}{\theta} Q_{y}^{0} Q_{y}^{1}\right)\right]-\left(1+\frac{1}{\eta}\right) \frac{\theta-1}{\theta} Q_{y}^{1} \log (\bar{X})\right\} \Gamma_{1} \frac{(1-\theta)^{2}}{4}\left[Q_{p}^{1}\right]^{2}
$$

$\Theta_{4}=-\frac{1}{2} \frac{(1-\beta h)}{\left(1-\bar{g}_{y}\right)} \theta^{2}\left\{\left[Q_{y}^{1}\left(\frac{1}{\theta}-1\right)+\left(1+\eta^{-1}\right)\left(1+\frac{\theta-1}{\theta} Q_{y}^{0} Q_{y}^{1}\right)\right]-\left(1+\frac{1}{\eta}\right) \frac{\theta-1}{\theta} Q_{y}^{1} \log (\bar{X})\right\} \Gamma_{1}$,

$\Theta_{5}=-\frac{1}{2} \frac{(1-\beta h)}{\left(1-\bar{g}_{y}\right)} \theta^{2}\left\{\left[Q_{y}^{1}\left(\frac{1}{\theta}-1\right)+\left(1+\eta^{-1}\right)\left(1+\frac{\theta-1}{\theta} Q_{y}^{0} Q_{y}^{1}\right)\right]-\left(1+\frac{1}{\eta}\right) \frac{\theta-1}{\theta} Q_{y}^{1} \log (\bar{X})\right\} \Gamma_{1}$,

$\Theta_{6}=-\frac{2}{3}\left(\frac{(1-\beta h)}{\left(1-\bar{y}_{y}\right)} \theta^{2}\left\{\left[Q_{y}^{1}\left(\frac{1}{\theta}-1\right)+\left(1+\eta^{-1}\right)\left(1+\frac{\theta-1}{\theta} Q_{y}^{0} Q_{y}^{1}\right)\right]-\left(1+\frac{1}{\eta}\right) \frac{\theta-1}{\theta} Q_{y}^{1} \log (\bar{X})\right\} \Gamma_{1}\right.$,

$\Theta_{7}=-\frac{1}{3} \frac{(1-\beta h)}{\left(1-\bar{y}_{y}\right)} \theta^{2}\left\{\left[Q_{y}^{1}\left(\frac{1}{\theta}-1\right)+\left(1+\eta^{-1}\right)\left(1+\frac{\theta-1}{\theta} Q_{y}^{0} Q_{y}^{1}\right)\right]-\left(1+\frac{1}{\eta}\right) \frac{\theta-1}{\theta} Q_{y}^{1} \log (\bar{X})\right\} \Gamma_{1}$,

$\Theta_{8}=-\frac{1}{3}\left(\frac{(1-\beta h)}{\left(1-\bar{y}_{y}\right)} \theta^{2}\left\{\left[Q_{y}^{1}\left(\frac{1}{\theta}-1\right)+\left(1+\eta^{-1}\right)\left(1+\frac{\theta-1}{\theta} Q_{y}^{0} Q_{y}^{1}\right)\right]-\left(1+\frac{1}{\eta}\right) \frac{\theta-1}{\theta} Q_{y}^{1} \log (\bar{X})\right\} \Gamma_{1}\right.$, 


$$
\begin{aligned}
& \Theta_{9}=-\frac{1}{2} \frac{(1-\beta h)}{\left(1-\bar{g}_{y}\right)} \theta^{2}\left\{\left[Q_{y}^{1}\left(\frac{1}{\theta}-1\right)+\left(1+\eta^{-1}\right)\left(1+\frac{\theta-1}{\theta} Q_{y}^{0} Q_{y}^{1}\right)\right]-\left(1+\frac{1}{\eta}\right) \frac{\theta-1}{\theta} Q_{y}^{1} \log (\bar{X})\right\} \Gamma_{1} \frac{1-\theta}{3} Q_{p}^{1}, \\
& \Theta_{10}=-\frac{1}{2} \frac{(1-\beta h)}{\left(1-\bar{g}_{y}\right)} \theta^{2}\left\{\left[Q_{y}^{1}\left(\frac{1}{\theta}-1\right)+\left(1+\eta^{-1}\right)\left(1+\frac{\theta-1}{\theta} Q_{y}^{0} Q_{y}^{1}\right)\right]-\left(1+\frac{1}{\eta}\right) \frac{\theta-1}{\theta} Q_{y}^{1} \log (\bar{X})\right\} \Gamma_{1} \frac{1-\theta}{3} Q_{p}^{1}, \\
& \Theta_{11}=-\frac{1}{2} \frac{(1-\beta h)}{\left(1-\bar{g}_{y}\right)} \theta^{2}\left\{\left[Q_{y}^{1}\left(\frac{1}{\theta}-1\right)+\left(1+\eta^{-1}\right)\left(1+\frac{\theta-1}{\theta} Q_{y}^{0} Q_{y}^{1}\right)\right]-\left(1+\frac{1}{\eta}\right) \frac{\theta-1}{\theta} Q_{y}^{1} \log (\bar{X})\right\} \Gamma_{1} \frac{1-\theta}{3} Q_{p}^{1}, \\
& \Theta_{12}=\frac{(1-\beta h)}{\left(1-\bar{g}_{y}\right)} \theta^{2}\left\{\left[Q_{y}^{1}\left(\frac{1}{\theta}-1\right)+\left(1+\eta^{-1}\right)\left(1+\frac{\theta-1}{\theta} Q_{y}^{0} Q_{y}^{1}\right)\right]-\left(1+\frac{1}{\eta}\right) \frac{\theta-1}{\theta} Q_{y}^{1} \log (\bar{X})\right\} \Gamma_{1} \frac{1-\theta}{3} Q_{p}^{1}, \\
& \Theta_{13}=\frac{1}{2} \frac{(1-\beta h)}{\left(1-\bar{g}_{y}\right)} \theta^{2}\left\{\left[Q_{y}^{1}\left(\frac{1}{\theta}-1\right)+\left(1+\eta^{-1}\right)\left(1+\frac{\theta-1}{\theta} Q_{y}^{0} Q_{y}^{1}\right)\right]-\left(1+\frac{1}{\eta}\right) \frac{\theta-1}{\theta} Q_{y}^{1} \log (\bar{X})\right\} \Gamma_{1} \frac{1-\theta}{3} Q_{p}^{1}, \\
& \Phi=-\log \left(\frac{\theta-1}{\theta}\right) .
\end{aligned}
$$

\section{Proof:}

From Lemma 5, we have $E_{i} \tilde{y}_{t}(i)=x_{t}-Q_{y}^{0}-\frac{1}{2} \frac{\theta-1}{\theta} Q_{y}^{1}\left(\operatorname{var}_{i} \hat{y}_{t}(i)-\bar{\Upsilon}\right)+$ hot. Therefore, we can express the approximation from the disutility of labor supply given in Lemma 2 as follows:

$$
\begin{aligned}
& \int_{0}^{1} \tilde{v}\left(Y_{t}(i)\right) d i \quad \approx \bar{Y}_{t}^{F} \tilde{v}_{\bar{Y}_{t}^{F}}^{\prime}\left\{E_{i} \tilde{y}_{t}(i)+\frac{1}{2}\left(1+\eta^{-1}\right) \int_{0}^{1} \tilde{y}_{t}^{2}(i) d i\right\} \\
& =\bar{Y}_{t}^{F} \tilde{v}_{\bar{Y}_{t}^{F}}^{\prime}\left\{E_{i} \tilde{y}_{t}(i)+\frac{1}{2}\left(1+\eta^{-1}\right)\left(\operatorname{var}_{i} \hat{y}_{t}(i)+\left[E_{i} \tilde{y}_{t}(i)\right]^{2}\right)\right\} \\
& =\bar{Y}_{t}^{F} \tilde{v}_{\bar{Y}_{t}^{F}}^{\prime}\left\{\left(1-\left(1+\eta^{-1}\right) Q_{y}^{0}\right) \tilde{y}_{t}\right. \\
& +\frac{1}{2}\left[Q_{y}^{1} \theta^{-1}-Q_{y}^{1}+\left(1+\eta^{-1}\right)\left(1+\frac{\theta-1}{\theta} Q_{y}^{0} Q_{y}^{1}\right)\right] \operatorname{var}_{i} \hat{y}_{t}(i)+ \\
& +\frac{1}{2}\left(1+\eta^{-1}\right)\left(\frac{1}{4}\left(\frac{\theta-1}{\theta}\right)^{2}\left[Q_{y}^{1}\left(\operatorname{var}_{i} \hat{y}_{t}(i)-\bar{\Upsilon}\right)\right]^{2}-\frac{\theta-1}{\theta} x_{t} Q_{y}^{1}\left[\operatorname{var}_{i} \hat{y}_{t}(i)-\bar{\Upsilon}\right]\right) \\
& \left.+\frac{1}{2}\left(1+\eta^{-1}\right) \tilde{y}_{t}^{2}+\left(1+\eta^{-1}\right)\left[Q_{y}^{0}\right]^{2}-Q_{y}^{0}+\frac{\theta-1}{\theta} Q_{y}^{1}\left[\frac{1}{2}-\left(1+\eta^{-1}\right) Q_{y}^{0}\right] \bar{\Upsilon}\right\}+ \text { hot + tip }
\end{aligned}
$$

As Woodford (2003) shows, $\tilde{v}_{\bar{Y}_{t}^{F}}^{\prime}=(1-\beta h) u_{\bar{C}_{t}^{F}}^{\prime}(1-\Phi)$, where (with $\log$ utility) $\Phi=-\ln \left(\frac{\theta-1}{\theta}\right)$ which follows from the intra-temporal condition for labor supply. Hence,

$$
\begin{aligned}
\int_{0}^{1} \tilde{v}\left(Y_{t}(i)\right) d i= & (1-\beta h)\left(1-\bar{g}_{y}\right)^{-1} \hat{C}_{t}^{F} u_{\hat{C}_{t}^{F}}^{\prime}(1-\Phi)\left\{\left(1-\left(1+\eta^{-1}\right) Q_{y}^{0}\right) \tilde{y}_{t}+\frac{1}{2}\left(1+\eta^{-1}\right) \tilde{y}_{t}^{2}+\right. \\
& +\frac{1}{2}\left[Q_{y}^{1} \theta^{-1}-Q_{y}^{1}+\left(1+\eta^{-1}\right)\left(1+\frac{\theta-1}{\theta} Q_{y}^{0} Q_{y}^{1}\right)\right] \operatorname{var}_{i} \hat{y}_{t}(i) \\
& +\frac{1}{2}\left(1+\eta^{-1}\right)\left(\frac{1}{4}\left(\frac{\theta-1}{\theta}\right)^{2}\left[Q_{y}^{1}\left(\operatorname{var}_{i} \hat{y}_{t}(i)-\bar{\Upsilon}\right)\right]^{2}-\frac{\theta-1}{\theta} x_{t} Q_{y}^{1}\left[\operatorname{var}_{i} \hat{y}_{t}(i)-\bar{\Upsilon}\right]\right) \\
& \left.+\left(1+\eta^{-1}\right)\left[Q_{y}^{0}\right]^{2}-Q_{y}^{0}+\frac{\theta-1}{\theta} Q_{y}^{1}\left[\frac{1}{2}-\left(1+\eta^{-1}\right) Q_{y}^{0}\right] \bar{\Upsilon}\right\}+ \text { hot }+ \text { tip }
\end{aligned}
$$

As in Lemma 1, $\hat{C}_{t}^{F} u_{\hat{C}_{t}^{F}}^{\prime}=1$. Using equation (42) and Lemma 4 (Taylor) we replace the cross-section dispersion of output in (A.17) with the cross-sectional dispersion of prices.

Using $E\left(\pi_{t}-\bar{\pi}\right)=0$, we compute the expected value of $\Xi_{t}$ :

$$
\begin{aligned}
E\left(\Xi_{t}\right) & =\Gamma_{1}\left\{\operatorname{var}\left(\hat{b}_{t}\right)+\operatorname{var}\left(\hat{\pi}_{t}\right)-\frac{4}{3} \operatorname{cov}\left(\hat{b}_{t-1}, \hat{\pi}_{t}\right)-\frac{2}{3} \operatorname{cov}\left(\hat{b}_{t-2}, \hat{\pi}_{t}\right)+\frac{2}{3} \operatorname{cov}\left(\hat{\pi}_{t}, \hat{\pi}_{t-1}\right)\right] \\
& +\frac{1-\theta}{3} Q_{p}^{1}\left[\operatorname{cov}\left(\hat{b}_{t}, \Xi_{t}\right)+\operatorname{cov}\left(\hat{b}_{t-1}, \Xi_{t}\right)+\operatorname{cov}\left(\hat{b}_{t-2}, \Xi_{t}\right)-2 \operatorname{cov}\left(\hat{\pi}_{t}, \Xi_{t}\right)-\operatorname{cov}\left(\hat{\pi}_{t-1}, \Xi_{t}\right)\right] \\
& \left.+\frac{(1-\theta)^{2}}{4}\left[Q_{p}^{1}\right]^{2} \operatorname{var}\left(\Xi_{t}\right)\right\}
\end{aligned}
$$

where 


$$
\Gamma_{1}=\left[1+(\theta-1) Q_{p}^{1}\left(\bar{b}-\bar{\pi}+Q_{p}^{0}\right)\right]^{-1}
$$

Note that from the definition of $\Xi_{t}$, we have

$$
E\left(\Delta_{t}\right)=E\left(\Xi_{t}\right)+\bar{\Delta}
$$

Since all variables are stationary and $y_{t}=\hat{X}_{t}-\log (\bar{X})$, we can compute the expected per period utility as follows

$$
\begin{aligned}
E U_{t} \quad \approx & E\left\{\left(\tilde{c}_{t}-h \tilde{c}_{t-1}\right)\right. \\
& -(1-\beta h)(1-g)^{-1}(1-\Phi)\left(1-\left(1+\eta^{-1}\right) Q_{y}^{0}\right) \tilde{y}_{t} \\
& -\frac{1}{2}(1-\beta h)(1-g)^{-1}(1-\Phi)\left(1+\eta^{-1}\right) \tilde{y}_{t}^{2} \\
& -\frac{1}{2}(1-\beta h)(1-g)^{-1}\left[Q_{y}^{1} \theta^{-1}-Q_{y}^{1}+\left(1+\eta^{-1}\right)\left(1+\frac{\theta-1}{\theta} Q_{y}^{0} Q_{y}^{1}\right)\right] \theta^{2} \Delta_{t} \\
& -\frac{1}{8}(1-\beta h)(1-g)^{-1}\left(1+\eta^{-1}\right)\left(\frac{\theta-1}{\theta}\right)^{2}\left[Q_{y}^{1}\right]^{2} \theta^{2} \Xi_{t}^{2} \\
+ & \frac{1}{2}(1-\beta h)(1-g)^{-1}\left(1+\eta^{-1}\right) \frac{\theta-1}{\theta} Q_{y}^{1} \theta^{2} \tilde{y}_{t} \Xi_{t} \\
& \left.-(1-\beta h)(1-g)^{-1}(1-\Phi)\left[\left(1+\eta^{-1}\right)\left[Q_{y}^{0}\right]^{2}-Q_{y}^{0}+\frac{\theta-1}{\theta} Q_{y}^{1}\left[\frac{1}{2}-\left(1+\eta^{-1}\right) Q_{y}^{0}\right] \bar{\Upsilon}\right]\right\}+h o t+t i p \\
= & {\left[1-h-(1-\beta h)(1-g)^{-1}(1-\Phi)\left(1-\left(1+\eta^{-1}\right) Q_{y}^{0}\right)\right] \log (\bar{X}) } \\
& -(1-\beta h)(1-g)^{-1}(1-\Phi)\left[\left(1+\eta^{-1}\right)\left[Q_{y}^{0}\right]^{2}-Q_{y}^{0}+\frac{\theta-1}{\theta} Q_{y}^{1}\left[\frac{1}{2}-\left(1+\eta^{-1}\right) Q_{y}^{0}\right] \bar{\Upsilon}\right] \\
& -\frac{1}{2}(1-\beta h)(1-g)^{-1}\left(1+\eta^{-1}\right)\left\{(1-\Phi)[\log (\bar{X})]^{2}+\operatorname{var}\left(\hat{y}_{t}\right)\right\} \\
& -\frac{1}{2}(1-\beta h)(1-g)^{-1}\left[Q_{y}^{1} \theta^{-1}-Q_{y}^{1}+\left(1+\eta^{-1}\right)\left(1+\frac{\theta-1}{\theta} Q_{y}^{0} Q_{y}^{1}\right)\right] \theta^{2} E\left(\Delta_{t}\right) \\
& -\frac{1}{8}(1-\beta h)(1-g)^{-1}\left(1+\eta^{-1}\right)\left(\frac{\theta-1}{\theta}\right)^{2}\left[Q_{y}^{1}\right]^{2} \theta^{4} \operatorname{var}\left(\Xi_{t}\right) \\
& +\frac{1}{2}(1-\beta h)(1-g)^{-1}\left(1+\eta^{-1}\right) \frac{\theta-1}{\theta} Q_{y}^{1} \theta^{2} \operatorname{cov}\left(\hat{y}_{t}, \Xi_{t}\right)+ \\
& +\frac{1}{2}(1-\beta h)(1-g)^{-1}\left(1+\eta^{-1}\right) \frac{\theta-1}{\theta} Q_{y}^{1} \theta^{2} \log (\bar{X}) E\left(\Xi_{t}\right) \\
& +h o t+t i p
\end{aligned}
$$

After using (A.18) and (A.22) and collecting terms, one arrives at equation (D.16). 